\title{
Las aguas subterráneas y los Espacios Naturales Protegidos del Estado español. Caracterización hidrogeológica de los Parques Nacionales
}

\author{
José Manuel Murillo y Leticia Vega \\ Instituto Geológico y Minero de España, Ríos Rosas 23, 28003 Madrid, España \\ jm.murillo@igme.es y l.vega@igme.es
}

\begin{abstract}
RESUMEN
En el presente trabajo se identifican los espacios naturales protegidos que presentan relación con las aguas subterráneas en España. La metodología que se ha empleado se ha aplicado a los espacios naturales que se contemplan dentro del ámbito de los tres marcos jurídicos que establece la Ley 42/2007, de 13 de diciembre, del Patrimonio Natural y de la Biodiversidad. Estos son los siguientes: a) Espacios protegidos por el Estado español o por sus Comunidades Autónomas; b) Espacios protegidos de la Red Natura 2000 y c) Áreas protegidas por instrumentos internacionales. Dentro de la primera tipología se analizan: los Parques Naturales, las Reservas Naturales, los Monumentos Naturales y los Paisajes Protegidos. La segunda contempla los espacios protegidos de la Red Natura 2000 y la tercera los Humedales de Importancia Internacional del Convenio de Ramsar; los sitios naturales de la Lista del Patrimonio Mundial; las áreas protegidas del Convenio para la protección del medio ambiente marino del Atlántico del nordeste (OSPAR); las Zonas Especialmente Protegidas de Importancia para el Mediterráneo (ZEPIM); los Geoparques declarados por la UNESCO; las Reservas de la Bioesfera declaradas por la UNESCO; y las Reservas biogenéticas del Consejo de Europa. Por último se realiza una caracterización hidrogeológica de cada uno de los15 Parques Nacionales que hay en España. El artículo tiene como objetivo identificar y proponer un primer catálogo de espacios naturales protegidos que presentan relación con las aguas subterráneas bien sea esta de recarga al acuífero o de drenaje a través de ríos, manantiales o humedales.
\end{abstract}

Palabras clave: Espacio natural protegido, Hidrogeología, Humedal, Parque Nacional, Relación río-acuífero.

\section{Groundwater and Protected Natural Areas in Spain. The hydrogeological characterization of National Parks}

\begin{abstract}
This study identifies protected natural areas that are related to groundwater in Spain. The methodology used has been applied to the natural areas covered within the scope of the three legal frameworks established in Law 42/2007, 13 December 2007 on Natural Heritage and Biodiversity. These are as follows: (a) areas protected by the Spanish State or its Autonomous Communities; (b) areas protected by the Natura 2000 Network and (c) areas protected by international instruments. Within the first typology the Natural Parks, Natural Reserves, Natural Monuments and Protected Landscapes are analyzed. The second includes the protected areas of the Natura 2000 Network and the third the Wetlands of International Importance of the Ramsar Convention; natural sites of the World Heritage List; Convention for the Protection of the Marine Environment of the north-east Atlantic (OSPAR); Specially Protected Areas of Mediterranean Importance (SPAMI); GEOparks declared by UNESCO; Biosphere Reserves declared by UNESCO and European Network of Biogenetic Reserve. Finally, a hydrogeological characterization of each of the 15 National Parks in Spain is carried out. The aim of the paper is to identify and propose a first catalogue of protected natural areas that have a relationship with groundwater either from recharging the aquifer or drainage through rivers, springs or wetlands.
\end{abstract}

Keywords: hydrogeology, National Park, protected natural area, river-aquifer relationship, wetland. 


\section{Introducción}

En España, los espacios naturales protegidos se definen y regulan en la Ley 42/2007, de 13 de diciembre, del Patrimonio Natural y de la Biodiversidad, que los agrupa en tres tipos atendiendo al origen de sus marcos jurídicos:

- Espacios Naturales Protegidos por el Estado español o por sus Comunidades Autónomas.

- Espacios protegidos de la Red Natura 2000.

- Áreas protegidas por instrumentos internacionales.

Así, los primeros, derivan de la legislación nacional y autonómica. Los segundos de normativas establecida por la Unión Europea, y los terceros de acuerdos y convenios de carácter internacional a los que se encuentra adherido el Reino de España. Es importante reseñar, que en caso de solapamiento sobre un mismo territorio de figuras derivadas de la legislación autonómica y de la Red Natura 2000, la normativa que prevalece es la europea.

Aunque la legislación española y europea emplean la terminología de espacio natural protegido, todos los enclaves que se designan como tales, tanto por la normativa española como por la europea, se ajustan y responden al concepto de área protegida que establece la Unión Internacional para la Conservación de la Naturaleza (UICN), cuya definición en ingles es la siguiente: " $A$ clearly defined geographical space, recognised, dedicated and managed, through legal or other effective means, to achieve the long-term conservation of nature with associated ecosystem services and cultural values" (Dudley, 2008). Su traducción, no literal al español, pero fundamentada en la idea que dicha organización quiere transmitir, podría ser la siguiente: Un espacio geográfico perfectamente delimitado y acreditado mediante normativa legal, gestionado y destinado, a través de la aplicación de medidas y medios adecuados, para lograr la conservación a largo plazo de la naturaleza, de sus servicios ecosistémicos asociados y de sus valores culturales.

La UICN ha desarrollado y establecido un sistema de categorización de las áreas protegidas que se encuentra ampliamente descrito en las siguientes publicaciones: "Guidelines for Applying Protected Area Management Categories" (Dudley, 2008) y "Guidelines for applying the IUCN protected area management categories to marine protected areas" (Day et al., 2012). La denominación de cada una de las seis áreas protegidas que ha definido la UICN es la siguiente: la) Reserva natural estricta (Strict Nature Reserve); Ib) Área silvestre (Wilderness Area); II) Parque Nacional (National Park); III) Monumento
Natural (Natural Monument); IV) Área de gestión de hábitats/especies (Habitat/Species Management Area); V) Paisajes terrestres/marinos protegidos (Protected Landscape/Seascape); VI) Área protegida para la conservación y protección de valores culturales y sistemas tradicionales de gestión que permiten un uso sostenible de los recursos naturales (Managed Resource Protected Area).

La categorización formulada por la UICN se encuentra aceptada, reconocida y avalada por numerosas organizaciones internacionales, así como por una infinidad de gobiernos nacionales, regionales y locales.

En la tabla 1 se especifican las diferentes categorías que se establecen dentro de cada una de las tipologías contenidas en la Ley 42/2007, de 13 de diciembre, del Patrimonio Natural y de la Biodiversidad. En la categoría de Parques se distinguen dos subtipologías: Ios Parques Naturales y los Parques Nacionales. Estos últimos se rigen por una legislación específica (Ley 30/2014 de Parques Nacionales) y se integran en la denominada Red de Parques Nacionales.

Actualmente hay en España 15 parques nacionales, 152 parques naturales, 291 reservas naturales, 342 monumentos naturales, 57 paisajes protegidos y 2 áreas marinas protegidas (Mújica et al., 2019). Las cifras anteriormente reseñadas no solo corresponden a espacios naturales protegidos que se engloban específicamente dentro de las cinco categorías que contempla la Ley 42/2007, de 13 de diciembre, del Patrimonio Natural y de la Biodiversidad, sino también dentro de un sexto grupo de amplia casuística y normativa autonómica que el "Anuario 2018 del estado de las áreas protegidas en España" denomina

\begin{tabular}{|c|l|l|}
\hline $\begin{array}{c}\text { Espacios naturales } \\
\text { protegidos por el } \\
\text { Estado español }\end{array}$ & \multicolumn{1}{|c|}{$\begin{array}{c}\text { Red Natura } \\
2000\end{array}$} & \multicolumn{1}{|c|}{$\begin{array}{c}\text { Áreas protegidas } \\
\text { por instrumentos } \\
\text { internacionales }\end{array}$} \\
\hline - Parques & - Lugares de & - Humedales Ramsar \\
- Reservas & Comportancia \\
naturales & - Zonas de & - Reservas de la Biosfera \\
- Monumentos & Especial & - OSPIM \\
naturales & Orotección & - Sitios Patrimonio \\
- Paisajes & para las Aves & Natural Mundial \\
protegidos & - Zonas & - Geoparques \\
- Áreas marinas & Especiales de \\
protegidas & Conservación & - Reservas biogenéticas \\
\hline
\end{tabular}

Tabla 1. Diferentes categorías de espacios naturales protegidos establecidos de acuerdo a la Ley 42/2007, de 13 de diciembre, del Patrimonio Natural y de la Biodiversidad.

Table 1. Different categories of protected natural areas established in accordance with Law 42/2007 December 13, 2007, natural heritage and biodiversity. 
"otras figuras", que asimila las figuras autonómicas de Parque Regional y Parque Rural a la de Parque Natural; las de Reserva Natural Concertada, Reserva Natural de Fauna Salvaje, Reserva Natural Dirigida, Reserva Natural Especial, Reserva Natural Integral, Reserva Natural Parcial, Reserva de Fauna, Reserva Fluvial, Reserva Integral, Reserva Natural Marina y Refugio de Fauna a la de Reserva Natural; y las de Monumento Natural de Interés Nacional, Árbol Singular y Enclave Natural a las de Monumento Nacional.

Aparte de las figuras autonómicas anteriormente mencionadas, las Comunidades Autónomas que componen el Estado español han declarado otros 805 espacios naturales protegidos de acuerdo a la constitución e instauración de figuras propias de protección de muy diversa denominación (Mújica et al., 2019). Así, se han establecido en Andalucía (Paraje Natural; Parque Periurbano), Cantabria (Área Natural de Especial Interés), Castilla-La Mancha (Microrreserva), Cataluña (Paraje Natural de Interés Nacional), Comunidad Foral de Navarra (Área Natural Recreativa), Comunidad de Madrid (Paraje Pintoresco), Comunidad Valenciana (Paraje Natural Municipal; Microrreserva de Flora; Cuevas; Zonas Húmedas), Extremadura (Corredor Ecológico y de Biodiversidad; Parque Periurbano de Conservación y Ocio; Área Privada de Interés Ecológico; Lugar de Interés Científico; Corredores Ecoculturales), Galicia (Humedal Protegido; Espacio Natural de Interés Local; Sitio Natural de Interés Nacional; Espacio Privado de Interés Natural), Illes Balears (Paraje Natural; Lugar de Interés Científico), Islas Canarias (Sitio de Interés Científico); La Rioja (Área Natural Singular) y País Vasco (Biotopo Protegido). La legislación autonómica contempla más de 40 figuras diferentes de protección de los espacios naturales protegidos (MITECO, 2019).

De acuerdo al objetivo que se plantea en el presente artículo cabe indicar que el primer trabajo que intenta cuantificar el número de Unidades Hidrogeológicas definidas por DGOH-ITGE en 1988 que podían presentar algún tipo de interrelación hídrica con espacios naturales protegidos con catalogación oficial de protección se titula "Hidroquímica de Unidades Hidrogeológicas Asociadas a Espacios Naturales Protegidos" (Murillo, 1994).

Los resultados que se obtuvieron en dicho trabajo mostraron que el $50 \%$ de los espacios naturales protegidos de la España peninsular se emplazaban en todo o en parte de su superficie sobre las unidades hidrogeológicas definidas por DGOH-ITGE en 1988.

Transcurridos casi 25 años, desde la fecha en que se publicó el trabajo anteriormente referenciado, el grado de conocimiento que se tiene de la hidrogeolo- gía de los espacios naturales protegidos parece que no ha avanzado en demasía, pues en el Congreso de Aguas Subterráneas, Medio Ambiente, Salud y Patrimonio celebrado en Salamanca a finales de 2018 se afirma en la ponencia titulada "Hidrogeología de espacios naturales protegidos" que el ciclo del agua en los espacios naturales protegidos es todavía insuficientemente conocido, pues presenta notables carencias y escasa divulgación (Durán, 2018).

Un segundo trabajo realizado con la misma filosofía, pero a escala autonómica, se presenta en el Atlas Hidrogeológico de Andalucía en el capítulo titulado "El agua y los espacios naturales protegidos" (Durán y Murillo, 1998). En el mismo se manifiesta que en torno al $45 \%$ de los espacios naturales protegidos de Andalucía tienen correspondencia geoespacial con alguna de las Unidades Hidrogeológicas definidas en el año 1988 por DGOH-ITGE.

Otro trabajo análogo al anteriormente expuesto se incluye en el Atlas Hidrogeológico de Cádiz dentro del capítulo titulado "Agua y Medio Ambiente" (Durán, 2005). En dicho trabajo se pasa revista a todos los espacios naturales protegidos de la provincia indicándose que muchos de ellos tienen una relación muy estrecha con el agua subterránea.

Salvo las incipientes tentativas apuntadas anteriormente todavía no se ha elaborado un catálogo de espacios naturales protegidos en los que se contemple la interacción hídrica de estos con el recurso hídrico subterráneo, tanto en lo que respecta a su recarga como a su descarga. La elaboración de un documento como el explicitado constituye el principal objetivo del presente artículo.

\section{Aguas subterráneas y Espacios Naturales Protegidos por la Ley 42/2007, de 13 de diciembre, del Patrimonio Natural y de la Biodiversidad}

Para la elaboración del presente apartado se ha partido de la estructura de división y clasificación de espacios naturales protegidos que se emplea en el "Anuario 2018 del estado de las áreas protegidas en España". Es decir, se han analizado todos los espacios naturales protegidos que se contemplan en la Ley $42 / 2007$, de 13 de diciembre, del Patrimonio Natural y de la Biodiversidad, salvo aquellos de carácter autonómico que en el anuario referenciado anteriormente se especifica que no se han podido asimilar a ninguna de las 5 figuras que contempla la legislación nacional como Espacios Naturales Protegidos por el Estado español. La exposición de los resultados obtenidos en el análisis planteado se aborda en los siguientes apartados de acuerdo a los 
tres marcos jurídicos que se establecen en ley anteriormente citada.

\section{Espacios Naturales Protegidos por el Estado español o por sus Comunidades Autónomas}

En el presente subapartado se analiza la posible interdependencia hídrica que puede existir entre las aguas subterráneas y los Parques Naturales, las Reservas Naturales, los Monumentos Naturales y los Paisajes Protegidos.

\section{Parques Naturales}

Según su definición legal son "áreas naturales" que, en razón a la belleza de sus paisajes, la representatividad de sus ecosistemas o la singularidad de su flora, de su fauna o de su diversidad geológica, incluidas sus formaciones geomorfológicas, poseen unos valores ecológicos, estéticos, educativos y científicos cuya conservación merece una atención preferente" (Ley 42/2007 del Patrimonio Natural y de la Biodiversidad). De acuerdo con la catalogación establecida por la UICN (Dudley, 2008) se encuadran dentro de la categoría V (Paisajes Protegidos). En España ocupan más de 4 millones de hectáreas, lo que supone un $8 \%$ de su superficie.

Todas las comunidades autónomas han hecho uso de esta figura de protección y son las competentes en su planificación y gestión. En la tabla 2 se listan los Parques Naturales incluidos en el Anuario 2018 de áreas protegidas en España que los autores del presente artículo estiman vinculados a las aguas subterráneas en función del actual grado de conocimiento hidrogeológico que existe en el Estado español. La propuesta realizada no implica que entre los Parques Naturales que en principio se han descartado existan áreas de drenaje, generalmente ligadas a materiales de baja permeabilidad y reducidos volúmenes de descarga, que pueden ser fuente de alimentación hídrica de hábitats más o menos singulares y significativos. Esta premisa es igualmente aplicable al resto de espacios naturales protegidos que se analizan en el presente artículo.

El número de parques naturales que se encuentran interrelacionados con las aguas subterráneas ascienden a 109 sobre un total de 152 (Tabla 2). Dicha cantidad constituye el 72 por ciento de los declarados oficialmente mediante esa figura de protección.

La Comunidad Autónoma de Andalucía constituye la región española con un mayor número de Parques Naturales que presentan relación hídrica con las aguas subterráneas y también la Comunidad Autónoma donde se ha realizado uno de los trabajos más significativo que atañe a la hidrogeología y a la figura de Parque Natural. Dicho trabajo concierne a una serie de guías elaboradas por el Instituto Geológico y Minero de España con la colaboración de la Diputación Provincial de Jaén y la Agencia Andaluza del Agua. La primera en publicarse fue la del Parque Natural de las Sierras de Cazorla, Segura y Las Villas (Villalobos Mejía et al., 2006). A esta le siguieron: Parque Natural de Sierra Mágina (Gollonet et al., 2007); Parque Natural de Sierra Huétor (Pérez Muñoz et al., 2008); Parque Natural de Despeñaperros y el Paraje Natural de la Cascada de la Cimbarra (Martín Montañés et al., 2009); Parque Natural de la Sierra del Castril (González Ramón et al., 2009); Parque Natural de la Sierra de Aracena y Picos de Aroche (Moriz Sánchez y Pérez Fernández, 2010); Parque Natural marítimo-terrestre de Cabo de GataNíjar (Villalobos Mejías et al., 2010); Parque Natural Sierra de Grazalema (del Val y Gálvez, 2010); Parque Natural Sierra de Andújar (Martín Montañés et al., 2011); y Parque Natural Sierras Subbéticas (López Chicano et al., 2013).

A las anteriores publicaciones es menester unir el trabajo titulado "El modelado Kárstico en los Parques Naturales de la Provincia de Jaén" (Durán, 2002), por dos razones muy diferentes. La primera la constituye el hecho de que dicha provincia es uno de los territorios administrativos del Estado español que presenta un mayor porcentaje de superficie ocupada por espacios naturales protegidos. La segunda la determina la singularidad kárstica que acompaña a los espacios naturales protegidos que se localizan en dicha provincia, que se concreta en la presencia de numerosos lugares exokárticos, así como de cavidades endokársticas. Además, una gran parte de la superficie ocupada por los espacios naturales protegidos constituye una importante área de recarga a los acuíferos. Los principales manantiales por los que descargan dichos acuíferos son el origen de ríos tan importantes como el Guadalquivir y el Segura, así como de algunos de sus principales afluentes como el Borosa, Guadalentín, Madera, Tus y Zumeta. Otro trabajo de indudable interés realizado en la Comunidad Autónoma de Andalucía es el titulado "Estudio hidrogeológico del Parque Natural de los Montes de Málaga" (Vallejo y Duran, 1996).

\section{Reservas Naturales}

Según el artículo 21 de la Ley 33/2015, de 21 de septiembre, son espacios naturales, cuya creación tiene 


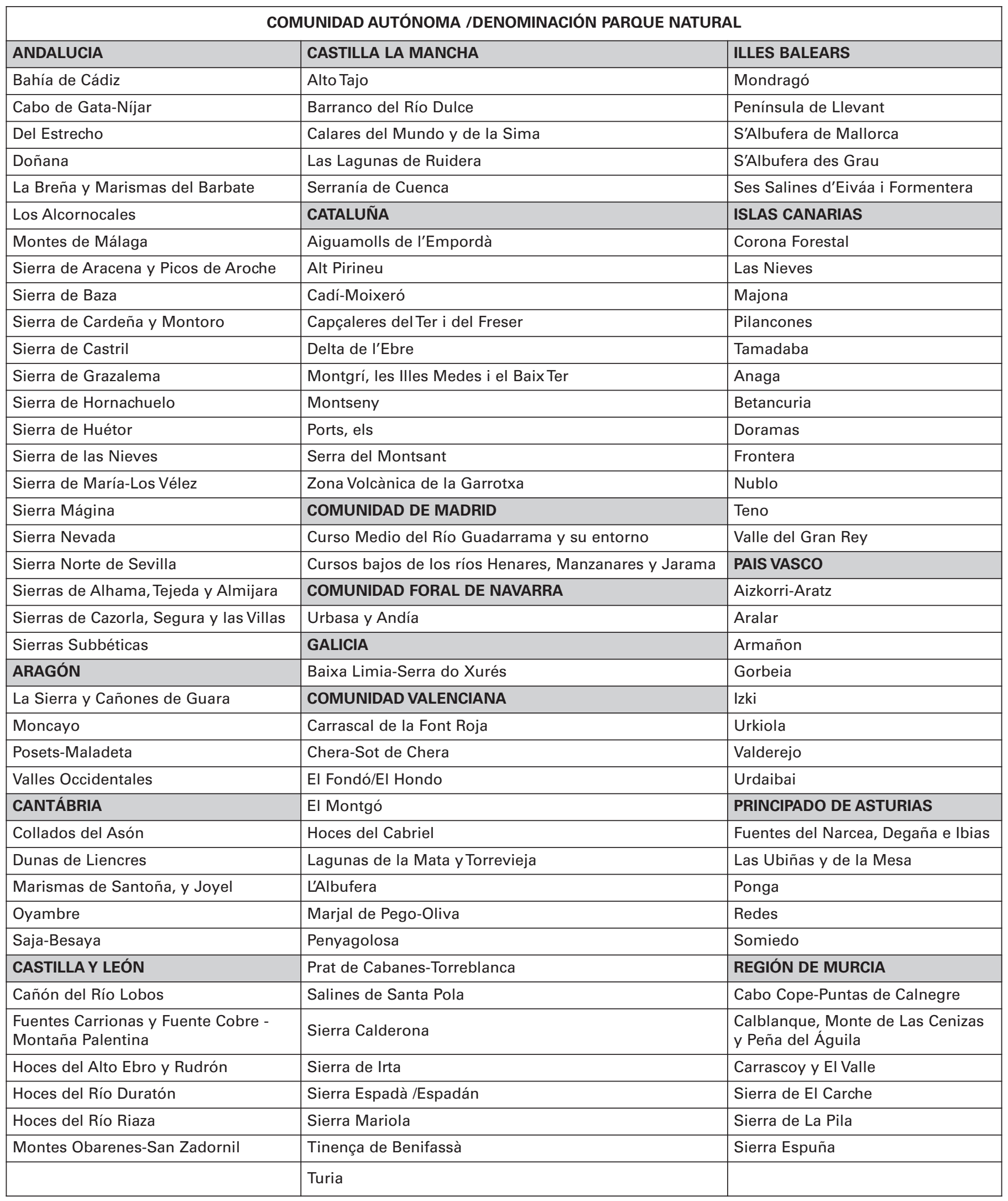

Tabla 2. Parques Naturales del Estado español vinculados con las aguas subterráneas.

Table 2. Natural Parks in Spain linked to groundwater. 
como finalidad la protección de ecosistemas, comunidades o elementos biológicos que, por su rareza, fragilidad, importancia o singularidad merecen una valoración especial. En ellas está limitada la explotación de recursos, salvo en aquellos casos en que la misma sea compatible con la conservación de los valores que se pretenden proteger. Con carácter general está prohibida la recolección de material biológico o geológico, salvo en aquellos casos que por razones de investigación, conservación o educativas se permita la misma, previa la pertinente autorización administrativa. De acuerdo con la catalogación establecida por la UICN (Dudley, 2008) se encuadran dentro de la categoría la y lb (Reserva Natural Estricta y Áreas Silvestres).

En la tabla 3 se identifican 94 Reservas Naturales donde bien se recargan los acuíferos o bien se descarga agua subterránea tanto a través de manantiales como de manera difusa a ríos. El número de espacios naturales anteriormente mencionados supone el 32 por ciento del total de los declarados oficialmente protegidos mediante dicha figura.

\section{Monumentos Naturales}

Según la legislación vigente se definen como espacios o elementos de la naturaleza constituidos básicamente por formaciones de notoria singularidad, rareza o belleza, que merecen ser objeto de una protección especial. En general se trata de árboles singulares y monumentales, formaciones geológicas, yacimientos paleontológicos y mineralógicos, estratotipos y demás elementos de la gea que reúnen un interés especial por la singularidad o importancia de sus valores científicos, culturales o paisajísticos. Sus dimensiones suelen ser reducidas. De acuerdo con la catalogación establecida por la UICN (Dudley, 2008) se encuadran dentro de la categoría III (Monumento Natural).

\begin{tabular}{|c|c|}
\hline Comunidad Autónoma & Denominación Reserva Natural \\
\hline Andalucía & $\begin{array}{l}\text { Albufera de Adra, Cañada de los Pájaros, Charca Suárez, Laguna Amarga, Laguna de Fuente de Piedra, } \\
\text { Laguna de Zóñar, Laguna del Conde o Salobral, Laguna del Gosque, Laguna del Portil, Laguna del Rincón, } \\
\text { Lagunas de Archidona, Peñón de Zaframagón. }\end{array}$ \\
\hline Aragón & Laguna de Gallocanta, Saladas de Chiprana, Sotos y Galachos del Ebro. \\
\hline Castilla y León & Lagunas de Villafáfila, Riberas de Castronuño - Vega del Duero. \\
\hline Cataluña & $\begin{array}{l}\text { Aiguamolls del BaixTer, Barranc de la Trinitat, Desembocadura del Gaià, Les Llaunes, Llacuna de la Tancada, } \\
\text { Muga-Albanyà, Noguera Pallaresa-Bonaigua, Noguera Pallaresa-Collegats, Noguera Ribagorçana-Montrebei, } \\
\text { Remolar-Filipines, Ribera de I'Algars, Ribera de I'Ebre a Flix, Ricarda-Ca I'Arana, Riera d'Arbúcies-Hostalric, } \\
\text { Riera de Merlès, Sant Llorenç de Montgai, Segre-Isòvol, Segre-Prullans, Torrent del Pi. }\end{array}$ \\
\hline Comunidad Valenciana & $\begin{array}{l}\text { Barranc de I'Horteta, Barranc del Salt, Fuente la Collara, Irta, Laguna de Salinas, Nacimiento del Río Cazuma, } \\
\text { Torretes Font-Roja. }\end{array}$ \\
\hline Illes Balears & Estany Pudent, S'Albufereta y Serra Tramuntana \\
\hline Islas Canarias & Azuaje, Barranco del Infierno, Benchijigua, El Brezal, El Pijaral, Mencafete. \\
\hline La Rioja & Sotos del Ebro en Alfaro. \\
\hline Principado de Asturias & Cueva de las Caldas, Cueva del Lloviu, Cueva del Sidrón, Cueva Rosa, Muniellos, Ría de Villaviciosa. \\
\hline Región de Murcia & Cañaverosa. \\
\hline
\end{tabular}

Tabla 3. Reservas Naturales vinculadas a las aguas subterráneas.

Table 3. Natural Reserves linked to groundwater. 
En la tabla 4 se han identificado 74 Monumentos Naturales que de alguna u otra forma se encuentran interrelacionados con las aguas subterráneas. El número de espacios naturales anteriormente mencionados supone el 22 por ciento del total (342) de los declarados oficialmente protegidos mediante dicha figura.

\section{Paisajes Protegidos}

La legislación vigente define los paisajes protegidos como aquellas partes del territorio que las
Administraciones competentes consideran merecedores de una protección especial por sus valores naturales, estéticos y culturales de acuerdo con el Convenio Europeo del Paisaje del Consejo de Europa. De acuerdo con la catalogación establecida por la UICN (Dudley, 2008) se encuadran dentro de la categoría V (Paisaje terrestre/marino protegido).

En la tabla 5 se han identificado 20 Paisajes Protegidos que bien desde el punto de vista de la recarga o la descarga de las aguas subterráneas se encuentran relacionados con ellas. El número de espacios naturales anteriormente mencionados supo-

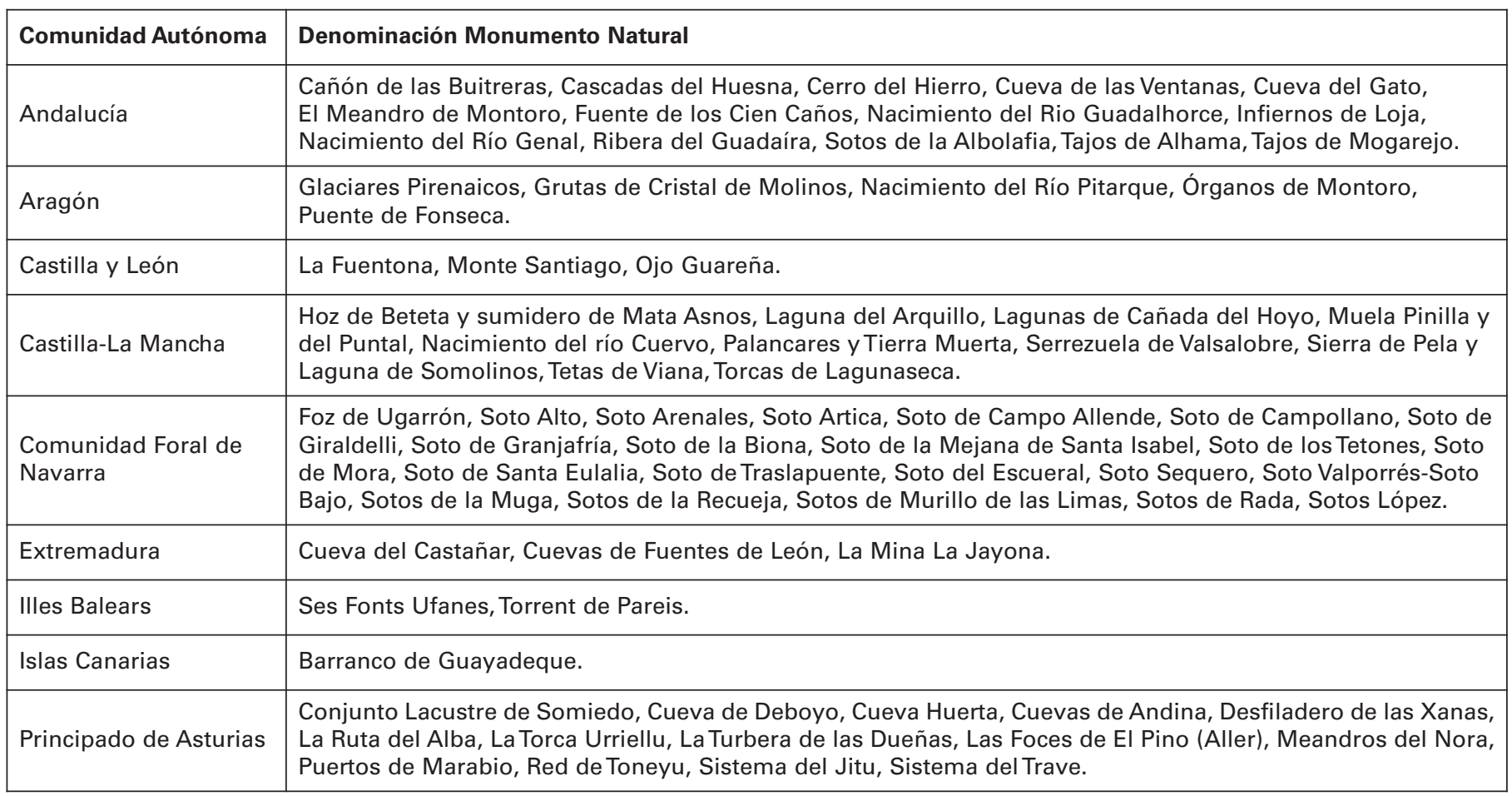

Tabla 4. Monumentos Naturales vinculados con las aguas subterráneas.

Table 4. Natural Monuments linked to groundwater.

\begin{tabular}{|l|l|}
\hline Comunidad Autónoma & Denominación Paisaje Protegido \\
\hline Andalucía & Corredor Verde del Guadiamar, Río Tinto. \\
\hline Aragón & Foces de Fago y Biniés, Sierra de Santo Domingo. \\
\hline Principado de Asturias & Cuencas Mineras. \\
\hline Canarias & Barranco de Erques, Barranco de Las Angustias, La Rambla de Castro, Las Lagunetas, Orone, Tenegüime. \\
\hline Comunidad Valenciana & Desembocadura del Mijares, Serpis, Sierra de Bernia y Ferrer, Sierra del Maigmó y Sierra del Sit. \\
\hline Región de Murcia & $\begin{array}{l}\text { Cabezo Gordo, Humedal del Ajauque y Rambla Salada, Saladares del Guadalentín, Sierra de las Moreras, } \\
\text { Sierra de Salinas. }\end{array}$ \\
\hline
\end{tabular}

Tabla 5. Paisajes Protegidos vinculados con las aguas subterráneas.

Table 5. Protected landscapes linked to groundwater. 
ne el 35 por ciento del total de los declarados oficialmente protegidos mediante dicha figura.

\section{Aguas subterráneas y espacios protegidos de la Red Natura 2000}

Estos espacios naturales constituyen la red ecológica europea de áreas de conservación de la biodiversidad. Hasta la fecha de publicación del presente artículo estaba constituida por más de 26.000 lugares. Es la red de zonas protegidas más extensa del mundo en la que se realiza una gestión coordinada. Cubre el $18 \%$ de la superficie terrestre de la UE y amplias zonas de sus mares. En España, dicha Red está constituida en la actualidad por 1.467 Lugares de Importancia Comunitaria (LIC) y por 644 Zonas de Especial Protección para las Aves (ZEPA).

El Instituto Geológico y Minero de España y la Dirección General del Agua publicaron en el año 2014 el libro titulado “Las aguas subterráneas y la Red Natura 2000" (IGME-DGA, 2014) que proporciona una exhaustiva información sobre la relación río-acuífero de los espacios naturales que componen la Red Natura 2000 en las 9 cuencas intercomunitarias del Estado español. Los principales resultados que proporcionó dicho trabajo se sintetizan a continuación:

- 665 lugares de la Red Natura 2000 (438 LICs y 227 ZEPAs) se localizan sobre masas de agua subterránea por lo que pueden presentar algún tipo de interrelación hídrica con las aguas subterráneas. Esta cifra supone aproximadamente el $44 \%$ de los espacios naturales incluidos en la Red Natura 2000 que se localizan sobre las 9 cuencas intercomunitarias del Estado español.

- El porcentaje de superficie de masas de agua subterránea definidas sobre las 9 cuencas intercomunitarias del Estado español sobre la que se emplazan LICs es del $20 \%$ y el de ZEPAs de aproximadamente el $19 \%$.

- El número total de tramos de ríos con relación ríoacuífero en lugares pertenecientes a la Red Natura 2000 es de 1.233. Esta cantidad representa el $63 \%$ del total de tramos de ríos en los que existe relación hídrica entre aguas superficiales y subterráneas en las demarcaciones hidrográficas intercomunitarias. El número de tramos ganadores, perdedores y con régimen variable con relación río-acuífero en lugares pertenecientes a la Red Natura 2000, que se localizan sobre las 9 cuencas intercomunitarias, es respectivamente de 1.002, 165 y 66.
Las aguas subterráneas y las áreas protegidas por instrumentos internacionales

Contempla todos aquellos espacios naturales que son formalmente designados según lo dispuesto en los Convenios y Acuerdos internacionales en los que España participa. Como más significativos cabe citar los siguientes:

- Los Humedales de Importancia Internacional del Convenio de Ramsar.

- Los sitios naturales de la Lista del Patrimonio Mundial de la Convención sobre la Protección del Patrimonio Mundial, Cultural y Natural.

- Las áreas protegidas del Convenio para la protección del medio ambiente marino del Atlántico del nordeste (OSPAR).

- Las Zonas Especialmente Protegidas de Importancia para el Mediterráneo (ZEPIM) del Convenio para la protección del medio marino y de la región costera del Mediterráneo.

- Los Geoparques declarados por la UNESCO.

- Las Reservas de la Biosfera declaradas por la UNESCO.

- Las Reservas biogenéticas del Consejo de Europa.

\section{Humedales de importancia internacional del Convenio de Ramsar}

España tiene en estos momentos 75 zonas húmedas incluidas en el mismo. De ellas, 54 se estima que bien se localizan total o parcialmente sobre la superficie de una o varias masas de agua subterránea o bien existe información contrastada que permite asegurar su dependencia hídrica en parte o en todo de las aguas subterráneas.

Humedales españoles Ramsar de reconocida importancia internacional, y con una significativa ligazón con la fase subterránea del recurso hídrico se pueden citar los siguientes: Albufera de Valencia, Aiguamolls de L'Empordà,Tablas de Daimiel, Doñana, Delta del Ebro, Fuente de Piedra, Gallocanta, Lagunas de Ruidera y Mar Menor. En todos ellos existe una notable información hidrogeológica. A este respecto cabe destacar las tesis realizadas por Bach (1991) en el Parque Natural de los Aiguamolls de L'Empordà; Rodríguez Arévalo (1988), Romero (1998), Olías (1994), Trick (1997); Iglesias (1999), Coleto (2003) y Lozano (2004) en el Parque Nacional de Doñana; González Monterrubio (1985), García Rodríguez (1995); Castaño (2002), Martínez Santos (2007) y Zorrilla (2009) en el Parque Nacional de las Tablas de Daimiel; Linares (1989) y Montalván (2018) en la Laguna de Fuente de Piedra; y Montero (1991) en las 
Lagunas de Ruidera. Como bibliografía representativa del conocimiento hidrogeológico de los otros humedales que se citan en el presente apartado cabe referenciar en el Delta del Ebro a Bayó et al., (1997); Octavio de Toledo y García Lapresta (1992) y San Román et al. (2007) en Gallocanta; Rodriguez Estrella (2009) y García Aróstegui et al. (2016) en el Mar Menor; y Ballesteros (2001) y Fornés et al. (2008) en la Albufera de Valencia.

EI IGME a lo largo de los años 2004 y 2005 abordo una primera fase de actualización y mejora del conocimiento sobre la dinámica hidrogeológica de los acuíferos relacionados con 13 humedales Ramsar. En dicho trabajo, que se publicó con el título "Humedales del mediterráneo español: modelos geológicos e hidrogeológicos" se cuantificaba en un $58 \%$ la alimentación a estos enclaves naturales mediante aportes de agua subterránea, que bien podía proceder de acuíferos próximos a los humedales, pero sin conexión hídrica directa con los mismos, o bien por descarga a través del fondo del lecho de la cubeta sobre la que se asienta la zona húmeda (Durán et al., 2005).

\section{Sitios naturales inscritos en la Lista del Patrimonio Mundial}

A esta tipología pertenecen los Parques Nacionales de Garajonay, Doñana y El Teide, que se catalogan como de estricto carácter natural, mientras que Pirineos-Monte Perdido y la isla de Ibiza se clasifican como sitios mixtos (naturales y culturales). En todos ellos se puede afirmar que existen importantes áreas de recarga a los acuíferos a la par que notables puntos de descarga y aportes de aguas subterráneas a los ríos y al mar. En el presente artículo ya se han proporcionado diversas referencias al Parque Nacional de Doñana y a su dependencia de las aguas subterráneas. Por lo que respecta al Parque Nacional de Garajonay y al Parque Nacional del Teide cabe citar las tesis doctorales de Skupien (1998) para el primero y Marrero (2010) para el segundo. En la isla de Ibiza hay tres trabajos que resultan claves para entender la evolución de los recursos hídricos subterráneos acaecida en la misma desde los años setenta de la pasada centuria hasta hoy en día. Estos son los siguientes: Estudio de los recursos hídricos totales de las islas de Mallorca e Ibiza (SGOP-IGME-IRYDA, 1973); Manuales de utilización de acuíferos: Isla de Ibiza (López Geta et al. 1990) y Plan Hidrológico de las Illes Balears (DGRH-Govern Illes Balears, 2018). El sitio natural de Pirineos-Monte Perdido sobresale por ser un bien de Patrimonio Mundial de índole transfronteriza, que cuenta con numerosos manantiales, sumideros y cursos fluviales alimentados por importantes surgencias de agua subterránea, que se encuentran asociadas a acuíferos que presentan espectaculares desarrollos kársticos que los hacen muy sensibles al efecto del cambio climático (Lambán et al., 2014; Jodar et al., 2016)

\section{Áreas protegidas para la protección del medio ambiente marino del Convenio del Atlántico del nordeste (OSPAR)}

España ha incorporado dos espacios naturales a este convenio, aunque únicamente el Parque Nacional de las Islas Atlánticas tiene cierto interés hidrogeológico, pues, a pesar de que no se encuentra incluido dentro de ninguna de las masas de agua subterránea establecidas por la Dirección General del Agua definidas en el segundo ciclo de planificación, existen descargas de agua subterránea que afloran en diversos lugares de las islas (Ruiz-Pico y Samper, 2000; Alegre, 2000).

\section{Zonas Especialmente Protegidas de Importancia para el Mediterráneo (ZEPIM)}

En la actualidad existen en España nueve ZEPIM adscritas al Convenio para la protección del medio marino y de la región costera del Mediterráneo. Cuatro de ellas, según la bibliografía consultada, presentan afloramientos permeables que constituyen áreas de recarga a los acuíferos, así como descargas de aguas subterráneas de mayor o menor envergadura. Estas son las siguientes: Cabo de Gata-Níjar (Villalobos Mejías et al., 2010); Acantilados de Maro-Cerro Gordo (López Alcaide y Andreu, 2011); Mar Menor y zona mediterránea oriental de la costa murciana (Rodriguez Estrella, 1995; Jiménez-Martínez et al., 2016; Alcolea et al., 2019); y Archipiélago de Cabrera (Robledo, 2016).

\section{Geoparques}

En 2015 la UNESCO aprobó la figura de Geoparque, que se puede definir como un territorio que posee un especial y notable patrimonio geológico tanto desde un punto de vista científico como didáctico y estético. De los trece Geoparques declarados hasta el momento en España se puede afirmar, conforme a la información consultada, que presentan relación con las aguas subterráneas, bien mediante descarga directa a 
través de manantiales o diferida a ríos o bien porque constituyen áreas de recarga a los acuíferos, los siguientes: Cabo de Gata-Níjar (Villalobos Mejías et al., 2010); Maestrazgo (Antón-Pacheco et al., 2005; Mejías et al., 2007); Sierras Subbéticas de Córdoba (López Chicano et al., 2013); Sobrarbe-Pirineos (Sánchez, 1988; Oliván, 2016); Sierra Norte de Sevilla (López Geta et al., 2011); Villuerca-lbores-Jara (APRODERVI, 2019); Molina de Aragón-Alto Tajo (DGOH. 1991.; Carcavilla et al., 2008); Isla de El Hierro (PHEH, 2018); Lanzarote y archipiélago de Chinijo (PHIL, 2018); Las Loras (DPB-ITGE, 1998); y Conca de TrempMontsec (Pascual, 1992).

\section{Reservas de la Biosfera}

Las Reservas de la Biosfera son zonas que pertenecen a ecosistemas terrestres o costeros designados por la UNESCO. España, que es el país con más reservas de la biosfera declaradas en el mundo, tiene 52 que se distribuyen a lo largo de 15 de las 17 Comunidades Autónomas. Tres de ellas son transfronterizas y una intercontinental. En la tabla 6 se listan las 31 Reservas de la Biosfera que de alguna u otra forma presentan interrelación hídrica con las aguas subterráneas. EI número de espacios naturales anteriormente mencionados supone el 60 por ciento del total (52) de los protegidos oficialmente mediante dicha figura.

\section{Reservas biogenéticas del Consejo de Europa}

Es una figura de protección en desuso. En España sólo está reconocida como tal la Albufera de
Mallorca. Información hidrogeológica al respecto de la misma se puede encontrar en Custodio et al. (1992) y DGRH-Govern Illes Balears (2018).

\section{Hidrogeología de los Parques Nacionales del Estado español}

Según establece la Ley 30/2014, de 3 de diciembre, de Parques Nacionales, los parques nacionales son espacios naturales de alto valor ecológico y cultural, poco transformados por la explotación o actividad humana que, en razón de la belleza de sus paisajes, la representatividad de sus ecosistemas o la singularidad de su flora, de su fauna, de su geología o de sus formaciones geomorfológicas, poseen unos valores ecológicos, estéticos, culturales, educativos y científicos destacados cuya conservación merece una atención preferente y se declara de interés general del Estado.

La denominación "Parque Nacional" no es exclusiva de la categoría II definida por la Unión Internacional para la Conservación de la Naturaleza (UICN) (Dudley, 2008). En las 6 categorías que esta organización establece pueden y de hecho concurren espacios naturales denominados Parques Nacionales. Incluso existen algunos Parques Nacionales en el mundo que ni siquiera son áreas protegidas según los criterios instituidos por la UICN. En muchos países los Parques Nacionales constituyen la figura más emblemática de su red de Espacios Naturales Protegidos.

En el mundo hay 3143 Parques Nacionales según datos de la Unión Internacional para la Conservación de la Naturaleza. Su distribución por continentes es la

\begin{tabular}{|l|l|l|}
\hline \multicolumn{2}{|c|}{ RESERVAS DE LA BIOSFERA VINCULADAS CON LAS AGUAS SUBTERRÁNEAS } \\
\hline Terras do Miño & Somiedo & Lanzarote \\
\hline Picos de Europa & Babia & El Hierro \\
\hline Redes & Valles de Omaña y Luna & Gran Canaria \\
\hline Los Argüellos & Sierra Nevada & Fuerteventura \\
\hline Valles de Leza, Jubera, Cidacos y Alhama & Transfronteriza de Geres-Xures & La Gomera \\
\hline La Mancha Húmeda & Doñana & Las Ubiñas - La Mesa \\
\hline El Alto Bernesga & Urdaibai & Terres de L'Ebre \\
\hline Sierras de Cazorla, Segura y las Villas & Ordesa - Viñamala & Ponga \\
\hline Intercontinental del Mediterráneo & Cabo de Gata-Nijar & Alto Turia \\
\hline Sierra de Grazalema & La Palma & Valle del Cabriel \\
\hline Sierra de las Nieves y su entorno & & \\
\hline
\end{tabular}

Tabla 6. Reservas de la Biosfera vinculadas con las aguas subterráneas.

Table 6. Biosphere reserves linked to groundwater. 
siguiente: 280 en África, 1036 en Asia, 510 en Europa, 311 en América del norte y central, 295 en América del sur y 704 en Oceanía.

Asia y Australia son respectivamente el continente y el país con un mayor número de Parques Nacionales. Los países que en cada continente poseen un mayor número de Parques Nacionales son los siguientes: Madagascar con 25 en África; China con 244 en Asia; Rusia con 48 en Europa; Estados Unidos con 61 en América del norte y central; Brasil con 72 en América del Sur; y Australia con 685 en Oceanía. España ocupa el décimo lugar -ex aequo con Alemania- sobre un total de 42 países que han declarado hasta la fecha Parques Nacionales en Europa y el cuadragésimo segundo a escala mundial sobre un total de 121 países que poseen esta figura de protección.

En España la Ley 30/2014 establece en su anexo los sistemas naturales que tienen que estar representados en la Red de Parques Nacionales. Estos se subdividen en dos categorías: sistemas naturales terrestres y sistemas naturales marinos. Dentro de los primeros se establecen 27 tipologías, mientras que para los segundos el número de estas es de 13. A continuación se relacionan las tipologías donde las aguas subterráneas en mayor o menor medida están presentes en la Red de Parques Nacionales del Estado español.

Para los sistemas naturales terrestres se han identificado 15 tipologías:

- Formas de relieve y elementos geológicos singulares del macizo Ibérico y las cordilleras Alpinas.

- Formaciones y relieves singulares de montaña y alta montaña.

- Sistemas naturales singulares de origen glaciar y periglaciar.

- Sistemas naturales singulares de origen kárstico.

- Sistemas y formaciones asociadas a las cuencas terciarias continentales y marinas.

- Zonas desérticas costeras y de interior.

- Cursos de agua y bosques de ribera.

- Cañones fluviales sobre relieves estructurales.

- Depósitos y formas con modelado singular de origen fluvial y eólico.

- Costas, acantilados, dunas y depósitos litorales.

- Humedales y lagunas de alta montaña.

- Lagunas halófilas, saladares y aljezares.

- Lagunas de agua dulce, carrizales, espadañales y juncales, y herbazales de tabla con encharcamiento temporal.

- Humedales costeros y marismas litorales.

- Sistemas naturales singulares de origen volcánico. Para los sistemas naturales marinos se han identificado un total de dos tipologías:

- Fondos detríticos y sedimentarios.
- Grandes montañas, cuevas, túneles, y cañones submarinos.

En la tabla 7 se muestran el número de masas de agua subterráneas, que se han definido en el segundo ciclo de planificación hidrológica, sobre las que se extienden total o parcialmente los límites de los 15 Parques Nacionales declarados oficialmente hasta la fecha en España. En la tabla 8 se muestra el código y la denominación de dichas masas de agua subterránea, así como su superficie y la demarcación hidrográfica a la que se encuentran adscritas. Por último, en las tablas 9 y 10 se proporciona la superficie absoluta y porcentual de los diferentes terrenos aflorantes en los parques atendiendo a la diferente permeabilidad -seis tipos- que estos presentan de acuerdo a la leyenda que se facilita en la figura 1. Los resultados que se muestran en las tablas enumeradas anteriormente se complementan con una serie de mapas donde se refleja la distribución espacial de dicho parámetro en el interior de cada parque. En la figura

\begin{tabular}{|c|c|}
\hline Parque Nacional (PN) & $\begin{array}{l}\text { Masas de Agua subterránea } \\
\text { definidas en el segundo ciclo de } \\
\text { planificación sobre las que se } \\
\text { extienden total o parcialmente los } \\
\text { PN }\end{array}$ \\
\hline Picos de Europa & 4 \\
\hline Ordesa y Monte Perdido & 1 \\
\hline Teide & 2 \\
\hline Caldera de Taburiente & 2 \\
\hline $\begin{array}{l}\text { Aigüestortes i Estany de } \\
\text { Sant Maurici }\end{array}$ & 1 \\
\hline Doñana & 5 \\
\hline Tablas de Daimiel & 1 \\
\hline Timanfaya & 0 \\
\hline Garajonay & 2 \\
\hline $\begin{array}{l}\text { Marítimo-Terrestre del } \\
\text { Archipiélago de Cabrera }\end{array}$ & 0 \\
\hline Cabañeros & 1 \\
\hline Sierra Nevada & 3 \\
\hline $\begin{array}{l}\text { Marítimo-Terrestre de las } \\
\text { Islas Atlánticas de Galicia }\end{array}$ & 0 \\
\hline Monfragüe & 2 \\
\hline Sierra de Guadarrama & 2 \\
\hline
\end{tabular}

Tabla 7. Número de masas de agua subterránea definidas en el segundo ciclo de planificación hidrológica sobre las que se localizan total o parcialmente los Parques Nacionales.

Table 7. Number of groundwater bodies on which national parks are fully or partially located. 
José Manuel Murillo y Leticia Vega, 2019. Las aguas subterráneas y los Espacios Naturales... Boletín Geológico y Minero, 130 (4): $549-592$

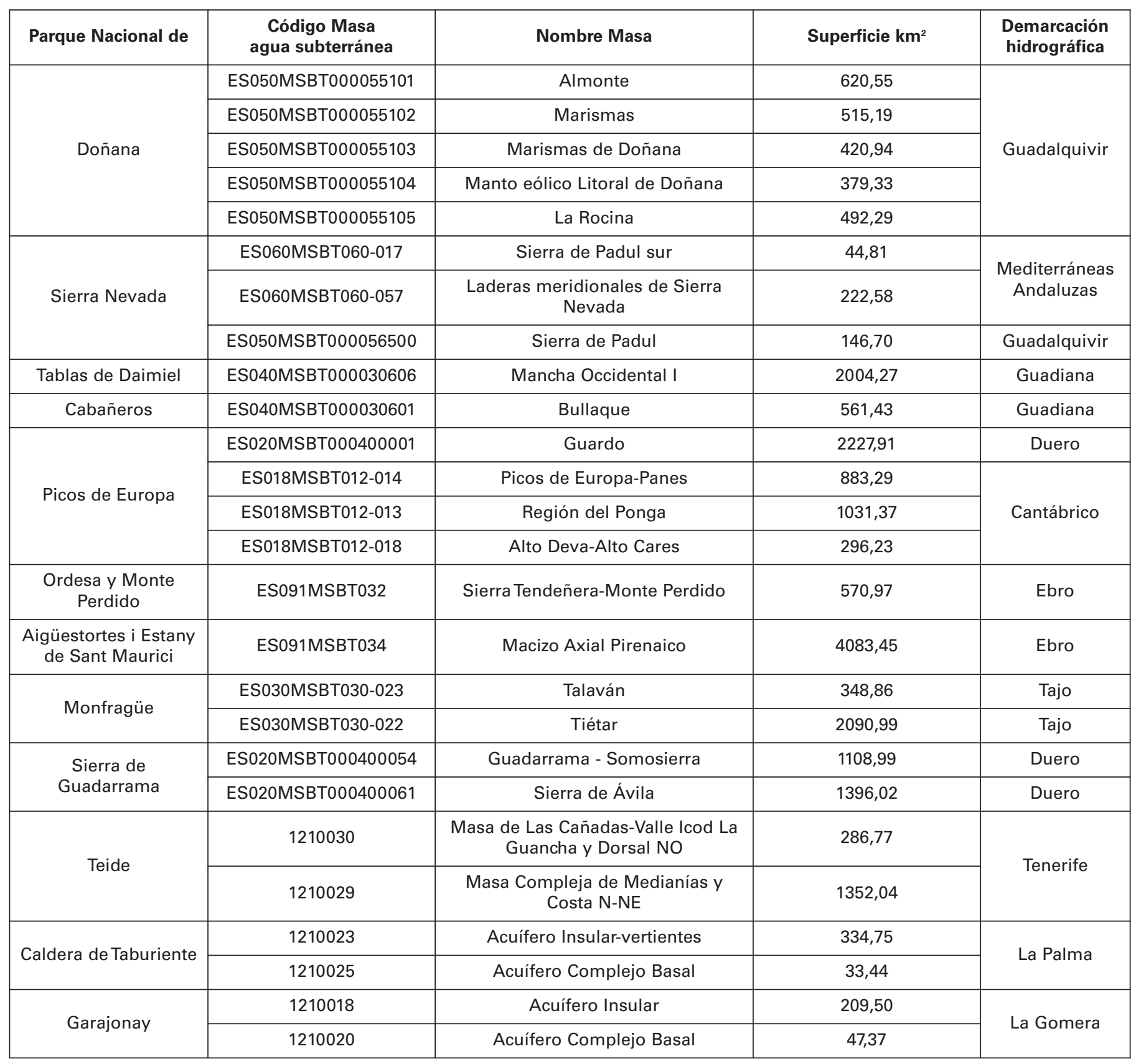

Tabla 8. Nomenclatura y características de las masas de aguas subterráneas vinculadas con los Parques Nacionales.

Table 8. Nomenclature and characteristics of groundwater bodies linked to National Parks.

2 se aporta un mapa de España con la localización de cada uno de los Parques Nacionales y las masas de agua subterráneas establecidas en el segundo ciclo de planificación hidrológica.

Sobre cada una de esas cartografías (Figuras 3 a la 16) se han volcado los manantiales que el IGME tiene inventariados para cada Parque Nacional en su Base de Datos, que, como se puede apreciar en dichas figuras, es una información relativamente escasa o inclu- so nula en un número importante de parques, salvo algunas excepciones como es el caso del Parque Nacional de los Picos de Europa, Caldera de Taburiente, Garajonay y Sierra Nevada. También se han delineado sobre dichos gráficos los principales ríos que discurren sobre los parques al objeto de que en función de la permeabilidad de los materiales geológicos que afloran se pueda deducir algún aspecto sobre la relación río-acuífero, ya que este fenómeno 


\begin{tabular}{|c|c|c|c|c|c|c|c|c|}
\hline \multirow{3}{*}{ Denominación del Parque Nacional } & \multicolumn{8}{|c|}{ Superficie $\left(\mathbf{k m}^{2}\right)$} \\
\hline & \multicolumn{6}{|c|}{ Tipo de permeabilidad } & \multirow{2}{*}{$\begin{array}{l}\text { Lámina } \\
\text { de agua }\end{array}$} & \multirow{2}{*}{$\begin{array}{l}\text { Total PN } \\
\quad\left(\mathbf{k m}^{2}\right.\end{array}$} \\
\hline & la & lb & Ila & Illb & IIla & IIIIb & & \\
\hline Picos de Europa & 225,05 & 191,5 & 17,97 & & 113,3 & 111,83 & 1,38 & 661,03 \\
\hline Ordesa y Monte Perdido & 82,86 & 10,25 & 3,39 & 0,73 & 27,53 & 31,83 & 0,19 & 156,78 \\
\hline Teide & & 1,23 & 17,26 & 140,2 & 29,54 & & & 188,25 \\
\hline Caldera de Taburiente & & 5,91 & 3,75 & & 24,33 & 9,99 & & 43,98 \\
\hline Aigüestortes i Estany de Sant Maurici & & & 0,17 & 23,16 & 6,04 & 107,2 & 2,69 & 139,26 \\
\hline Doñana & & & & 1,46 & 516,05 & & 15,94 & 533,45 \\
\hline Tablas de Daimiel & 2,03 & 5,08 & 2,91 & 0,23 & & & 19,86 & 30,11 \\
\hline Timanfaya & & & 47,42 & 4,34 & & & & 51,76 \\
\hline Garajonay & & & & & 36,35 & 0,7 & & 37,05 \\
\hline $\begin{array}{l}\text { Marítimo-Terrestre del Archipiélago de } \\
\text { Cabrera }\end{array}$ & 4,69 & 6,45 & 0,12 & 0,65 & 1,5 & 0,27 & & 13,68 \\
\hline Cabañeros & & & 15,97 & 58,03 & 3,35 & 331,38 & 0,02 & 408,75 \\
\hline Sierra Nevada & 54,99 & & 0,02 & 2,22 & & 801,41 & 0,19 & 858,83 \\
\hline $\begin{array}{l}\text { Marítimo-Terrestre de las Islas } \\
\text { Atlánticas de Galicia }\end{array}$ & & & & & & 9,68 & & 9,68 \\
\hline Monfragüe & & & 42,28 & 9,43 & 112,25 & & 16,13 & 180,09 \\
\hline Sierra de Guadarrama & & 0,74 & 60,79 & 7,92 & 340,46 & & 0,13 & 410,04 \\
\hline \multicolumn{9}{|l|}{ Superficie por tipos de permeabilidad } \\
\hline$\left(\mathrm{km}^{2}\right)$ & 369,62 & 221,16 & 212,1 & 248,4 & 1210,7 & 1404,29 & 56,53 & 3722,74 \\
\hline
\end{tabular}

Tabla 9. Superficie absoluta de los diferentes terrenos aflorantes en los Parques nacionales atendiendo a su permeabilidad. Los diferentes tipos de permeabilidad están definidos en la figura 1.

Table 9. Absolute surface of the different types of outcrops in the National Parks according to their permeability. The different types of permeability are deffined in figure 1.

de interacción entre aguas superficiales y subterráneas puede verse muy afectado por las variaciones que debidas al cambio climático puedan tener lugar en la recarga a los acuíferos, tanto por precipitación como por infiltración del agua que circula por los cursos fluviales, $y$, por consiguiente, sobre las diferentes tipologías de descarga de las aguas subterráneas que alimentan a los ecosistemas acuáticos o semiacuáticos, como son los sistemas terrestres de agua salada o salobre; los ríos y demás corrientes superficiales de agua, bien sean estas permanentes o temporales; las llanuras de inundación; los lagos y humedales, independientemente de su alimentación, drenaje e hidroperiodo; las cuencas endorreicas; los hábitats y ambientes xéricos o xerófilos; las cuevas y los sistemas kársticos; los manantiales, las fuentes, los rezumes, los oasis y los sumideros; las manifestaciones de índole geotermal; el bosque de ribera y las áreas ripárias; las cascadas y cataratas, los deltas interiores y costeros; y los estuarios.

De la observación de la tabla 7 se advierte que los Parques Nacionales Marítimo-Terrestre del Archipiélago de Cabrera, Marítimo-Terrestre de las Islas Atlánticas y Timanfaya no se localizan sobre ninguna masa de agua subterránea. Esto no quiere decir que dichos parques no posean afloramientos permeables, carezcan de manantiales o de descargas subterráneas al mar, sino solo que la Dirección General del Agua (DGA) atendiendo a los artículos 2 y 7 de la Directiva Marco del Agua (DOCE, 2000) no ha considerado oportuno establecer en dichos territorios masas de agua subterráneas, bien porque en un futuro próximo o en la actualidad no hay captación de agua destinada al consumo humano que proporcio- 
José Manuel Murillo y Leticia Vega, 2019. Las aguas subterráneas y los Espacios Naturales... Boletín Geológico y Minero, 130 (4): $549-592$

\begin{tabular}{|c|c|c|c|c|c|c|c|c|}
\hline \multirow{3}{*}{ Denominación Parque Nacional } & \multicolumn{8}{|c|}{ Porcentaje de superficie de cada tipología con respecto a la total del PN } \\
\hline & \multicolumn{6}{|c|}{ Tipo de permeabilidad } & \multirow{2}{*}{$\begin{array}{l}\text { Lámina } \\
\text { de agua }\end{array}$} & \multirow{2}{*}{ Suma } \\
\hline & la & lb & Ila & Ilb & IIla & IIllb & & \\
\hline Picos de Europa & 34,05 & 28,97 & 2,72 & & 17,14 & 16,92 & 0,21 & 100 \\
\hline Ordesa y Monte Perdido & 52,85 & 6,54 & 2,16 & 0,47 & 17,56 & 20,30 & 0,12 & 100 \\
\hline Teide & & 0,65 & 9,17 & 74,49 & 15,69 & & & 100 \\
\hline Caldera de Taburiente & & 13,44 & 8,53 & & 55,32 & 22,71 & & 100 \\
\hline Aigüestortes i Estany de Sant Maurici & & & 0,12 & 16,63 & 4,34 & 76,98 & 1,93 & 100 \\
\hline Doñana & & & & 0,27 & 96,74 & & 2,99 & 100 \\
\hline Tablas de Daimiel & 6,74 & 16,87 & 9,66 & 0,76 & & & 65,96 & 100 \\
\hline Timanfaya & & & 91,62 & 8,38 & & & & 100 \\
\hline Garajonay & & & & & 98,11 & 1,89 & & 100 \\
\hline $\begin{array}{l}\text { Marítimo-Terrestre del Archipiélago de } \\
\text { Cabrera }\end{array}$ & 34,28 & 47,15 & 0,88 & 4,75 & 10,96 & 1,97 & & 100 \\
\hline Cabañeros & & & 3,91 & 14,20 & 0,82 & 81,07 & & 100 \\
\hline Sierra Nevada & 6,40 & & & 0,26 & & 93,31 & 0,02 & 100 \\
\hline $\begin{array}{l}\text { Marítimo-Terrestre de las Islas } \\
\text { Atlánticas de Galicia }\end{array}$ & & & & & & 100,00 & & 100 \\
\hline Monfragüe & & & 23,48 & 5,24 & 62,33 & & 8,96 & 100 \\
\hline Sierra de Guadarrama & & 0,18 & 14,83 & 1,93 & 83,03 & & 0,03 & 100 \\
\hline $\begin{array}{l}\text { Porcentaje de superficie de cada tipolo- } \\
\text { gía respecto de la superficie total de } \\
\text { todos los PN }\end{array}$ & 9,93 & 5,94 & 5,70 & 6,67 & 32,52 & 37,72 & 1,52 & 100 \\
\hline
\end{tabular}

Tabla 10. Porcentaje de los diferentes tipos de terrenos aflorantes en los Parques Nacionales según su permeabilidad. Los diferentes tipos de permeabilidad están definidos en la figura 1.

Table 10. Percentage of the different types of outcrops in the National Parks according to their permeability. The different types of permeability are deffined in figure 1.

nen un promedio de más de $10 \mathrm{~m}^{3}$ diarios o que abastezcan a más de cincuenta personas o bien porque considera que no existe en el subsuelo un volumen claramente diferenciado de aguas subterráneas en el acuífero o en los acuíferos que se extienden bajo la superficie de dichos parques.

En el Parque Nacional de Guadarrama se da la paradoja de que en la vertiente que drena a la Demarcación Hidrográfica del Duero se han identificado dos masas de agua subterránea, mientras que en la correspondiente alTajo, que presenta materiales hidrogeológicos de semejante o idéntica litología, no se ha identificado ninguna. Esto no quiere decir que en dicha vertiente no afloren materiales graníticos más o menos permeables ni descarguen manantiales de similares o parecidos caudales a los existentes en la vertiente que drena al Duero.

En el presente apartado se ha procedido a realizar una descripción y caracterización hidrogeológica de cada uno de los Parques Nacionales declarados hasta el momento en España. Su redacción se ha estructurado según la fecha en que fueron fundados, por lo que el primero que se analiza es Picos de Europa y el último el Parque Nacional de la Sierra de Guadarrama. Se trata de un trabajo eminentemente bibliográfico que ha comportado una extensa labor de consulta. Entre los principales documento que se han revisado es menester destacar las Guías Geológicas de los Parques Nacionales de España que ha elaborado el Instituto Geológico y Minero de España conjuntamente con el Organismo Autónomo Parques Nacionales (OAPN) y cuyo editor es Roberto Rodríguez Fernández. Dichas guías son de libre acceso y se pueden consultar en la web del Instituto Geológico y Minero de España.

La mayor parte de los documentos que se han utilizado para elaborar el presente apartado ya se han citado en anteriores epígrafes. Cuando a lo largo del 


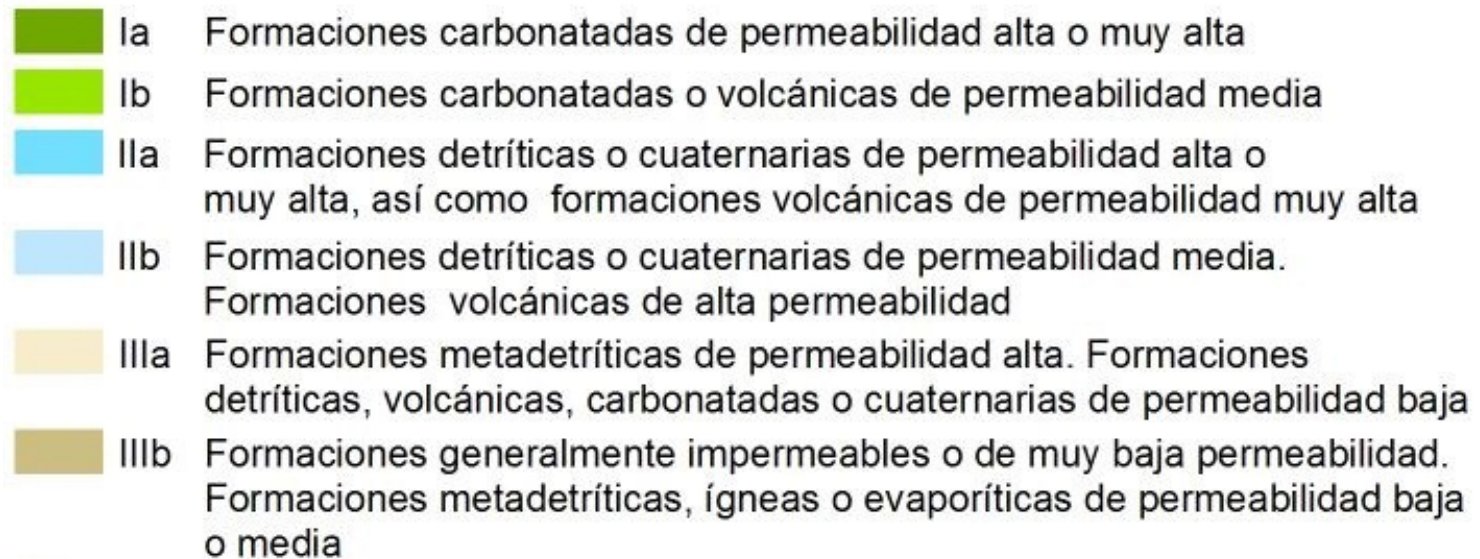

Figura 1. Leyenda de los diferentes tipos de permeabilidad que se presentan en los Parques Nacionales.

Figure 1. Legend of the different types of permeability that are present in the National Parks.

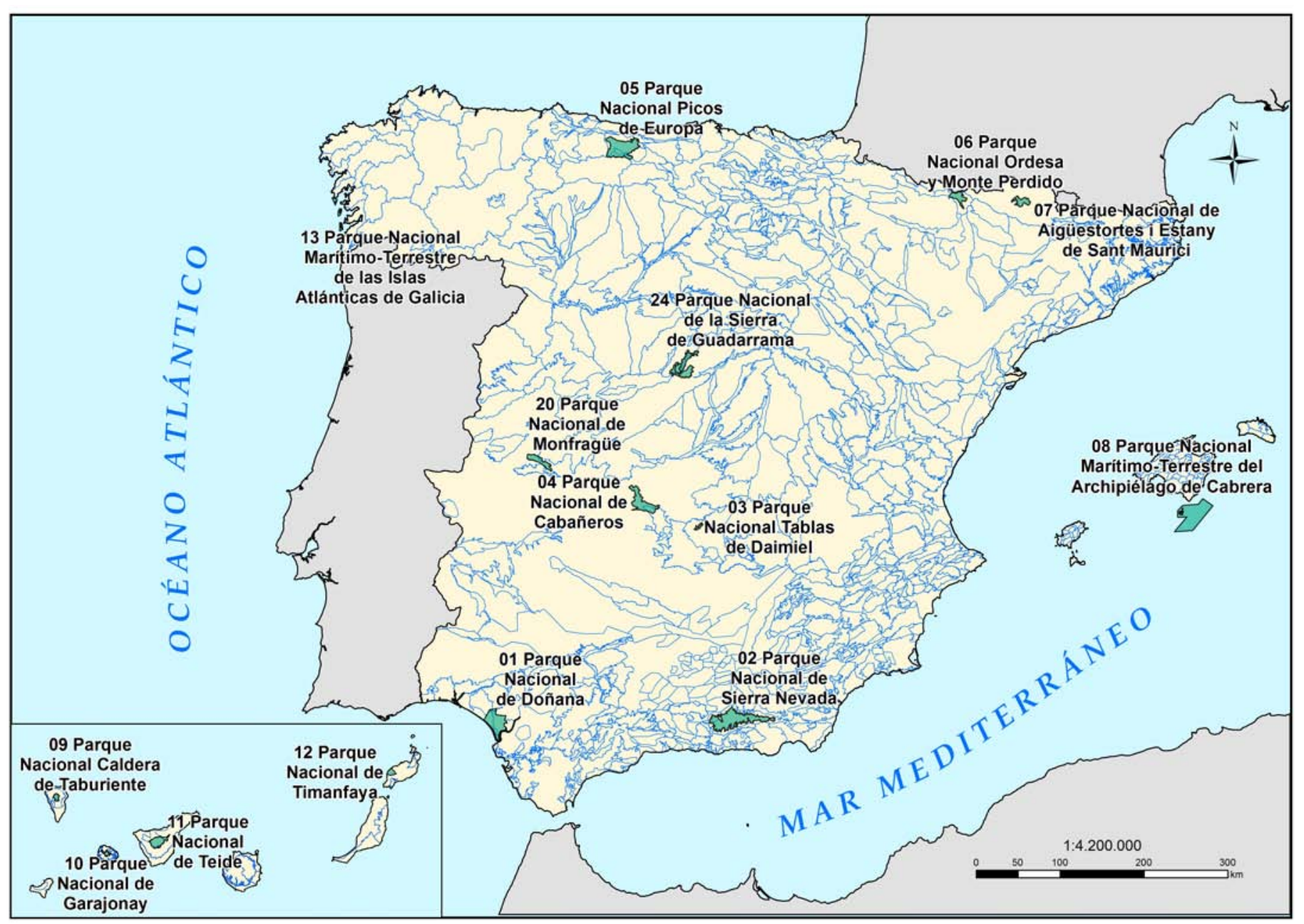

Figura 2. Mapa de situación de los Parques Nacionales españoles.

Figure 2. Map with the location of the Spanish National Parks. 
presente capítulo se aporta nueva información se referencia expresamente su autoría y procedencia de acuerdo a la normativa establecida por el Boletín Geológico y Minero.

\section{Parque Nacional Picos de Europa}

Se localiza en la parte central de la cordillera Cantábrica entre las provincias de Asturias, León y Cantabria. Se trata de un inmenso edificio carbonatado sujeto a una gran karstificación, por lo que abundan los lapiaces, dolinas, uvalas, sumideros o póneres, poljés y valles ciegos. También hay inventariados un gran número de sistemas endokársticos entre los que destacan por su desarrollo vertical el sistema de Trave con simas que superan los 1500 metros de profundidad y por su extensión horizontal la Red de Toneyu con $20 \mathrm{~km}$ de galerías. Entre las formaciones exokársticas se encuentran el Polje de Comeya que se localiza en el sector noroccidental (cuenca hidrográfica de Covadonga-Sella) y el Polje de Vega de Liordes que se ubica en el sector suroriental (cuenca hidrográfica del Deva). Como sumideros de cierta entidad se pueden citar los de Orandi (cuenca hidrográfica de Covadonga-Sella), Pozo de los Agustinos y Toneyu (cuenca hidrográfica del Sella). En la zona media del área septentrional del macizo hay un importante número de depresiones glacio-kársticas, especialmente en su sector occidental.

Litológicamente está compuesto mayoritariamente por calizas muy compactas y masivas, así como por dolomías algo más permeables del Carbonífero; pizarras y areniscas cuarcíticas del Cámbrico y el Ordovícico inferior; y por margas, pizarras, lutitas y areniscas del Pérmico y el Triásico inferior. Salvo las rocas carbonatadas, que presentan una gran permeabilidad por karstificación, el resto de formaciones litológicas presentes en el parque son de carácter impermeable. En el mapa que se presenta en la figura 3 se

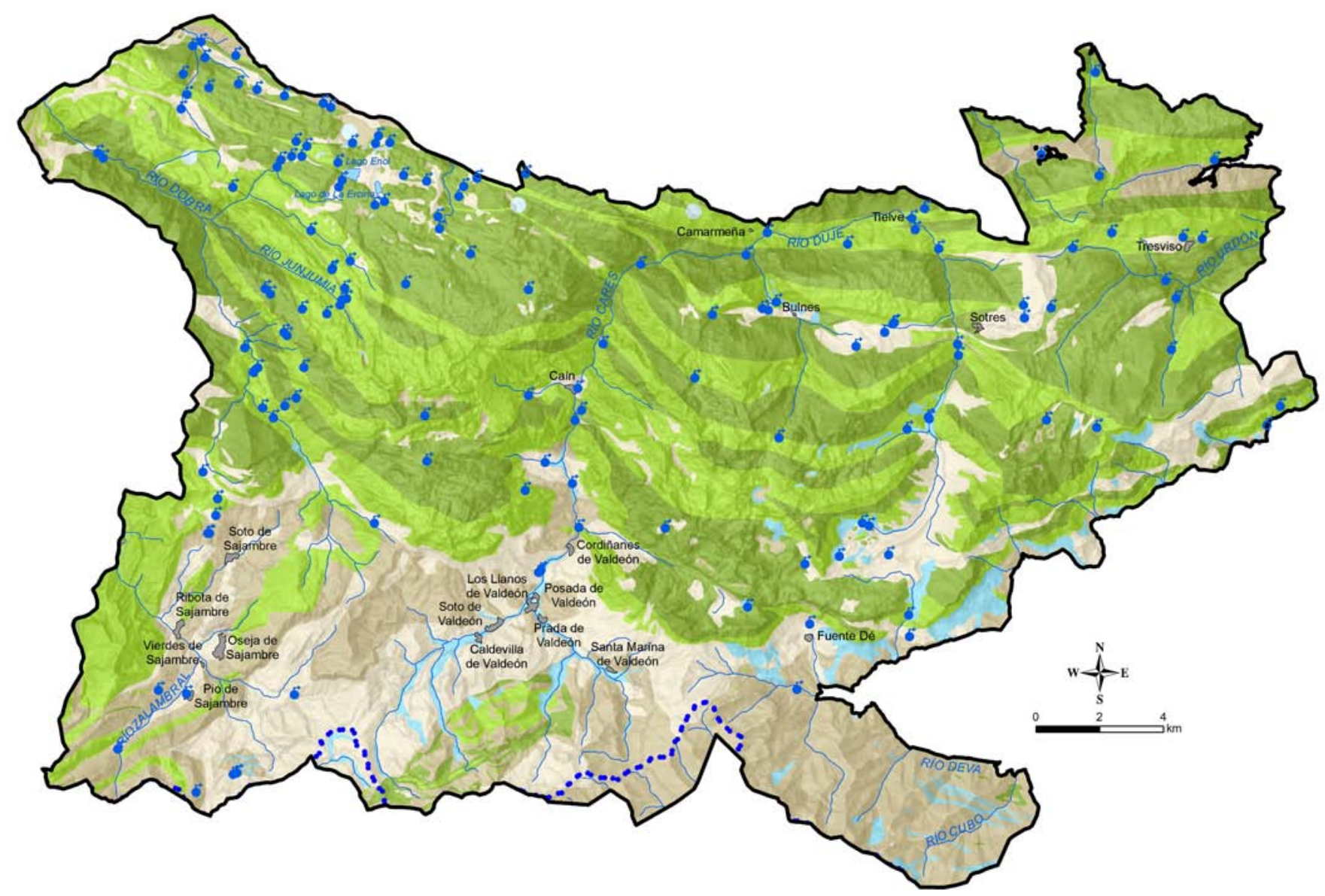

Figura 3. Mapa de permeabilidades del Parque Nacional de Picos de Europa.

Figure 3. Map of the permeability of the Picos de Europa National Park. 
denota que en el área septentrional afloran materiales que presentan una mayor permeabilidad que los que se extienden por la zona meridional, donde predominan las pizarras, areniscas y conglomerados.

En esta última área también se detecta una mayor red de drenaje superficial, mientras que en las zonas medias y altas del macizo septentrional se produce una intensa infiltración kárstica que impide la circulación superficial de agua. Únicamente los cursos principales del Sella-Dobra, Cares-Duje y Deva mantienen caudal a lo largo de todo el año. Sus tributarios están sujetos a grandes variaciones estacionales y pueden secarse parcial o totalmente durante los meses de estío. La recarga a los acuíferos se produce por infiltración directa de las precipitaciones sobre la superficie permeable del parque y por el caudal que pierden los cursos superficiales tanto a través de los sumideros como de forma difusa.

Dado que el área del parque se vio sometida a la orogenia Varisca durante el Carbonífero y a la alpina durante el Terciario, la tectónica del área se caracteriza por un gran número de fallas y cabalgamientos que han dado origen a una superposición y repetición de la serie estratigráfica. Este hecho justifica el gran número de manantiales que surgen junto a cada cabalgamiento a lo largo de los principales cursos de agua. La mayor parte de estas descargas acontecen en el contacto de las calizas con las pizarras o las areniscas por contraste de permeabilidades, pero también por la presencia de fallas. En el interior del parque hay inventariados 21 manantiales de una cierta entidad.

Por lo que respecta a los sistemas lénticos, estos son escasos, dada la gran karstificación que presentan las calizas. Únicamente se presentan asociados a depresiones excavadas por el hielo de los antiguos glaciares en un sustrato formado por pizarras, como es el caso de los lagos permanentes de Enol y de La Ercina. Otros lagos, como el Bricial, que es efímero, solo se origina cuando existen importantes precipitaciones que ocasionan un caudal en el Torrente de Resecu que supera la capacidad de admisión de agua en el sumidero de la Vega de Bricial, por lo que su cubeta se inunda formándose una laguna temporal.

\section{Parque Nacional de Ordesa y Monte Perdido}

El Parque Nacional de Ordesa y Monte Perdido se localiza en el norte de la Península Ibérica, concretamente en el centro de la cordillera pirenaica. Administrativamente se ubica en la provincia de Huesca que forma parte de la Comunidad Autónoma de Aragón.
Litológicamente se encuentra constituido mayoritariamente por rocas mesozoicas del cretácico superior y del cenozoico. La serie estratigráfica la forman conglomerados, brechas, areniscas, lutitas rojas, margocalizas y yesos del Permo-Trias; calizas micríticas y bioclásticas del Cenomaniense-Coniaciense; calizas de rudistas (Formación del Estrecho) del Santoniense; calizas arenosas, areniscas y margas (Formación Areniscas de Marboré) de Maestrichtiense-Campaniese; calizas blancas, dolomías y calizas arenosas (Formación Salarons) del Paleoceno; calizas arenosas, calizas bioclásticas, areniscas cuarcíticas y margas (Formación Gallinera) del Paleoceno-Ilardiense inferior; margas, margocalizas y lutitas grises del llerdiense medio; areniscas, lutitas y margas (Formación Tabacor) del Cuisiense; y turbiditas (Grupo Hecho) del Luteciense. Estas últimas solo afloren en el SO del parque, mientras que el PermoTrias solo lo hace en los Llanos de La Larri (cuenca del Cinca). En el mapa que se presenta en la figura 4 se denota que los materiales que presentan una mayor permeabilidad se extienden en torno a las cuencas de los ríos Yaga, Arazas y su afluente Aras. Las formaciones más permeables corresponden a las calizas de Gallinera y a las calizas y dolomías de la Formación Salarons. La Formación Areniscas de Marboré constituye el impermeable de base de los anteriores acuíferos.

La intensa actividad tectónica a la que se ha visto sometida la zona ha originado una repetición de la sucesión normal de los estratos mediante superposición de las rocas más antiguas sobre otras más modernas a través de la acción de numerosos cabalgamientos. El resultado final de esta dinámica es un gran edificio rocoso de un considerable espesor.

El relieve del parque se ha visto modelado por los siguientes factores: la diferente resistencia de las rocas a la erosión; la compleja tectónica a la que se ha visto sometido; la acción del glaciarismo; la dinámica de los ríos; y la karstificación. Este último ha dado origen tanto a fenómenos endokársticos como exokársticos. Entre los primeros se encuentran cavidades ocupadas por hielo como la Gruta de Casteret; importantes sistema kárstico de desarrollo horizontal como la Punta de las Olas; la Sima de Marboré y la sima de la Brecha de Rolando. En cuanto a la profundidad destaca el sistema de la Fuentes de Escuaín (cuenca del río Yaga) que presenta un desnivel entre el sumidero y la surgencia de $1151 \mathrm{~m}$. y el sistema de Arañonera en el valle de Bujaruelo (cuenca del río Aras) que tiene un desnivel de $1349 \mathrm{~m}$ y un recorrido de más de $43 \mathrm{~km}$. La surgencia principal de este sistema tiene lugar en la cueva de Santa Elena que se sitúa a unos $150 \mathrm{~m}$ por encima del lecho del río Aras. 


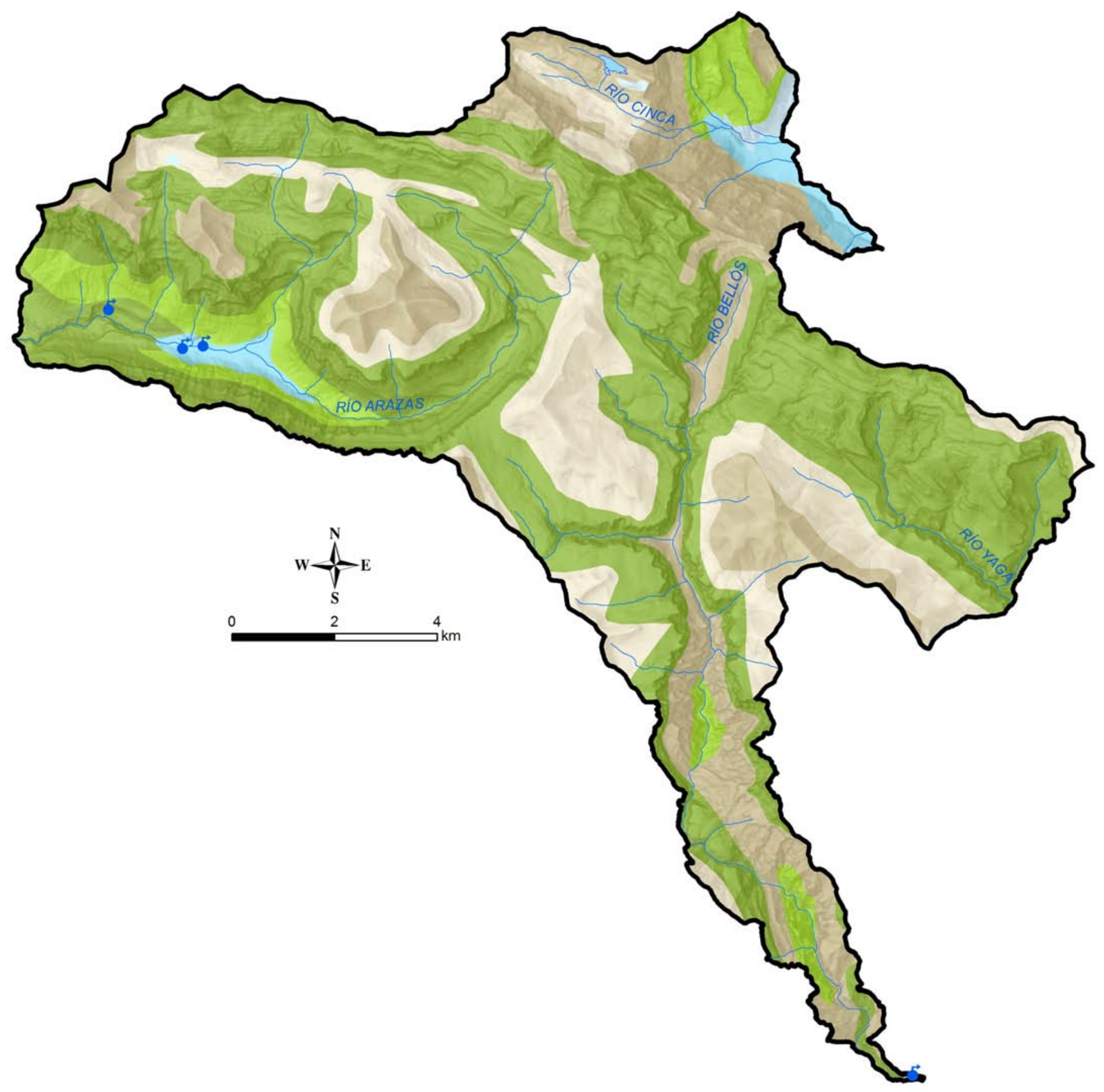

Figura 4. Mapa de permeabilidades del Parque Nacional de Ordesa-Monte Perdido.

Figure 4. Map of the permeability of the Ordesa-Monte Perdido National Park.

Por lo que respecta a las formaciones exokárticas es menester indicar que la red de fisuras y sumideros presenta en la cuenca alta de los ríos del parque una notable intensidad, por lo que prácticamente no exista circulación superficial de agua en estos. A este respecto cabe destacar los lapiaces y sumideros que se localizan en la parte más alta de la Formación calizas de Gallinera. El agua infiltrada en estos sumideros, situados a más de $2300 \mathrm{~m}$, descarga en el manantial Fuente Garcés que alimenta la cascada de La Cola de Caballo (cuenca del río Arazas). Otro importante manantial que surge en el interior del parque es la 
Font Blanca (cuenca del río Bellos), que descarga en mitad de una pared rocosa en el contacto entre las areniscas de Marmoré (impermeables) y las dolomías de Salarons (permeables), dando lugar a una espectacular cascada.

En la figura 4 solo se han representado los 3 manantiales que están cargados hasta la fecha en la Base de Datos del IGME. No obstante, en los trabajos que actualmente está realizando el IGME en el parque (Jodar y Lamban, 2017) se están muestreando 14 manantiales que se distribuyen de la siguiente manera: 7 en el valle de Ordesa (cuenca de los ríos Arazas y Ara); 2 en el valle de Añisclo (cuenca del río Bellos); 1 en el valle de Escuaín (Cuenca del ríoYaga); y 4 en el valle de Pineta (cuenca del río Cinca).

En el parque se ha desarrollado una importante red de cañones que son de tipo fluvio-karstico, pues en su génesis se combinan procesos fluviales y de disolución de las rocas. Los más espectaculares son el de Añisclo y el de Escuaín. Los sistemas lénticos son escasos en el interior del parque respecto a otras zonas de los Pirineos. Esto se debe a que en las cubetas glaciares que se desarrollan sobre roca caliza es frecuente que se formen cavidades y sumideros en su fondo por los que se infiltra el agua impidiendo un almacenamiento permanente de la misma.

En el Parque Nacional de Ordesa y Monte Perdido el lago que presenta un mayor atractivo y espectacularidad desde la óptica de su funcionamiento hidrogeológico es el lbón Helado de Monte Perdido. Esta masa de agua superficial permanece helada una gran parte del año y su cubeta carece de desagüe superficial. La tinción de sus aguas con fluorisceina ha permitido comprobar que, tras más de 2 kilómetros de recorrido subterráneo, descarga en la gran cascada de Gavarnier (Francia), que tiene más de $400 \mathrm{~m}$ de altura, produciéndose un trasvase natural de agua desde la vertiente mediterránea a la atlántica.

La recarga a los acuíferos se produce por infiltración directa de las precipitaciones sobre la superficie permeable del parque y por el caudal que pierden los cursos superficiales a través de los sumideros y de forma difusa. Los tiempos de tránsito del agua muestreada en los manantiales del valle de Ordesa están comprendidos entre uno y dos años. Estos valores tan bajos ponen de manifiesto un sistema hidrogeológico con muy poca inercia y un movimiento muy rápido de las aguas subterráneas (Jodar y Lamban, 2017).

\section{Parque Nacional del Teide}

El Parque Nacional del Teide está situado en la parte central de la isla de Tenerife en el término municipal de la Orotava. En el interior del parque se pueden distinguir tres grandes dominios volcánicos: la pared de las Cañadas donde afloran los materiales más antiguos; las erupciones postcaldera de relleno de la caldera que incluyen el complejoTeide-Pico Viejo y todas las erupciones periféricas asociadas; y las erupciones poscaldera de los ejes del rift que incluyen las erupciones históricas de los volcanes Chahorra y Chinyero (DGOH, 1975-b).

Como se puede apreciar en la figura 5 , si se exceptúa la pared de la caldera, todos los materiales que afloran en el parque son recientes y presentan una alta permeabilidad. Los principales tipos de rocas que se pueden distinguir en los terrenos que afloran en el parque son los siguientes: basaltos, fonolitas y toda la gama de rocas intermedias denominadas traquibasaltos. En el Parque abundan los malpaíses frente a las coladas pahoehoe.

Un elemento singular del parque son las fumarolas que se localizan en el interior del cráter del Pico delTeide. Se trata de emisiones difusas, cuya composición gaseosa está constituida por dos tercios de vapor de agua y un tercio de gases endógenos de origen volcánico, entre los que predomina el $\mathrm{CO}_{2}$ y los compuestos gaseosos de nitrógeno y azufre. Este último se sublima a la salida de las fumarolas dando lugar a diferentes complejos y agregados de azufre que son los responsables de la coloración amarillo verdosa que tapizan las aberturas por las que escapan los gases (Navarro, 1995).

Dado que el parque está constituido mayoritariamente por materiales recientes de alta permeabilidad (Figura 5) no hay cursos permanentes de agua, salvo algunas regatas, regueros y pequeños arroyos que se originan cuando se producen precipitaciones intensas o en las escasas épocas en que tiene lugar un deshielo brusco, por lo que la mayor parte de las precipitaciones se infiltran en el terreno y apenas encuentran obstáculos en su descenso vertical hacia la zona saturada, por lo que se incorporan rápidamente al flujo profundo del acuífero.

Una vez que el agua alcanza el acuífero de las Cañadas, esta tiende a dirigirse hacia los lugares por donde este se descarga de forma natural (valle de La Orotava). Esto es todavía posible gracias a que en la zona de la isla donde se asienta el Parque Nacional delTeide, dada su singular topográfica, apenas se han perforado galerías que lleguen al corazón de la zona saturada, aunque una de las galerías que proporciona un mayor caudal de agua se nutre precisamente del acuífero de Las Cañadas. A este respecto la nueva Ley de Parques Nacionales que se está gestando en estos momentos contempla que no se pueda extraer agua del acuífero del Teide. 


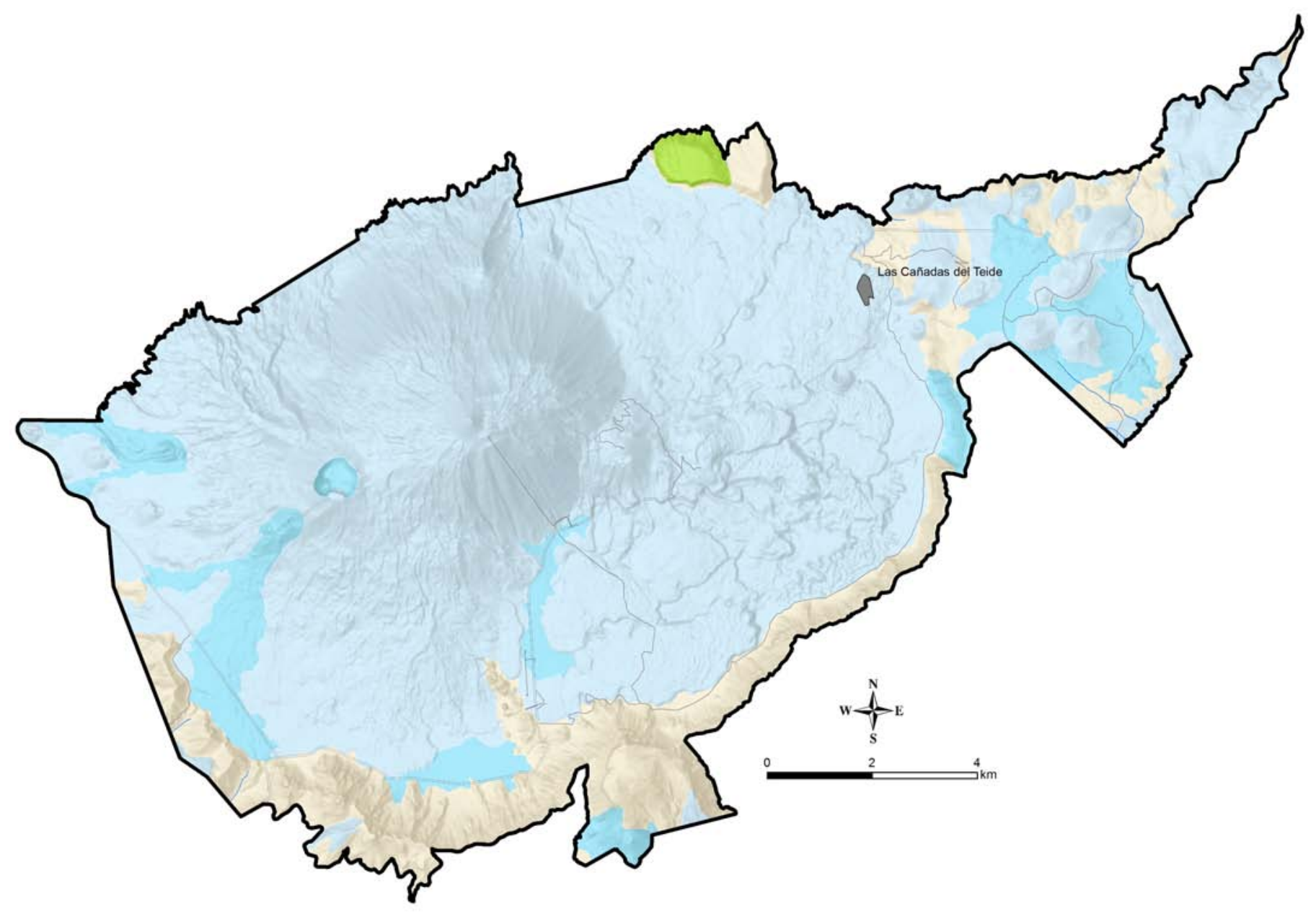

Figura 5. Mapa de permeabilidades del Parque Nacional del Teide. Figure 5. Map of the permeability of the Teide National Park.

Debido a la presencia de almagres impermeables pueden originarse pequeños acuíferos colgados de escasa entidad, aunque los elementos que más dificultan, desvirtúan e interrumpen la circulación del agua subterránea en el subsuelo del parque son los diques. Estas estructuras ocasionan un efecto de apantallamiento que eleva el nivel piezométrico del acuífero en zonas concretas del mismo dando origen a manantiales generalmente intermitentes y de reducido caudal.

\section{Parque Nacional de la Caldera de Taburiente}

Se localiza en el centro de la isla de La Palma en el archipiélago de Canarias. Geográficamente coincide con la formación geológica de la caldera de Taburiente, que es un relieve de erosión en forma de herradura que se abre hacia SE y presenta desniveles superiores a $1.500 \mathrm{~m}$. Geológicamente se pueden diferenciar dos grandes bloques de unidades estratigráficas: el complejo Basal y las Unidades Volcánicas Subaéreas. El primero lo constituyen materiales volcánicos submarinos (lavas, fonolitas y traquitas) y rocas plutónicas intrusivas (gabros). El segundo, que recubre discordantemente al primero, está formado por una serie de edificios volcánicos imbricados compuestos fundamentalmente por lavas y piroclastos que son atravesados por numerosos diques.

El primer conjunto constituye un medio de muy baja permeabilidad que se puede asimilar al basamento impermeable. El segundo, un acuífero volcánico complejo que se conoce con el nombre de "sistema acuífero insular". El flujo subterráneo que circula por este acuífero se dirige desde la zona de cumbres hacia el mar. En su camino se ve interrumpido y compartimentado por la presencia de múltiples diques que dan lugar a una cierta retención del agua subte- 
rránea y a una sobreelevación del nivel piezométrico, que puede alcanzar alturas próximas a los 1800 ms.n.m. y gradientes próximos al 15 por ciento (DGOH, 1975-b).

La recarga al acuífero se produce por infiltración de una parte significativa de la lluvia útil. La zona no saturada presenta un importante espesor que puede variar entre decenas y centenares de metros. La permeabilidad vertical es muy superior a la horizontal, lo que contribuye a que en pocos meses el agua llegue desde la superficie del terreno hasta la zona saturada. Existen dos sistemas de flujo: uno regional que pre- senta una circulación lenta con decenas y hasta centenares de años de tránsito por el acuífero y otro local de circulación rápida (Poncela, 2015).

Asociados a los cursos fluviales aparecen depósitos de barranco y multitud de manantiales en el contacto del complejo Basal con las Unidades Volcánicas Subaéreas. Los barrancos constituyen los ejes de drenaje del sistema debido a lo profundo de su encajamiento en el relieve (Figura 6). Existen numerosos acuíferos colgados que dan lugar a multitud de manantiales y nacientes de menor entidad que los asociados a los barrancos principales. En el mapa de

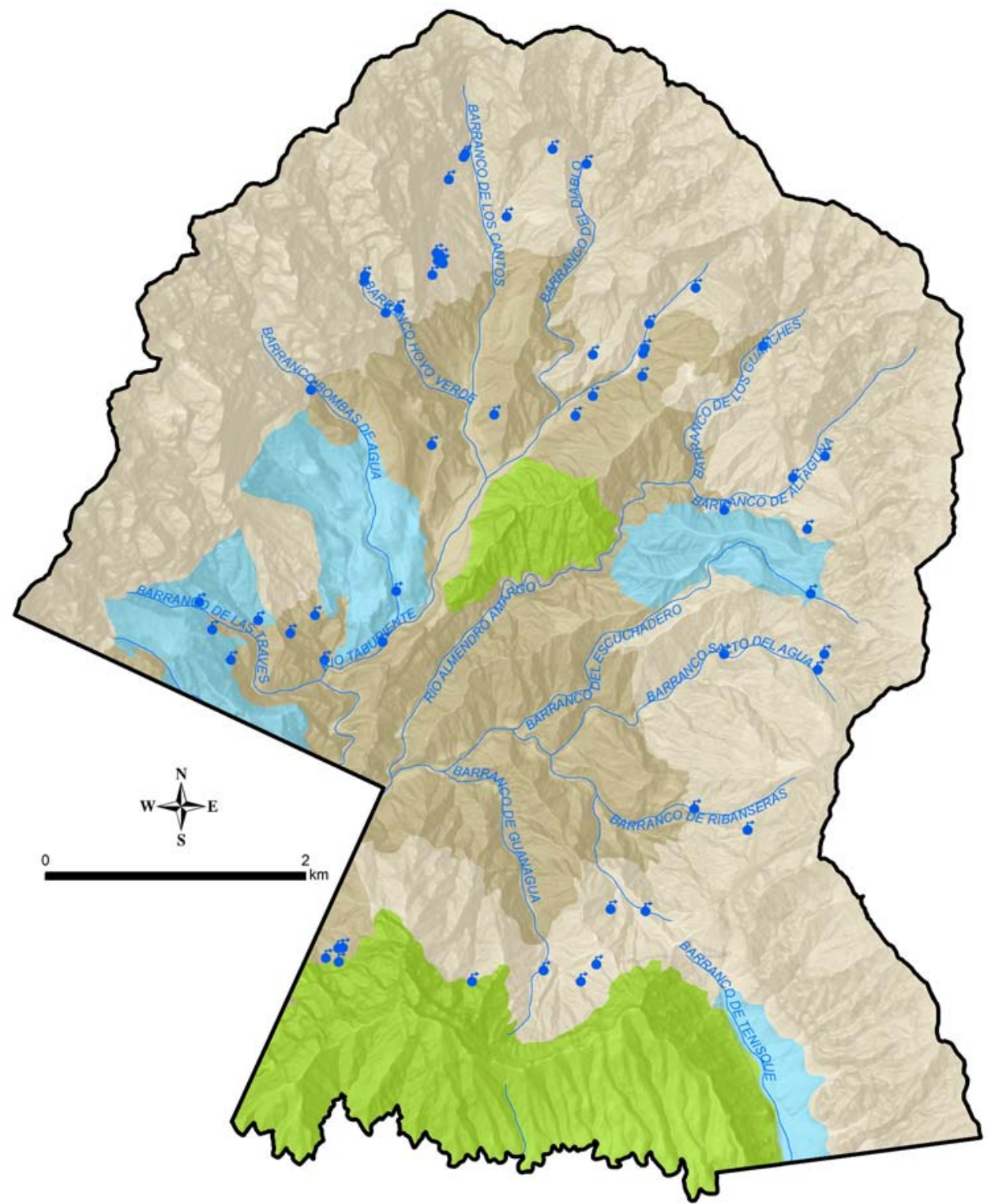

Figura 6. Mapa de permeabilidades del Parque Nacional de la Caldera de Taburiente. Figure 6. Map of the permeability of the Caldera de Taburiente National Park. 
la figura 6 hay representados 55 manantiales. Esta cantidad constituye algo más del 35 por ciento del total de los manantiales que hay inventariados en la isla de La Palma. En el SPA 15 (DGOH, 1975-b) se cita que en el interior de la caldera hay inventariados 120 manantiales. De la anterior cuantía, 93 presentan un caudal inferior a $1 \mathrm{l} / \mathrm{s} ; 23$ descargan un volumen de agua que se encuentra comprendido entre 1 y $10 \mathrm{l} / \mathrm{s}$ y en 4 aquel es superior a 10l/s. Todos los manantiales que afloran en el interior de la caldera drenan un volumen conjunto de agua de $300 \mathrm{l} / \mathrm{s}$.

\section{Parque Nacional de Aigüestortes y Estany de Sant Maurici}

El Parque Nacional de Aigüestortes i Estany de Sant Maurici se localiza en el área más noroccidental de la Comunidad Autónoma de Catalunya; concretamente en la provincia de Lérida. El substrato rocoso del Parque, que forma parte del batolito de la Maladeta, está constituido mayoritariamente por granodioritas $y$ en menor medida por leucogranitos. Ambos de fina- les del Paleozoico. El contacto entre las rocas intrusivas graníticas y las calizas del Devónico se conoce con el nombre de aureola de contacto y se debe a un metamorfismo de origen térmico. Su mayor exponente se localiza junto al lago de Sant Maurici en los picos del Encantats y en la margen izquierda del valle de San Nicolas. Paralelamente a esta margen y hasta pasado el embase de la LLebreta se disponen, paralelamente a la aureola de contacto, materiales de Devónico no metamorfizados, así como del Silúrico y del Cámbrico-Ordovícico. En el área del preparque afloran una mayor diversidad de materiales: pizarras grises, conglomerados, calizas margosas y cuarcitas del Cambrico-Ordovícico; pizarras grafitosas y calizas negras del Silúrico; y lutitas y areniscas rojas del Triásico. Tanto en el interior del parque como en el preparque abundan los sedimentos glaciares y de relleno de cubeta de edad Pleistocena y Holocena.

Atendiendo a la permeabilidad de los materiales cabe indicar que los citados en último lugar presentan unas excelentes características pudiéndose catalogar su permeabilidad de alta o muy alta, por lo que constituyen formaciones favorables para constituir

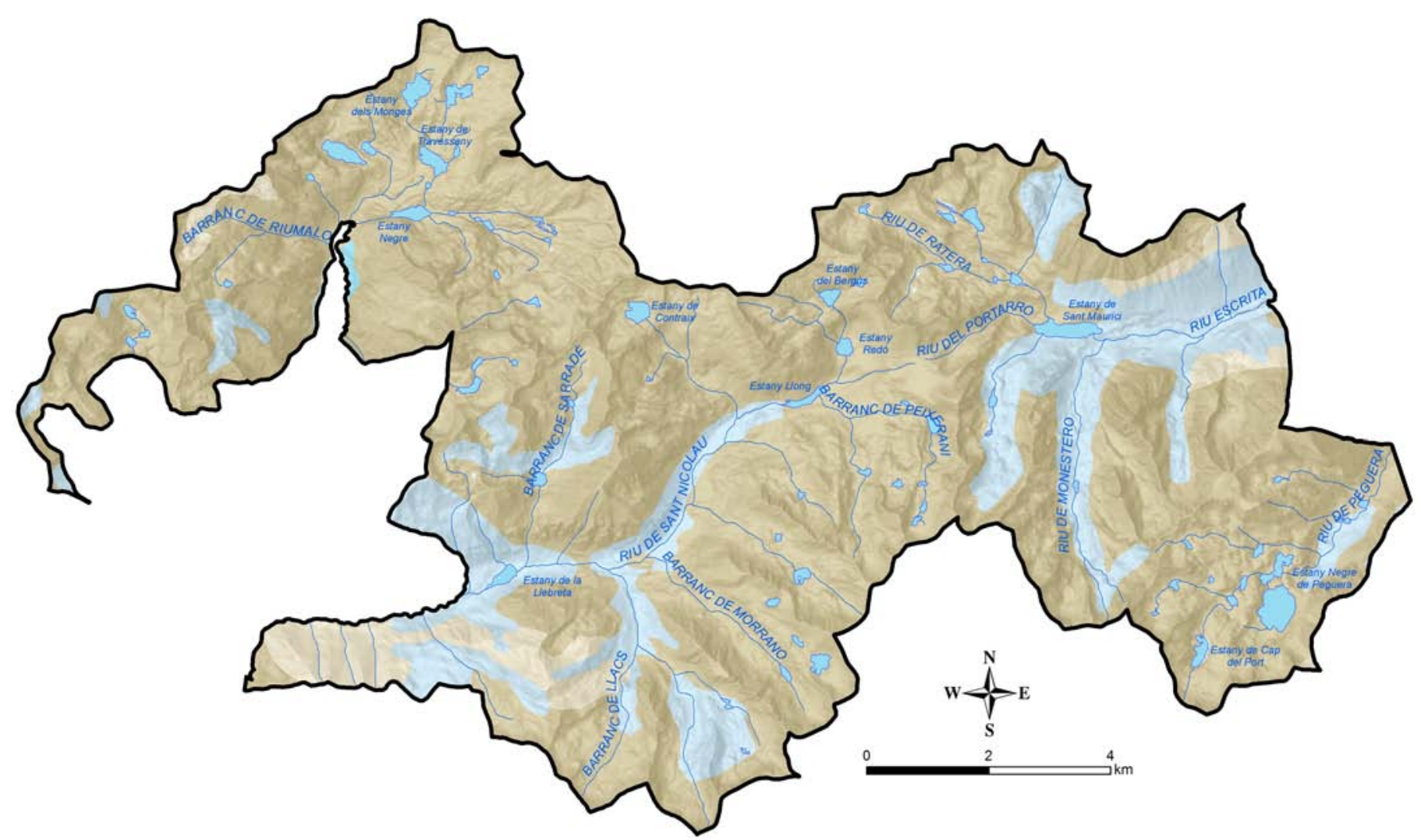

Figura 7. Mapa de permeabilidades del Parque Nacional de Aigüestortes y Estany de Sant Maurici. Figure 7. Map of the permeability of the Aigüestortes y Estany de Sant Maurici National Park. 
buenos acuíferos dependiendo del espesor de sus formaciones. En el mapa de la figura 7 se puede apreciar que dichas formaciones se extienden tanto a lo largo del río Escrita y sus principales afluentes, como del río de Sant Nicolau. Dada la litología de tipo granítico que constituye mayoritariamente su muro, se trata de ríos efluentes, aunque la aportación subterránea será considerablemente más reducida que la superficial, e incluso en algunos tramos testimonial o nula, dado el carácter mayoritariamente impermeable que se asigna a las formaciones graníticas.

No obstante, dichas formaciones, que están sometidas a un régimen climático extremo, se ven sometidas a un proceso de meteorización, que viene favorecido por la humedad ambiental y el elevado tiempo de contacto entre agua y roca, que puede dar lugar a una importante alteración de la franja superficial de la formación granítica, que pasará a funcionar como un acuífero libre más o menos homogéneo e isótropo. EI espesor de estas formaciones es difícil de determinar, pero en algunas cubetas podría ser relativamente significativo. Debajo de la anterior capa se encuentra el material granítico sano del batolito de la Maladeta, que presenta una densa red de fracturas y diaclasas que han determinado la dirección de la red de drenaje superficial. Estos materiales graníticos fracturados funcionan como un único acuífero fisurado, heterogéneo y anisótropo. Ambos acuíferos, aunque en realidad forman un único conjunto permeable, descargaran sus aguas en ríos y lagos del parque.

En el Parque se pueden diferenciar dos tipos de aguas en función de la roca por la que circulan: unas son de tipo blando y escasa mineralización (aguas asociadas a formaciones graníticas bien de origen superficial o subterráneo). Las otras son aguas carbonatadas ligadas a las calizas del Devónico.

Los ríos del parque en su tramo alto presentan caudales comprendidos entre $10 \mathrm{l} / \mathrm{s}$ y $100 \mathrm{l} / \mathrm{s}$. En su curso medio en torno a $800-1400 \mathrm{l} / \mathrm{s}$ y en su tramo bajo superiores incluso a los $2000 \mathrm{l} / \mathrm{s}$ (Empar Carrillo et al., 2013). Dada la litología de las formaciones presentes en el parque, resulta evidente que caudales de un orden de magnitud como los especificados solo los puede aportar la escorrentía superficial, aunque esto no es óbice para que la escorrentía subterránea pueda contribuir en una fracción que será relativamente pequeña comparada con la de origen superficial.

En el Parque hay identificados del orden de 40 manantiales (Empar Carrillo et al., 2013), aunque en la figura 7 no se ha representado ninguno. En estas surgencias, la temperatura del agua permanece constante a lo largo del año, por lo que dadas las oscilaciones térmicas que tienen lugar en el parque, contribuyen al mantenimiento y conservación de ecosistemas singulares al no verse afectado su entorno por grandes cambios estacionales.

Fuera del parque, pero dentro del preparque, se localiza el Balneario de Caldes de Boí en cuyo entorno afloran 37 manantiales termo-minero-medicinales, que de acuerdo a su composición química se pueden agrupar en tres tipologías: sulfurosas sódicas que emergen a temperaturas comprendidas entre $23^{\circ} \mathrm{C}$ y $55^{\circ} \mathrm{C}$; sulfatadas cálcicas que surgen a una temperatura entre $33^{\circ} \mathrm{C}$ y $38^{\circ} \mathrm{C}$; y cloruradas sódicas que descargan a través de una única fuente a una temperatura de $5^{\circ} \mathrm{C}$. La fuente que drena un mayor caudal es Font de Bou con 3,3 l/s (Empar Carrillo et al., 2013).

El elemento más singular del parque lo constituyen los lagos. Hay 272, de los cuales 150 son permanentes (Empar Carrillo et al., 2013). El resto son lagunas temporales que pueden secarse a finales del verano. La mayor parte de ellos se han originado por sobreexcavación de los glaciares, se localizan en las zonas altas, son bastante profundos y pobres en sales minerales. Otros lagos se han originado gracias a barreras de rocas dejadas por las morrenas glaciares, como es el caso del Estany Llong en el valle de Sant Nicolau, o por accidentes geológicos, como es el caso del Estany de Llebreta, que se originó por un desprendimiento de rocas. La dependencia de estos lagos de las aguas subterráneas es testimonial o muy escasa.

\section{Parque Nacional de Doñana}

El Parque Nacional de Doñana se localiza en el extremo sureste de la provincia de Huelva. Su superficie se extiende mayoritariamente por dicha provincia y en menor medida por las de Sevilla y Cádiz. Sus límites quedan establecidos por el espacio comprendido entre la urbanización de Matalascañas y la población del Rocío por el oeste; por un contorno aserrado que se inicia en el anterior núcleo urbano y finaliza en el brazo de LaTorre, por el norte; por el río Guadalquivir por el este; y por el océano Atlántico por el sur. No obstante, estos límites no permiten entender el funcionamiento hidrogeológico del parque que precisa encuadrarse en un contexto mucho más amplio que abarca lo que se denominó en su momento acuífero $27 \mathrm{y}$, dentro de este, en la subunidad acuífero Almonte-Marismas. Actualmente dicho espacio forma parte de 5 masas de aguas subterránea.

El muro del acuífero lo constituyen las margas azules del Mioceno superior-Plioceno inferior que presenta una progresiva disminución de cotas desde los 100 m s.n.m. en el área septentrional a los $200-250$ m 
b.n.m. en la vertical de la marisma (ITGE, 1992). Los materiales que componen el acuífero son los siguientes: arenas basales del Plioceno; gravas, arenas y conglomerados rojizos con matriz arcillosa del Plioceno superior-Cuaternario; manto eólico y dunas antiguas; barras costeras y dunas actuales; materiales cuaternarias de marisma. La potencia global de la formación permeable es de 15 a $20 \mathrm{~m}$ en el norte; 80 a $100 \mathrm{~m}$ en el sur y 200 bajo la marisma (ITGE, 1992). En el mapa de permeabilidades de la figura 8 se han

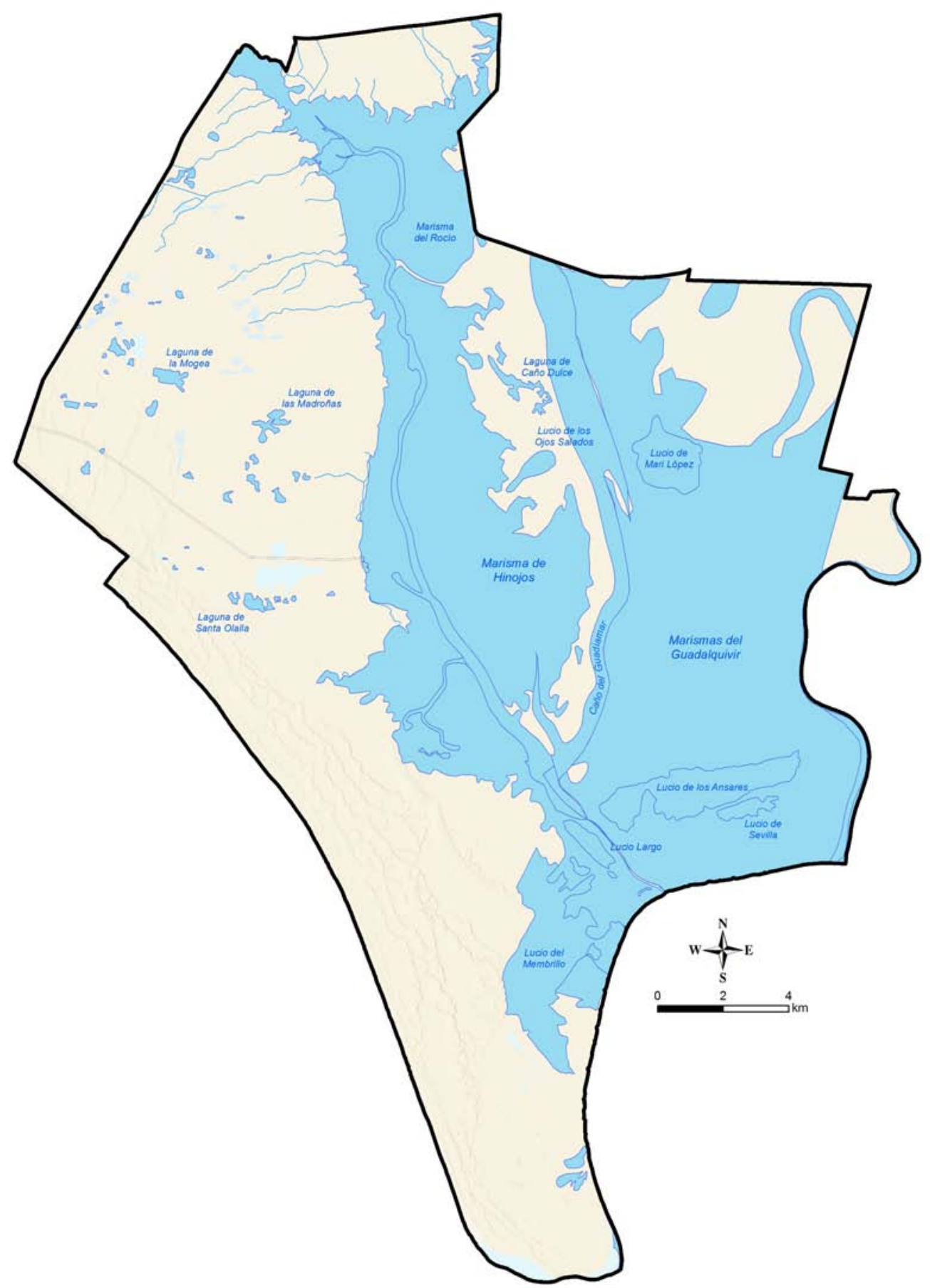

Figura 8. Mapa de permeabilidades del Parque Nacional de Doñana.

Figure 8. Map of the permeability of the Doñana National Park. 
catalogado a los terrenos que afloran en el parque como formaciones detríticas cuaternarias de permeabilidad baja.

El anterior conjunto de niveles detríticos permeables se comporta como un acuífero libre a excepción de los localizados bajo la marisma que funcionan como uno semiconfinado. La recarga al acuífero procede del agua de lluvia que cae sobre la superficie del acuífero en el sector en el que se comporta como libre, así como por las pérdidas de agua que tienen lugar en algunos arroyos. El drenaje del acuífero en régimen natural se produce por evapotranspiración en las zonas donde el nivel piezométrico se encuentra a una cota próxima a la topográfica de la superficie del terreno; en el área de la marisma por flujo vertical ascendente a través del paquete semipermeable; por los ríos y arroyos donde se establece conexión hídrica; a través de pequeños manantiales, zonas de rezume o directamente al mar en el área de costa; en el contacto con las margas azules en el borde norte; $y$ en el ecotóno de La Vera-La Retuerta. Es factible que la formación permeable infrayacente a la marisma descargue a través de un flujo subterráneo profundo tanto al río Guadalquivir en la estrecha franja que constituye su desembocadura como directamente en el mar. En la actualidad el acuífero se encuentra sometido a una intensa explotación por bombeo.

Se trata del Parque Nacional sobre el que se han realizado un mayor número de estudios hidrogeológicos. A título de ejemplo cabe indicar que el profesor Emilio Custodio junto con sus colaboradores han realizado a lo largo de diferentes épocas más de 40 publicaciones de índole hidrogeológico bien en dicho Parque Nacional o bien en su entorno.

\section{Parque Nacional de las Tablas de Daimiel}

En España se puede considerar al profesor Llamas como el pionero que despierta la atención sobre el papel fundamental que juegan las aguas subterráneas en el mantenimiento hídrico de muchos humedales. Especialmente, como comenta González Bernáldez (1992), a partir de sus reiteradas llamadas de atención sobre la situación y evolución del Parque Nacional de Las Tablas de Daimiel que se localiza en la zona central de la Península Ibérica, en plena comarca de La Mancha en la provincia de Ciudad Real.

Las Tablas de Daimiel constituyen uno de los pequeños relictos que restan de una gran zona húmeda de unos $150 \mathrm{~km}^{2}$ que se extendía entre Villarrubia de los Ojos y el embalse del Vicario. Se trata de un área ligada a los cursos de los ríos Gigüela y
Guadiana y a los grandes encharcamientos que estos originaban en régimen natural debido a la escasa pendiente de los terrenos por los que circulaban y a la importante interrelación hídrica que mantenían con el acuífero subyacente. Castaño (2008) apunta que la persistencia en esas zonas de una extensa lámina de agua se debía a tres procesos:

Aportes de agua procedente mayoritariamente del río Gigüela, pero a los que contribuía también en menor cuantía el río Azuer. El carácter efluente o influente que ambos ríos mantenían con el acuífero provocaba que las descarga de agua que estos ríos proporcionaban a las tablas fueran estacionales e irregulares, tanto para un ciclo anual como hiperanual, así como que unas veces predominara la escorrentía superficial sobre la de origen subterráneo y otras se diera el fenómeno contrario. La aportación del Gigüela fluctuaba entre 0 y 324 $\mathrm{hm}^{3} / \mathrm{a}$ y la del Azuer entre 0 y $67 \mathrm{hm}^{3} / \mathrm{a}$.

- Aportes de aguas subterráneas procedentes del nacimiento del río Guadiana en los manantiales que se denominan "Ojos del Guadiana", que descarga parte del agua que se almacena en el acuífero de la Mancha occidental y se localizan a unos 20 $\mathrm{km}$ al este del límite del Parque Nacional, así como de múltiples "ojillos" que aparecían en la propia zona húmeda. Según datos procedentes de medidas realizadas entre 1915 y 1932 la aportación media del Guadiana aguas arriba de su confluencia con el río Azuer era del orden de $60-70 \mathrm{hm}^{3} / \mathrm{a}$.

- Infiltración del agua retenida en una serie de presas que alimentaban a 14 molinos

Al tratarse de un área de descarga, el funcionamiento hidrogeológico del parque resulta difícil de entender si este no se contempla dentro de un contexto geológico más amplio, que no solo el delimitado por el territorio que abarca el espacio natural (García Rodríguez y Almagro Costa, 2004). A este respecto, se precisa analizarlo desde la óptica de la totalidad de lo que inicialmente se denominó "Acuífero 23", posteriormente “Unidad Hidrogeológica 04.04" y actualmente masa de agua subterránea "Mancha Occidental I".

Este gran acuífero está constituido por dos unidades hidrogeológicas separadas entre sí por un nivel detrítico intermedio que funciona como un acuitardo. La unidad superior, que se extiende por casi toda la superficie de la llanura manchega, está formada por calizas y calizas margosas del Mioceno Superior y por materiales detríticos del Plioceno y Cuaternario. Su espesor varía entre 35 y $200 \mathrm{~m}$, la transmisividad de las formaciones calcáreas del Mioceno Superior entre 50 y $20.000 \mathrm{~m}^{2} /$ día, el coeficiente de almacenamiento medio es de 1,5\% y la dirección de flujo subterráneo 
E-O (ITGE, 1989). La unidad hidrogeológica inferior, que no se manifiesta en la zona de Las Tablas de Daimiel, presenta una extensión de unos $3.500 \mathrm{~km}^{2}$. Se trata de un acuífero de carácter confinado o semiconfinado y litológicamente compuesto por formaciones calcáreas y dolomíticas del Jurásico y Cretácico, que son continuación geológica del Campo de Montiel y de la Sierra de Altomira. En la figura 9 se muestra el mapa de permeabilidades del Parque Nacional. Los terrenos que afloran en el parque se han catalogado como formaciones carbonatadas de permeabilidad media, alta y muy alta.

La explotación intensiva de aguas subterráneas se inicia en el acuífero en el año 1974. En 1983 se seca el manantial de los Ojos del Guadiana, se producen descensos del nivel piezométrico de hasta $35 \mathrm{~m}$ e inversiones del flujo subterráneo que provoca que este sea radial en torno a los principales pozos de bombeo en vez de dirigirse hacia las zonas donde tenía lugar el drenaje natural. Para corregir estos efectos negativos en 1988 se produce la primera tentativa de trasvasar agua desde el Tajo que se concreta al año siguiente (Martínez Santos et al. 2004). En la actualidad, aunque la recuperación del acuífero comienza a ser una realidad tangible, no se ha alcanzado un nivel de reposición que se pueda calificar de aceptable, por lo que el funcionamiento hídrico del parque todavía se tiene que catalogar como de un sistema muy modificado.

\section{Parque Nacional de Timafaya}

Se localiza en la costa occidental de la Isla de Lanzarote que es la más septentrional y más oriental de las Islas Canarias, y también la de menor relieve. Su superficie es de $51,76 \mathrm{~km}^{2}$ y está ocupada en casi

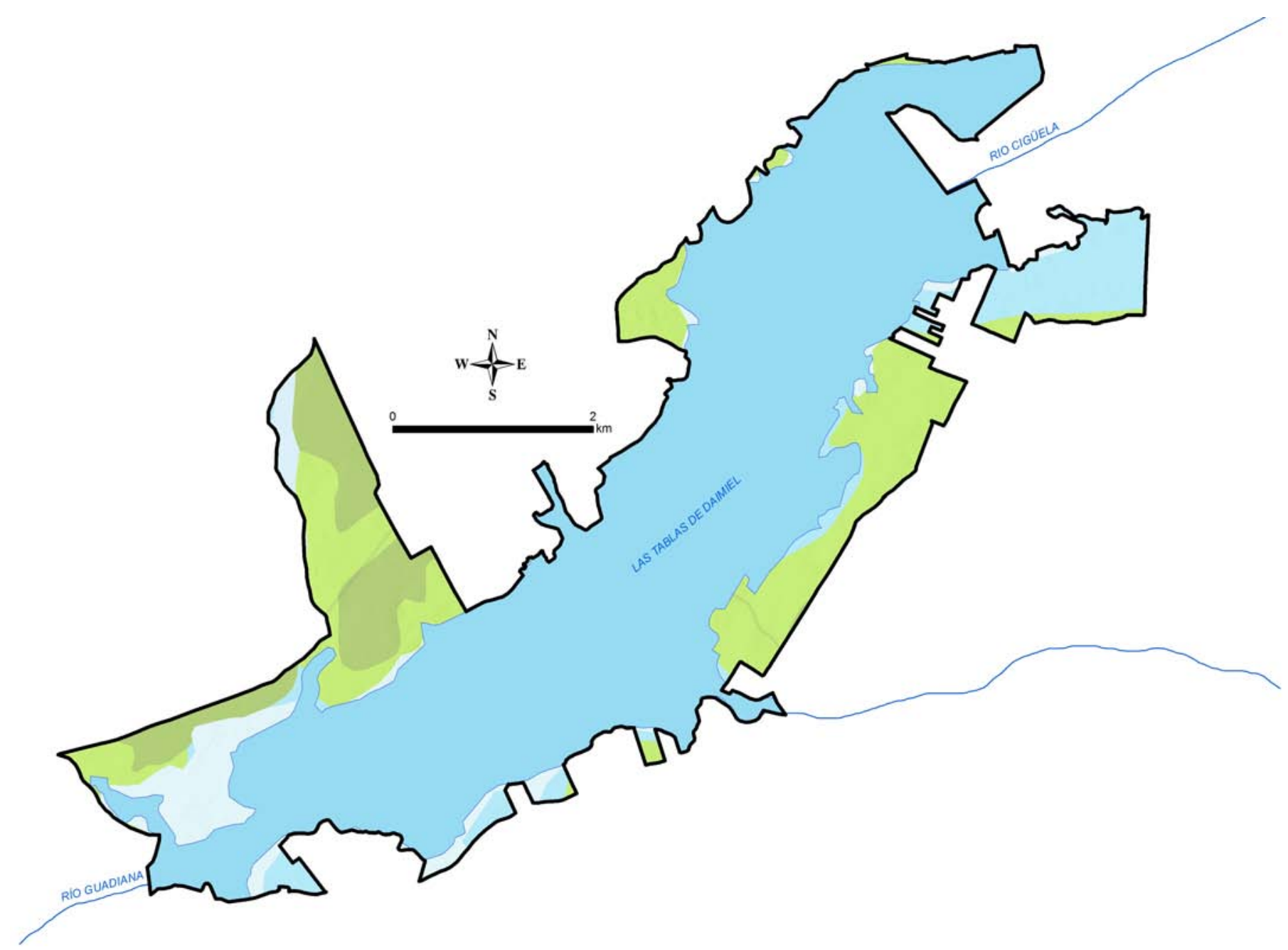

Figura 9. Mapa de permeabilidades del Parque Nacional de las Tablas de Daimiel. Figure 9. Map of the permeability of the Tablas de Daimiel National Park. 
su totalidad por lavas y piroclastos de muy alta permeabilidad (Figura 10) asociados a erupciones volcánicas históricas. La más importante es la de Timanfaya (1730-1736) que le da nombre. En 1824 hubo otra erupción de menor entidad en la que surgió Volcán Nuevo de Fuego. En el parque también se pueden observar una serie de conos estrombolianos con sus respectivos campos de lava que son anteriores al volcanismo histórico anteriormente citado.

El parque, a pesar de su aspecto árido, tiene una precipitación superior a la media de la isla. Esta es de $142,6 \mathrm{~mm}$, mientras que la pluviometría promedio en el parque es superior a los $150 \mathrm{~mm}$ (DGOH, 1975-a; PHIL, 2018). De acuerdo a su distribución temporal se distingue una época muy seca, que abarca aproximadamente los seis meses de primavera y verano -de abril a septiembre- en la que solo se genera algo menos del $10 \%$ del total de la precipitación, y un periodo húmedo que se concentra en los meses de noviembre, diciembre y enero en los que llueve aproximadamente el 60 por ciento del total de la precipitación anual. La evaporación en lámina libre es del

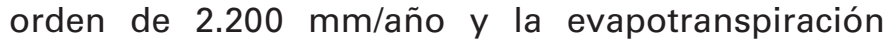
potencial de unos $1.600 \mathrm{~mm} / \mathrm{año}$ (DGOH, 1975-a).

En los malpaíses de Timanfaya no existe suelo capaz de retener el agua, por lo que una parte de la precipitación se evapora al quedar retenida y embalsada en las oquedades del terreno, mientras que otra percola a través de las grietas y fisuras del terreno y desciende verticalmente hasta alcanzar una cierta profundidad.

En estos malpaíses la tasa de infiltración se ha evaluado en un $6,8 \%$, que es un porcentaje relativamente elevado en relación a la tasa media de la isla, que es de 2,6\% (PHIL, 2018). En el Malpaís de Montaña del Fuego se ha estimado que la infiltración

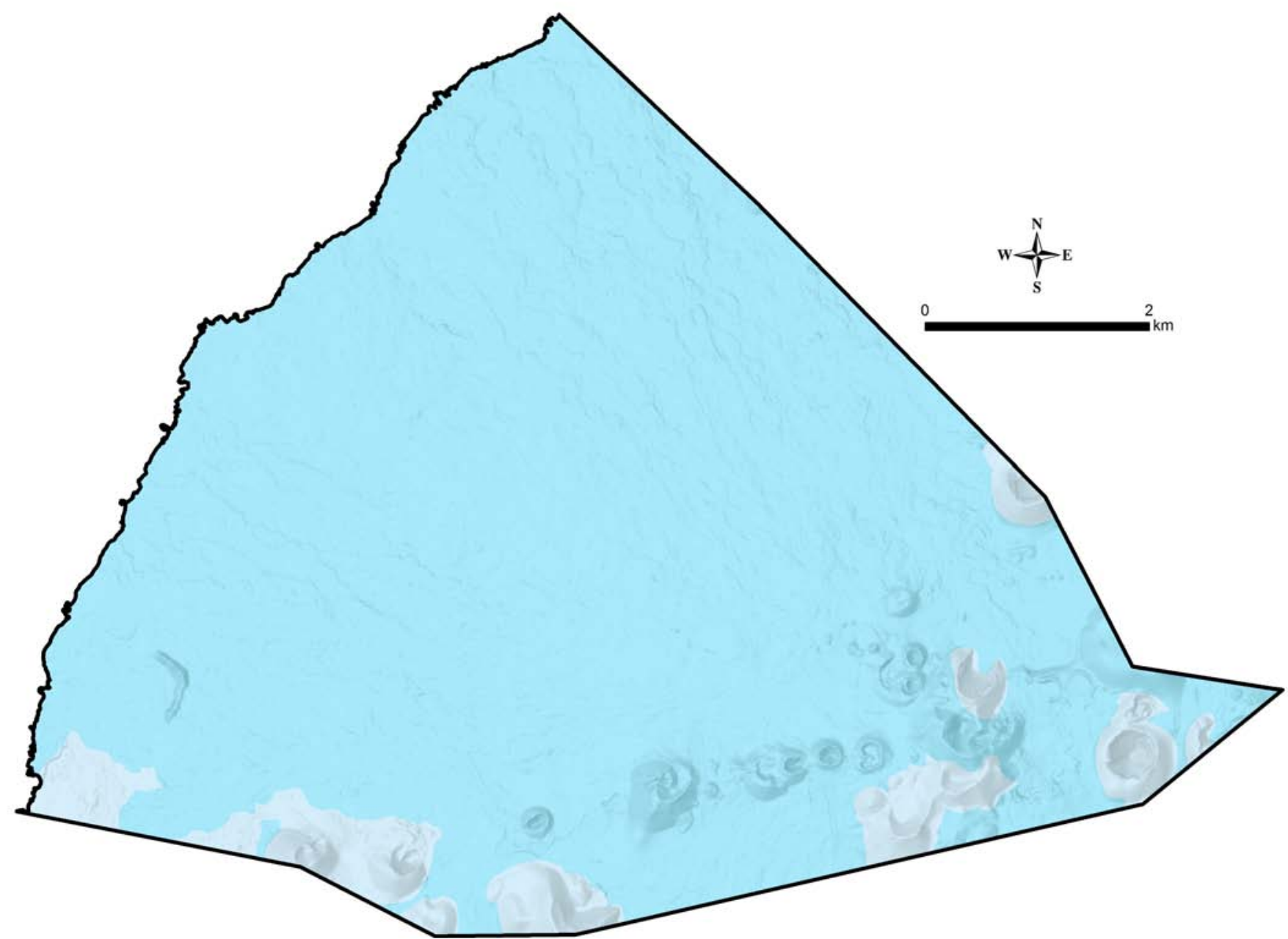

Figura 10. Mapa de permeabilidades del Parque Nacional deTimanfaya. Figure 10. Map of the permeability of the Timanfaya National Park. 
media es de $12 \mathrm{~mm} / a n ̃ o$, mientras que la máxima y la mínima son respectivamente de $15 \mathrm{~mm} / a$ ño y 10 $\mathrm{mm} / \mathrm{año}$. En función de los datos aportados, la infiltración de agua a través de los terrenos que afloran en el parque se puede cuantificar en un máximo de

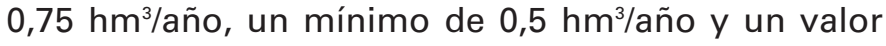
medio de 0,6 hm³/año (DGOH, 1975-a).

En el Parque Nacional de Timanfaya se ha identificado un campo geotérmico de aproximadamente 20 $\mathrm{km}^{2}$, que se localiza en torno a las Montañas del Fuego. En superficie se han medido temperaturas de hasta $100^{\circ} \mathrm{C}$, pero a pocos metros de profundidad estas alcanzan los $300^{\circ} \mathrm{C}$ e incluso $600^{\circ}$ cuando aqueIlas se localizan a $13 \mathrm{~m}$ (DGOH, 1975-a). Estas anomalías térmicas, que son fenómenos muy localizados, podrían afectar a la propia agua de infiltración, dado lo escaso de su cuantía, evaporándola y no permitiendo que esta profundice.

\section{Parque Nacional de Garajonay}

Se localiza en el centro de la isla de La Gomera en el archipiélago de Canarias. Geológicamente se pueden diferenciar dos grandes bloques de unidades estratigráficas: el complejo Basal y las Unidades Volcánicas Subaéreas. El primero, que casi no aflora en el área del parque, determina su límite noroeste, constituye el dominio ígneo más antiguo e integra el sustrato sobre el que se asientan discordantes los ciclos volcánicos acaecidos con posterioridad. Es de edad miocena y está compuesto por rocas plutónicas básicas y ultrabásicas y por lavas y piroclastos básicos de aspecto submarino. Todos sus materiales se encuentran atravesados por un denso enjambre de diques subverticales de composición preferentemente básica. Entre la población de la Herminia y el Monumento Natural del Roque de Ojila se extiende una estrecha banda de materiales pertenecientes al complejo Basal, que junto a materiales del primer ciclo volcánico, determinan el límite este del parque.

Las Unidades Volcánicas Subaéreas se estructuran en dos grandes episodios que se denominan primero y segundo ciclo volcánico. Los materiales proporcionados por el primer evento prácticamente no afloran en el interior del parque. Su presencia se restringe a pequeñas manifestaciones de coladas basálticas e intrusiones sálicas en el área situada en el este del parque, mientras que los debidos al segundo episodio constituyen casi la totalidad de los terrenos aflorantes. Estos están formados mayoritariamente por potentes coladas básicas del Plioceno con algunas intrusiones sálicas y traquibasálticas. A este episodio volcánico también se le denomina "Basaltos
Horizontales" por la disposición geométrica que estos adoptan.

El complejo basal presenta un comportamiento prácticamente impermeable por lo que actúa como un acuífugo. Por el contrario, las unidades volcánicas constituyen acuíferos. El que presenta mejores propiedades tanto por su permeabilidad como por su extensión dentro del parque es el constituido por los basaltos horizontales del Plioceno.

La recarga al acuífero tiene lugar por infiltración directa de la precipitación, por pérdida de caudal en los tramos altos de los barrancos, generalmente durante los episodios en que tienen lugar grandes precipitaciones, y por lo que se denomina lluvia horizontal o precipitación de niebla. Este fenómeno se genera al condensarse y contactar las partículas de agua que contienen las nubes con las hojas y el tronco de los árboles del bosque de laurisilva de Garajonay. Cuando las pequeñas gotas de agua que se van formando y depositando sobre la cubierta vegetal adquieren un determinado tamaño, estas caen al suelo y se infiltran en el terreno.

En el parque se presentan tres tipos de manantiales. En el borde norte y noroeste la descarga de agua tiene lugar en el punto topográfico de cota más baja en el que contactan los materiales impermeables del complejo Basal con las formaciones permeables de los basaltos subhorizontales, que generalmente se localizan en el fondo de los barrancos. También surgen manantiales por contraste de permeabilidad en los puntos de menor cota donde contactan las formaciones pertenecientes al primero y al segundo ciclo volcánico. El tercer tipo de manantiales aparece en cualquier lugar de la meseta basáltica ocupada por los materiales del segundo ciclo volcánico. Esto se debe a que dicha formación está constituida por una alternancia de materiales de distinta permeabilidad que dan origen en muchos lugares a acuíferos colgados. El agua que se infiltra en estos acuíferos, tras un corto recorrido subterráneo vertical, puede verse interrumpida en su camino descendente por una capa de menor o nula permeabilidad, que constituye el muro del acuífero colgado y obliga al agua a seguir un camino horizontal hasta que aflora en el exterior, alimenta por desborde a otro acuífero colgado más profundo o a la formación acuífera principal. En el mapa de la figura 11 hay representados 74 manantiales. Esta cantidad constituye algo más del 25 por ciento del total de los manantiales que hay inventariados en la isla de la Gomera.

El nivel piezométrico en el parque se sitúa entre los 800 y los 1000 ms.n.m. y el caudal de los manantiales es muy variable pudiendo oscilar entre varios litros por minuto y unas pocas decenas de litros por 


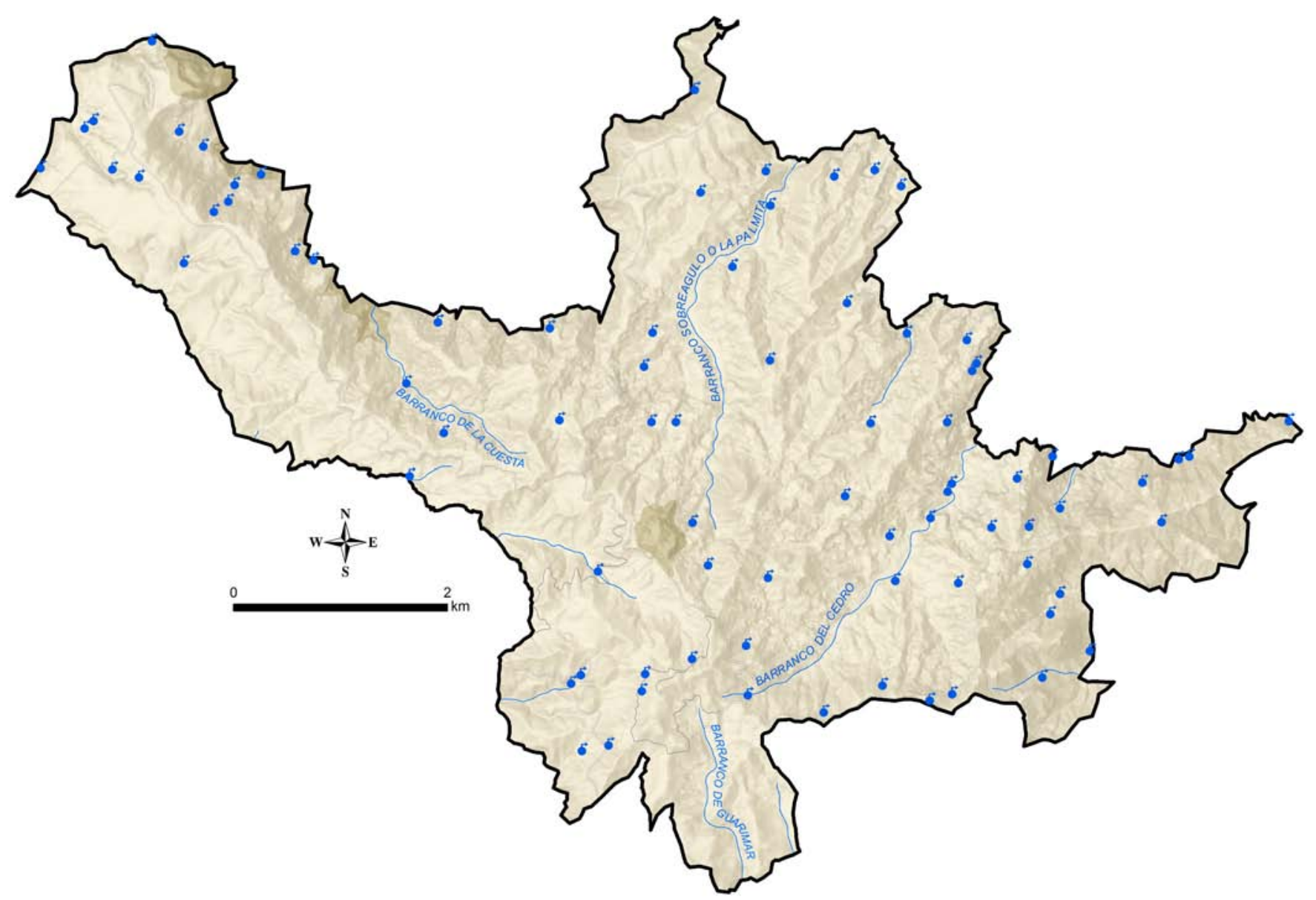

Figura 11. Mapa de permeabilidades del Parque Nacional de Garajonay.

Figure 11. Map of the permeability of the Garajonay National Park.

segundo (IGME, 1985). En la mayoría de los manantiales se observa una variación estacional correspondiendo el máximo al otoño e invierno y el mínimo a la primavera y verano. En algunos manantiales el régimen de descarga se encuentra muy influenciado por la recarga a partir de la niebla. El flujo del agua subterránea es radial y se dirige desde la zona central de la isla, que es la de cotas más altas, hacia la costa. Los gradientes hidráulicos son muy elevados en correspondencia con la topografía de la isla (IGME, 1985).

\section{Parque Nacional Marítimo-Terrestre del Archipiélago de Cabrera}

Se localiza al sur de isla de Mallorca. Se trata de un archipiélago formado por 18 pequeños islotes calcáreos. El más grande es la Isla de Cabrera. Le sigue en tamaño la Illa dels Conils que tiene una extensión notablemente inferior. Se trata de islas continentales que se separaron del resto de la península, conjuntamente con las islas de Mallorca y Menorca, durante el Plioceno. Su disgregación definitiva de la isla de Mallorca acaeció hace aproximadamente unos 12.000 años. Desde el punto de vista geológico, Cabrera es una prolongación de la Sierra de Levante de Mallorca.

Los materiales más antiguos que afloran en Cabrera pertenecen al Keuper y se trata de yesos y arcillas rojas. A continuación afloran materiales calizos y dolomíticos del Lías (Jurasico Inferior) y margas y margocalizas del Dogger-Malm (Jurasico Medio) y Cretácico Inferior entre los que aparecen olistolitos calizos. El Eoceno se presenta en discordancia erosiva y está constituido por calizas arenosas, calcarenitas y lutitas. Sobre este y también en discordancia erosiva aparecen arenas y conglomerados del Mioceno. Cronológicamente, los últimos materiales que afloran en la isla tiene en unos casos un origen fluvio-torrercial y en otros eólico. Los primeros están 
constituidos por arcillas rojas con intercalaciones de brechas. Los segundos por calcarenitas provenientes de dunas de arena que se han cementado.

En la figura 12 se muestra el mapa de permeabilidades del archipiélago que refleja un dominio mayoritario de formaciones carbonatadas de media, alta y muy alta permeabilidad, tanto en la isla de Cabrera como en la de Conills. Los materiales que presentan unas mejores características hidrogeológicas son las calizas y dolomías masivas del Lías, cuyo impermeable de base son las arcillas del Keuper. Los materiales liásicos se localizan mayoritariamente en el área occidental de la isla pero también afloran en otras partes de la misma.

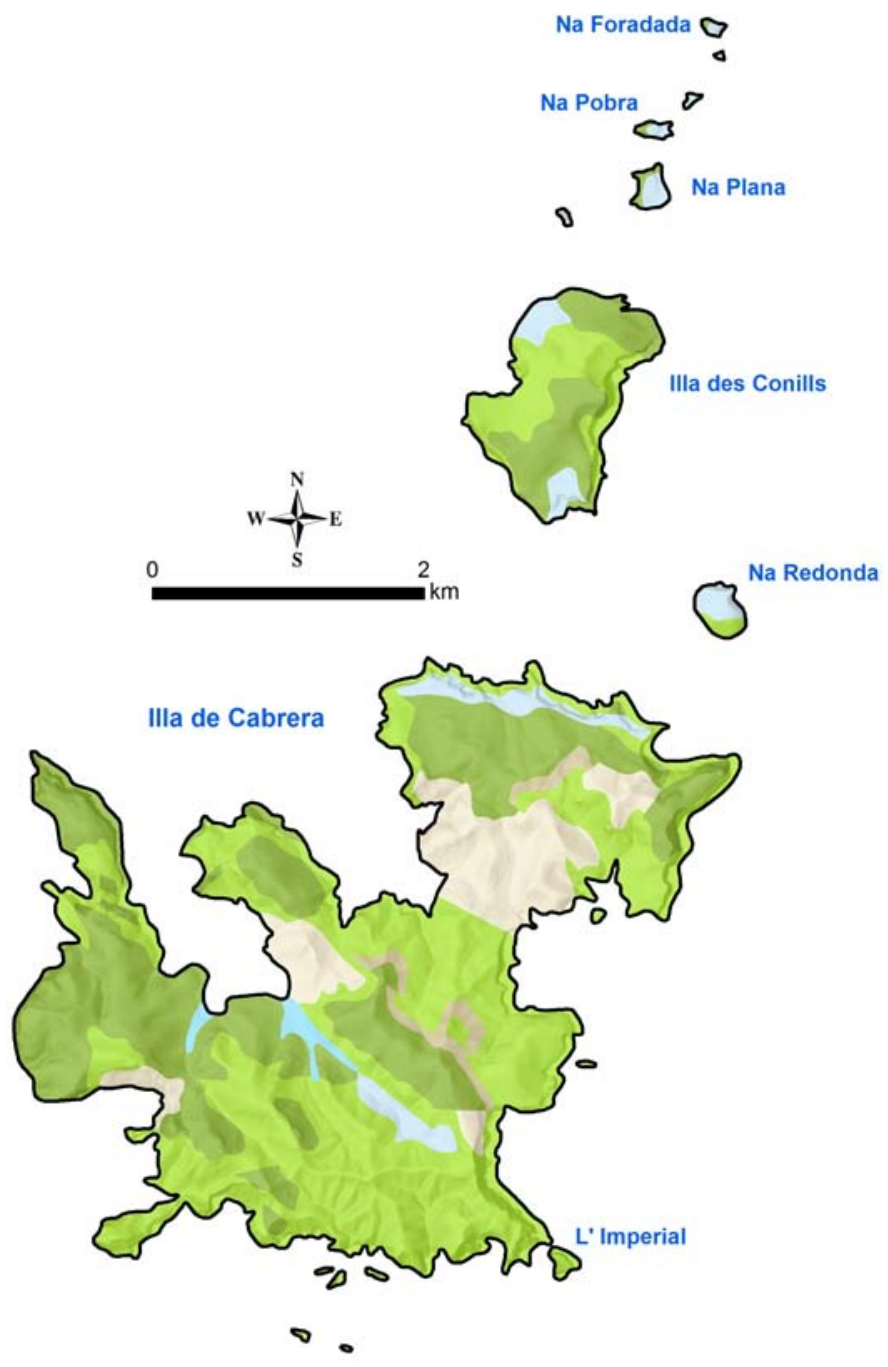

Figura 12. Mapa de permeabilidades del Parque Nacional Marítimo-Terrestre del archipiélago de Cabrera.

Figure 12. Map of the permeability of the Cabrera archipelago Maritime-Terrestrial National Park.
Los diferentes materiales acuíferos que existen en la isla se recargan por infiltración directa del agua de lluvia y por percolación de parte de los caudales esporádicos que circulan por la pequeña red fluvial que se ha desarrollado sobre su superficie. Como la mayor parte de los materiales que afloran son carbonatados se ha desarrollado un importarte epikarst, constituido fundamentalmente por lapiaces, que favorece la infiltración del agua. En la isla solo existe una fuente de entidad (Sa Font). Se trata de una surgencia kárstica que aflora en superficie debido a que el nivel freático intercepta la topografía del terreno. EI resto del agua contenida en el acuífero se descarga directamente al mar, bien de forma difusa o bien a través de surgencias kársticas submarinas, que hasta la fecha no se han identificado, pero que dado el desarrollo endokárstico que concurre en algunas zonas de la isla se presupone que existen.

\section{Parque Nacional de Cabañeros}

El parque Nacional de Cabañeros se localiza en el centro de la Península Ibérica, en la Comunidad Autónoma de Castilla-La Mancha, en las provincias de Ciudad Real y Toledo. En él se encuentra la divisoria hidrográfica entre las cuencas de los ríos Tajo y Guadiana, aunque los terrenos del parque se ubican mayoritariamente $(95,5 \%)$ en esta última.

Los materiales más antiguos que afloran en el parque pertenecen al Neoproterozoico y al Paleozoico, y litológicamente están constituidos por pizarras y cuarcitas. Se trata de rocas impermeables que carecen de interés hidrogeológico a escala regional. No obstante, las cuarcitas pueden estar fracturadas y permitir la infiltración de parte del agua de lluvia que tras recorrer un cierto camino subterráneamente descarga a través de pequeños manantiales como la Fuente del Fresno, Fuente Fría y Fuente de las Chinas. A los anteriores materiales de carácter impermeable se les unen otros más jóvenes del TerciarioCuaternario constituidos por depósitos tipo raña, glacis, abanicos, derrubios, coluviones y fondos de valle que presentan una mayor permeabilidad.

En el mapa de la figura 13 se puede apreciar que sobre la mayor parte del parque predominan los terrenos impermeables, salvo en el área comprendida entre los arroyos del Brezoso y de los Pescados y la localizada al sur del embalse de Torres de Abraham, que se encuentran asociadas a depósitos de tipo raña y terraza, que se han catalogado como de permeabilidad de tipo medio. Los aluviales del arroyo de los Pescados y del río Bullaque, que se localiza este último al sur del embalse de Torre de Abraham, son las 


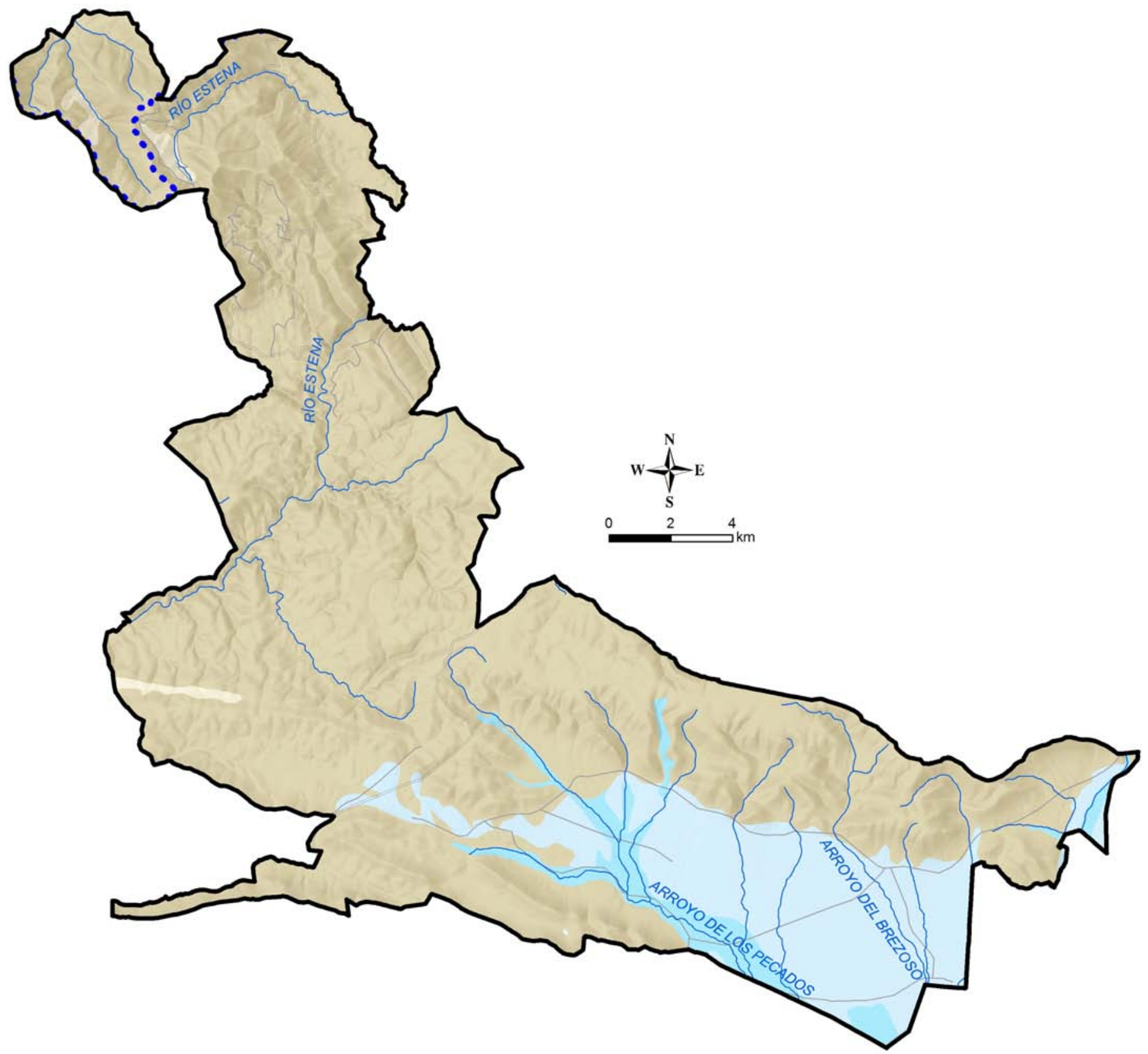

Figura 13. Mapa de permeabilidades del Parque Nacional de Cabañeros.

Figure 13. Map of the permeability of the Cabañeros National Park.

únicas áreas del parque que se ha catalogado como de permeabilidad alta o muy alta.

En el área del parque son numerosos los canchales y pedrizas originados a partir de la fracturación de las cuarcitas por gelifracción, por lo que la tasa de infiltración del agua de lluvia en estos terrenos es muy alta debido a su gran fragmentación, así como a la velocidad de circulación del agua subterránea en su interior. Esto unido a que se trata de depósitos de reducido espesor y escaso almacenamiento da como resultado un rápido vaciado de este tipo de acuíferos. No obstante, se tienen referencias de que los habitantes de Horcajo de los Montes, en otros tiempos, localizaban el agua por el ruido de los flujos subterráneos, y abrían pequeños pozos retirando las piedras para abastecerse. El mayor número de canchales se observa en la parte noroeste del parque (arroyos Chorro y Calanchera) que drenan al río Pusa, tributa- 
rio del Tajo por su margen izquierda, así como en la cuenca alta del río Estena.

En las orillas de los cauces del Bullaque, Estena, Arroyo de los Pescados y Arroyo de las Peralosas se localiza vegetación riparia ligada a las oscilaciones del nivel freático (García Herrera et al., 2011).

\section{Parque Nacional de Sierra Nevada}

El Parque Nacional de Sierra Nevada se enclava en el corazón de la Cordillera Bética. Se localiza íntegramente dentro de la Comunidad Autónoma de Andalucía, mayoritariamente en la provincia de Granada $(65 \%)$, aunque su área más oriental se extiende también por la provincia de Almería (35\%). Desde un punto de vista orográfico se trata de un espacio natural que presenta grandes elevaciones e hidrográficamente descarga sus aguas según dos vertientes: la norte drena hacia el océano Atlántico (Cuenca del Guadalquivir), mientras que la sur lo hace hacia el mar Mediterráneo (Cuencas Mediterráneas Andaluzas).

El Parque Nacional de Sierra Nevada está constituido por dos grandes conjuntos de rocas de diferente comportamiento hidrogeológico. El más extenso, que ocupa el 93 por ciento de la superficie aflorante, está formado mayoritariamente por micaesquistos pertenecientes al complejo Nevado-Filábride, que desde una óptica hidrogeológica clásica se consideran terrenos muy poco permeables, mientras que el segundo lo integran carbonatos (calizas y dolomías) del complejo Alpujárride, que afloran en el borde occidental. Estos últimos presentan una permeabilidad muy elevada debida fundamentalmente a una intensa fracturación y en menor medida a procesos de karstificación y constituyen el 6,5 por ciento de la superficie ocupada por el parque. El porcentaje de afloramientos que restan hasta el cien por cien corresponde a materiales detríticos recientes de diversa tipología.

El Complejo Alpujárride presenta una superficie de materiales permeables que se restringen en el interior del parque al área noroccidental del acuífero "carbonatado del borde oeste de Sierra Nevada" que está formado por las sierras de Padúl y La Peza. Los materiales carbonatados que afloran dentro del parque se encuentran atravesados por el río Dilar y los afluentes del río Monachil, que determina su límite norte, mientras que la frontera sur la marca el río Durcal. Existe un pequeño enclave de materiales carbonatados que afloran fuera de los anteriores límites que descarga sus aguas a la cuenca del río Genil. La superficie de materiales carbonatados aflorantes dentro del parque es de $60 \mathrm{~km}^{2}$, por lo que de acuerdo a los porcentajes de infiltración que figuran en Castillo et al. (1996), la recarga por precipitación que tiene lugar sobre los materiales del complejo Alpujárride dentro de los límites del parque es de 15 hm³/año. El drenaje de estos materiales tiene lugar de manera difusa a través de los ríos citados anteriormente y de manera puntual mediante descarga a través de

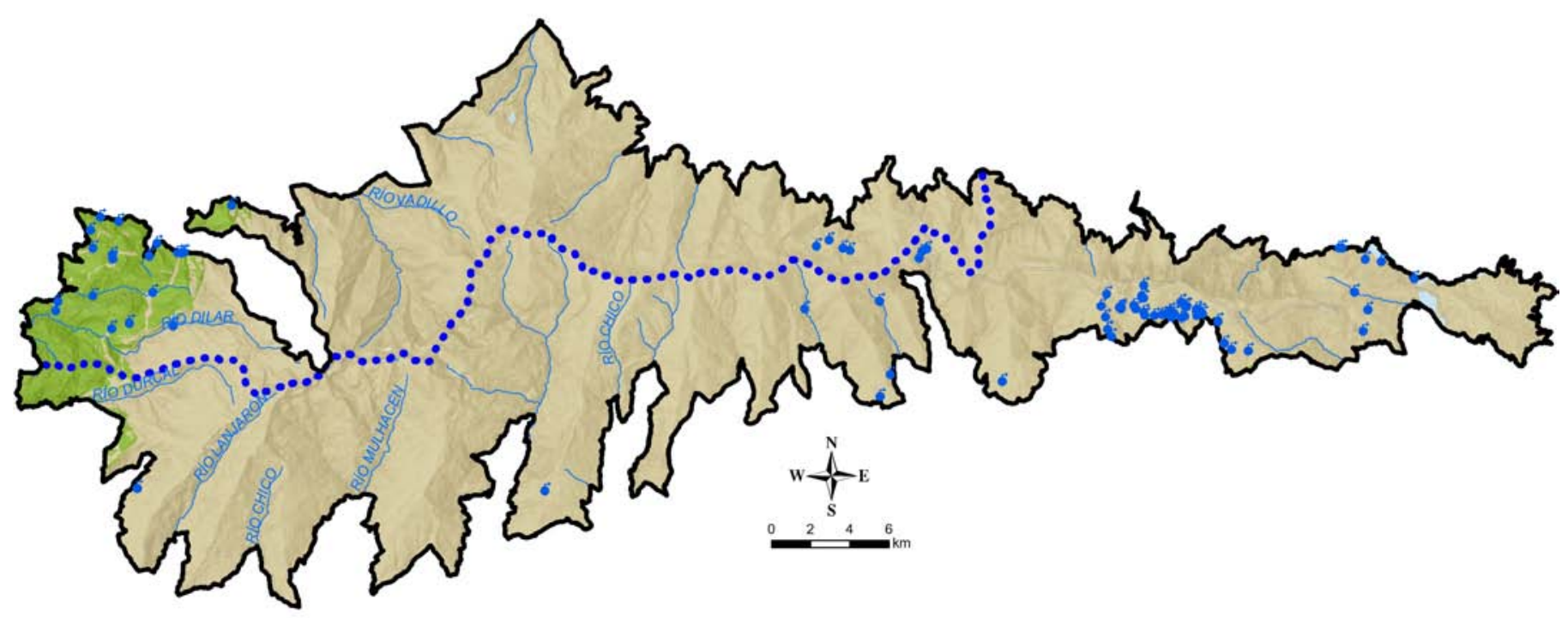

Figura 14. Mapa de permeabilidades del Parque Nacional de Sierra Nevada.

Figure 14. Map of the permeability of the Sierra Nevada National Park. 
numerosos manantiales (Figura 14) de escaso caudal medio $(2-3 \mathrm{l} / \mathrm{s})$, pero que esporádicamente dan lugar a grandes puntas (Castillo et al., 1996).

Por lo que respecta a los recursos subterráneos, que se generan en el interior del Parque Nacional, sobre los materiales del complejo Nevado-Filábride, estos se evalúan de acuerdo a los porcentajes de infiltración que figuran en Castillo et al. (1996) en 107 $\mathrm{hm}^{3} / a n ̃ o$, por lo que a pesar de su aparente baja permeabilidad presentan unos recursos anuales siete veces superiores a los del complejo Alpujárride. A este respecto, es necesario precisar que en el complejo Nevado-Filábride tienen lugar dos tipos de flujo: uno de naturaleza "epidérmica" subsuperficial, ligado a la franja de los depósitos de alteración y fracturación superficial, que aporta la mayor parte del volumen de agua anteriormente citado, y otro profundo de una cuantía notablemente menor, que se encuentra vinculado al drenaje a través de grandes fracturas, accidentes tectónicos y discontinuidades estructurales. Las principales características que presentan las aguas ligadas a este flujo profundo son su escaso poder transmisivo, su termalismo, su alta salinidad, la presencia de $\mathrm{CO}_{2}$ y caudales pequeños pero muy estables y regulares.

Casi la totalidad de los recursos que se generan en el complejo Nevado-Filábride se asocian al flujo subsuperficial, que tiene lugar a lo largo de toda la superficie de los afloramientos del macizo metapelítico, pero especialmente en las cotas superiores a los $2.000 \mathrm{~m}$ de altitud. La intensa infiltración que se produce en dichas zonas se debe a la combinación de varios factores: altas aportaciones pluviométricas en forma sólida; lenta y abundante liberación de agua por el deshielo; intensa acción ejercida por procesos glaciares y periglaciares relictos (gelifracción); procesos crioclásticos; procesos de reptación y descomposición de laderas; escaso desarrollado de suelos; limitada presencia de arcillas de carácter edáfico que puedan taponar la fracturación; y red de drenaje poco densa y escasamente desarrollada y jerarquizada.

Dado que la geometría de la franja de alteración y fracturación superficial es poco potente y se presenta paralela a la topografía del terreno, el acuífero o pseudoacuífero que aquella genera no destaca por su capacidad de almacenar grandes volúmenes de agua. No obstante, ejerce un importante papel regulador y laminador sobre la escorrentía de los ríos del parque y del lento agotamiento de las surgencias que afloran en el mismo, por lo que desempeña un gran influjo sobre el mantenimiento hídrico de importantes y singulares áreas húmedas de altísimo valor ecológico (chortales, lagunillas, praderas y borreguiles), así como sobre el caudal de base de los ríos del parque.
Las aguas de escorrentía epidérmica asociadas a los materiales metapelíticos presentan un quimismo muy similares a las aguas de escorrentía estrictamente superficial, aunque la ralentización del flujo originado por su circulación pseudosubterránea incrementa ligeramente su salinidad y temperatura.

En la Alpujarra esquistosa existe desde la presencia árabe-beréber (siglo VIII) un sistema de trasporte y almacenamiento subterráneo de las aguas de escorrentía superficial que se conoce con el nombre de acequias de careo (Pulido-Bosch y Sbih, 1995; MartosRosillo et al., 2019.). La misión primigenia de estas acequias era la de transportar el agua hasta los campos de cultivo que se extendían a lo largo de las laderas de Sierra Nevada. Dichas acequias se impermeabilizaron de una forma muy rudimentaria utilizando las lajas (esquistos) y launas (filitas) de la Sierra. Evidentemente, las pérdidas que se producían eran elevadas, por lo que con el tiempo pasaron a tener un uso mixto, que aparte de conducir las aguas de los ríos para su aprovechamiento en regadío, también contempló la recarga artificial del acuífero o pseudoacuífero metapelítico, mediante la construcción de boqueras o aliviaderos a lo largo de su recorrido, que permitían en cierta medida programar y aumentar la infiltración de agua en los materiales permeables y retrasar y aumentar la descarga en los manantiales localizados aguas abajo.

\section{Parque Nacional de las Islas Atlánticas}

Está constituido por una serie de archipiélagos que se localizan a lo largo de la costa meridional atlántica de Galicia. Consta de cuatro archipiélagos: islas Cíes, islas de Ons y Onza, islas de Sálvora e islas de Cortegada. El archipiélago de las islas Cíes está formado por las islas de Monteagudo, Do Faro y San Martiño; él de Sálvora por la isla de igual nombre, las islas de Vionta, Noro, Herbosa, Ságres y una multitud de islotes de pequeñas dimensiones; y él de Cortegada por la isla de igual denominación y las islas Malveira Grande y Chica.

Las islas Cíes están formadas casi en su totalidad por rocas ígneas graníticas que instruyeron entre rocas metamórficas (esquistos y gneises) de las que solo restan puntuales y pequeños afloramientos que se disponen en cuerpos dispersos. Las islas de Ons y Onza están constituidas por rocas ígneas y metamórficas de composición muy variada que se disponen en bandas más o menos paralelas asociadas a contactos intrusivos. El archipiélago de Sálvora está compuesto en su totalidad por rocas graníticas que forman parte del Plutón de Caldas de Reis. En las islas de 
Cortegada y Malveria Grande predominan las rocas metamórficas (esquistos, micaesquistos y cuarzoesquistos) entre las que afloran alargadas franjas de rocas graníticas. La isla de Malveria Chica está formada exclusivamente por rocas graníticas.

Los pequeños acuíferos que existen en Parque Nacional de las islas atlánticas se desarrollan en rocas alteradas y fracturadas graníticas que descargan a través de manantiales cuyos caudales se encuentran muy influenciados por el régimen pluvial. En la actualidad hay inventariados 11 manantiales en la isla de Ons, 6 en la de Faro, 4 en la de San Martiño y 2 en la de Monteagudo (Ruiz-Pico y Samper, 2000; Alegre, 2000). En la isla de Sálvora se localiza la fuente de Santa Catalina o Fonte de Telleira y en la isla de Cortegada un pequeño riachuelo que mana de la fuente del Monasterio.

Es factible que se pueda producir un cierto drena- je al mar a través de pequeños manantiales submarinos ubicados en las zonas de diaclasado y en el contacto entre las rocas graníticas y metamórficas, ya que estas últimas son algo más impermeables que las primeras. En algunas de las islas se han secado algunos manantiales bien por causa de un incremento del volumen de agua evapotranspirada desde la superficie freática debido a la reforestación realizada con matorral o bien a una menor recarga a los acuíferos por efecto del cambio climático.

\section{Parque Nacional de Monfragüe}

Se localiza al oeste de la Península Ibérica en la Comunidad Autónoma de Extremadura y más concretamente en la provincia de Cáceres. El parque está atravesado por los ríosTiétar y Tajo que se encuentran

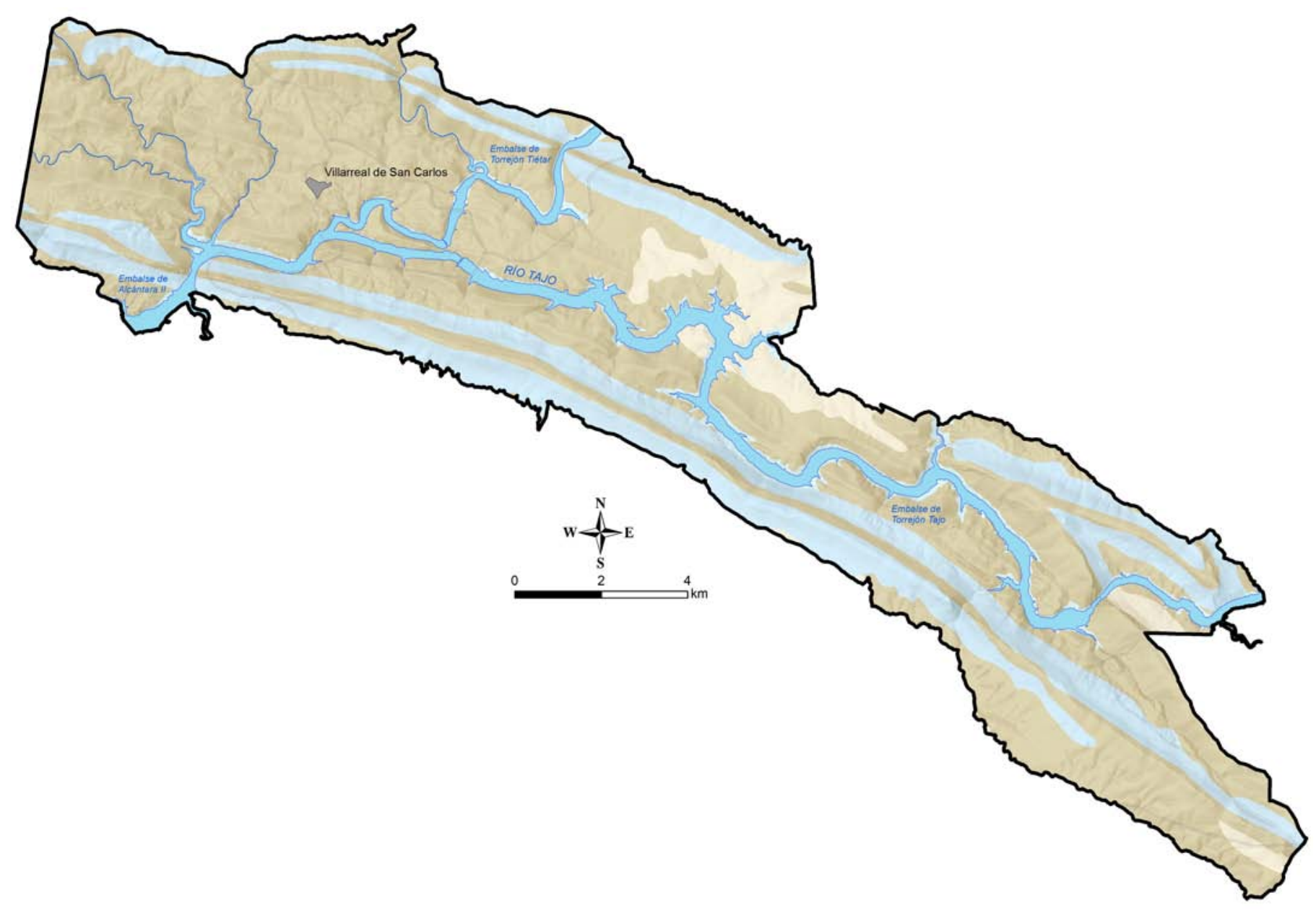

Figura 15. Mapa de permeabilidades del Parque Nacional de Monfrague. Figure 15. Map of the permeability of the Monfrague National Park. 
regulados en el interior del parque por tres embalses: Torrejón-Tiétar, Torrejón-Tajo y Alcántara II que se localiza en el río Tajo.

El parque se encuentra enclavado en la zona Centroibérica del Macizo Ibérico y se caracteriza por presentar una gran estructura sinclinal (sinclinal de Monfrague). Los materiales que afloran dentro de sus límites abarcan desde el Proterozoico hasta el Cenozoico. Los más antiguos, que llegan hasta el Silúrico, están deformados por la orogenia Varisca. Se trata fundamentalmente de pizarras, grauvacas, areniscas y cuarcitas de carácter impermeable. Estas últimas pueden dar lugar, cuando presentan permeabilidad secundaria que permite la infiltración de una pequeña fracción del agua de lluvia, a pequeñas descargas puntuales de agua subterránea.

En la figura 15 se puede apreciar que la mayor parte de los terrenos que afloran en el parque son impermeables o presentan una permeabilidad muy baja. En dicha figura no se ha representado ningún manantial, pues en la Base de Datos del IGME no se encuentra inventariado ninguno. No obstante, en el parque se localizan las siguientes descargas puntuales de agua: Fuente del Francés que se emplaza junto al ríoTajo; Fuente de la Parra que localizada en el sendero de la Umbría; la Fuente del Cardenal que se ubica junto al puente del mismo nombre; la Fuente de los Tres Caños que se sitúa muy cercana al penúltimo gran meandro del río Tietar y la Fuente del Alisa que se asienta relativamente próxima a la anterior.

Como se puede observar en la figura 15, dentro del parque también afloran materiales de permeabilidad media, que son de edad cenozoica, y tienen una parca repercusión hidrogeológica a nivel regional. A este periodo pertenecen:

- Una raña de escaso espesor, que está constituida por conglomerados de cuarcita y cuarzo embutidos en una matriz arenoso-arcillosa, que aflora en el sureste del borde meridional del parque.

- Una serie de retazos de terrazas fluviales, que se presentan sobreelevados sobre los cauces de los ríos Tiétar y Tajo, se apoyan directamente sobre el basamento Paleozoico-Neoproterozoico y están constituidos por conglomerados redondeados de cuarcita, arenisca, y cuarzo. Estos depósitos fluviales presentan un mejor desarrollo en la margen izquierda del río Tiétar aguas abajo de su portilla, mientras que en su margen derecha y en el río Tajo son de menor entidad e inferior superficie y número de afloramientos.

- Un importante número de pedreras o canchales formados por depósitos caóticos de grandes fragmentos rocosos con formas angulosas, que habilitan el paso del agua de la precipitación a través de ellos hasta que se topan con una capa impermeable, que permite un cierto almacenamiento y circulación del agua infiltrada, que se descarga a través de manantiales, generalmente de escaso caudal, o mediante rezumes, que surgen en superficie en aquellas zonas donde la cota del nivel freático del acuífero intercepta a la superficie topográfica del canchal.

- Depósitos aluviales. Sus afloramientos no suelen ser observables, salvo en épocas de marcada sequía, debido a que en dichos periodos queda al descubierto y prácticamente sin circulación de agua casi dos kilómetros del curso fluvial del río Tiétar que se localiza aguas abajo de la presa de Torrejón-Tiétar.

Este hecho acontece cada 5 o 6 años y se debe a dos causas: por un lado, un menor vertido de agua desde la presa de Torrejon-Tietar, ya que en los años secos se precisa ser más previsor y reservar un mayor volumen de agua embalsada $y$, por otro, a una reducción del volumen de agua almacenada en el embalse de Alcántara, que lleva aparejado una disminución de la altura de su lámina de agua y una merma del área encharcada en la cola de embalse, que no llega hasta el pie del muro de la presa de Tiétar-Torrejón, hecho que sí acontece siempre que se presenta una situación climática de tipología media o húmeda.

El impacto de la situación descrita se ve paliado gracias a un fenómeno ligado a la interacción río-acuífero, que se asemeja al que se conoce con el nombre de almacenamiento en ribera. Así, en las épocas húmedas tiene lugar una saturación casi total del acuífero aluvial al quedar este prácticamente cubierto por el agua almacenada en los embalses. Esta es devuelta al río paulatinamente durante los periodos secos al situarse el nivel piezométrico en el acuífero por encima de la cota de agua en el río. Esta descarga permite salvaguardar y asegurar un cierto caudal en el río que garantiza el mantenimiento de la vegetación riparia, el bosque de ribera y los procesos ligados a la zona hiporreica.

En un parque nacional como Monfragüe, constituido mayoritariamente por materiales impermeables o de muy baja permeabilidad, el anterior proceso es el fenómeno hidrogeológico más relevante que tiene lugar en el mismo.

\section{Parque Nacional de Guadarrama}

El Parque Nacional de la Sierra de Guadarrama se localiza entre las provincias de Segovia y Madrid que pertenecen a las Comunidades Autónomas de 
Castilla-León y Madrid respectivamente. Se encuentra enclavado en el Sistema Central y se emplaza en la divisoria natural entre las dos mesetas. Su vertiente norte drena a la cuenca del Duero mientras que la meridional lo hace a la Demarcación del Tajo.

En el parque afloran rocas anteriores a la orogenia Varisca que sufrieron un intenso metamorfismo durante la misma (fundamentalmente gneises) y rocas originadas por procesos ígneos durante las últi- mas etapas de dicha orogenia (fundamentalmente granitos). Estas rocas se consideran impermeables desde un punto de vista hidrogeológico estricto. En la figura 16 se observa que la mayor parte del parque se encuentra ocupado por formaciones geológicas impermeables. Las áreas que en dicha figura se han catalogado como de permeabilidad media corresponden a depósitos de rocas acumuladas por la acción de los ríos, torrentes, glaciares y procesos de ladera.

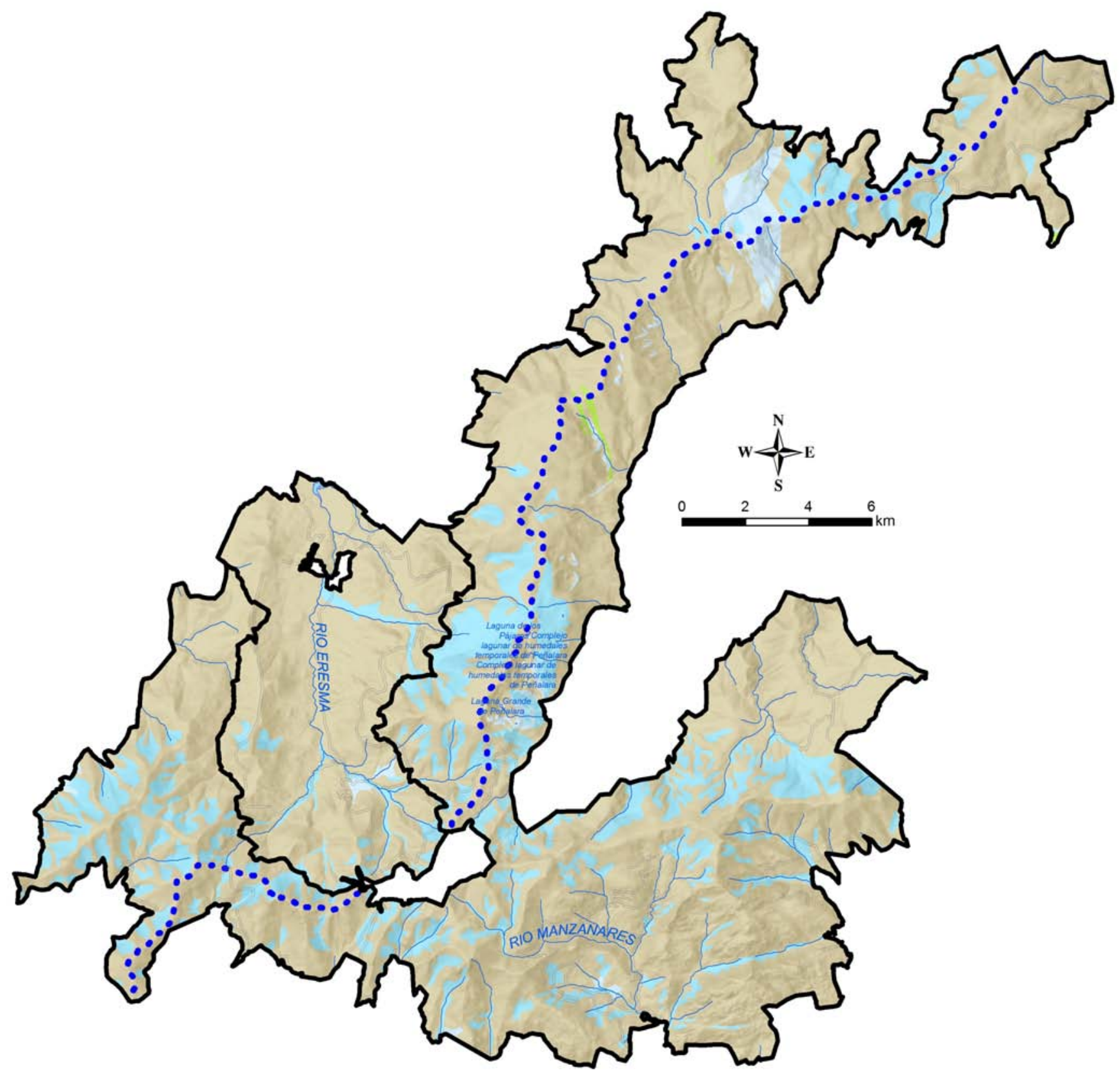

Figura 16. Mapa de permeabilidades del Parque Nacional de Guadarrama.

Figure 16. Map of the permeability of the Guadarrama National Park. 
Los gneises, aunque como se ha comentado anteriormente se consideran rocas impermeables, pueden dar lugar a acuíferos de baja capacidad de almacenamiento gracias a su esquistosidad que permite una cierta circulación subsuperficial de agua. Algo parecido ocurre con el granito alterado (lehm) o diaclasado que da lugar a acuíferos locales con una significativa capacidad de almacenamiento y transmisión de agua. A este respecto, García de Domingo en Mejias et al. (2015) establece que en el Parque Nacional de Guadarrama se pueden presentar las siguientes tipologías de acuíferos en gneis y granitos atendiendo tanto a la forma en que tiene lugar el almacenamiento de agua como a la manera en que se produce la descarga. Así se tienen: acuíferos graníticos ligados a depósitos de alteración; acuíferos en depósitos de ladera (coluviones); acuíferos ligados a depósitos de morrena (lagunas glaciares); acuíferos ligados a depósitos fluviales; acuíferos en depósitos metamórficos a favor de planos de esquistosidad; acuíferos en materiales graníticos a favor de fracturación y diaclasado; acuíferos en materiales graníticos a favor de diques y filones; acuíferos en materiales metamórficos a favor de fracturas; y acuíferos en materiales graníticos por contacto entre dos formaciones con diferente tamaño de grano.

A continuación se listan una serie de ríos que tienen su origen en manantiales ligados a formaciones graníticas o gnéisicas. Estos son los siguientes: Eresma (Fuente de Canalejas y de la Casilla); Moros (Ojos del río Moros); Pirón (Fuente del Mojón); Peces (canchal de Navahermosa); Milanillos (manantial de las Beceas); Guadarrama (Fuente de los Acebos, Fuente del Arranque y Fuente de los Alevines); Manzanares (Fuente de laTeja); y Lozoya (Fuente de la Lobera y fuente del Chorro de Rascafría).

\section{Conclusiones}

En la tabla 11 se muestran los resultados que se han obtenido para los Espacios Naturales Protegidos por el Estado español o por sus Comunidades Autónomas que de alguna u otra forma se encuentran vinculados con las aguas subterránea. Aunque en dicha tabla se proporciona una cifra global que asciende a 312 espacios, no es metodológicamente correcto sumar directamente el número de espacios reseñados en la misma, ya que existen solapamientos entre los mismos. Esta puntualización resulta también válida para las tipologías de espacios naturales que se contemplan en las tablas 12 y 13.

Los Parques Nacionales son los espacios naturales donde se ha detectado que existe una mayor vincula- ción hídrica con las aguas subterráneas. A este respecto cabe indicar que en todos ellos se ha detectado la presencia de ecosistemas dependientes en mayor o menor medida de este recurso hídrico. Dado que en este tipo de espacio natural existe una mayor información hidrogeológica que en el resto, su análisis y caracterización se han podido tratar con una mayor minuciosidad que la empleada para las otras categorías de Espacios Naturales Protegidos, donde solo se ha procedido a discernir si presentan o no vinculación hídrica con las aguas subterráneas sin entrar en un mayor detalle. Evidentemente, el hecho de que el presente monográfico versa sobre la hidrogeología de los Parques Nacionales del Estado español también ha contribuido a que el tema prioritario del contenido del artículo estuviera centrado en este tipo de espacio natural, por lo que el resto de espacios naturales, dado que no era el objeto principal del estudio se han tratado marginalmente y solo a título informativo al objeto de mostrar el gran número de espacios naturales protegidos que se encuentran vinculados con las aguas subterráneas.

Entre las conclusiones que se pueden extraer de la información expuesta en el capítulo dedicado a las aguas subterráneas y los Parques Nacionales es menester indicar que tres de los Parques Nacionales están constituidos mayoritariamente por formaciones carbonatadas de alta o muy alta permeabilidad. Estos son: Picos de Europa, Ordesa-Monte Perdido y el Parque Nacional marítimo-terrestre del archipiélago de Cabrera. Los tres constituyen áreas de recarga a los acuíferos, que en los dos primeros presentan una extensión muy importante de afloramientos. La descarga de agua en el caso de Picos de Europa se produce a través de más de 130 manantiales. En el segundo se tiene constancia de la existencia de algo más de diez grandes manantiales y en el archipiélago de Cabrera solo de uno, aunque es probable que se produzca alguna descargas kársticas focalizada de tipo submarino. En los dos citados en primer lugar tiene lugar una importante relación río-acuífero tanto desde el punto de visto de la ganancia como de la perdida de agua en los cursos fluviales.

En otros dos parques (Sierra Nevada y Agüestortes y Estany de Sant Maurici) también afloran rocas carbonatadas de permeabilidad alta o muy alta, junto a materiales de otras litologías de menor permeabilidad. Estos últimos presentan una extensión de afloramiento notablemente superior a los primeros, pero aunque su permeabilidad es notablemente menor, tienen la propiedad de ejercer un importante papel regulador y laminador sobre la escorrentía de los ríos y el almacenamiento de agua en humedales, lagos y lagunas. Este hecho es espe- 
cialmente significativo en el Parque Nacional de Sierra Nevada. En dicho parque tiene lugar una importante relación río-acuífero entre algunos de los cursos fluviales que lo atraviesan y los materiales carbonatados del complejo Alpujárride. Este intercambio de agua entre río y acuífero también acontece entre los micaesquistos del complejo Nevado-Filábride y los ríos de la vertiente sur del macizo de Sierra Nevada en una proporción que contrasta enormemente con el carácter poco permeable que se suele asignar a este tipo de rocas, pues el caudal de intercambio que se ha estimado es notablemente significativo. En el Parque Nacional de Agüestortes y Estany de Sant Maurici el fenómeno de la relación río-acuífero entre los materiales graníticos (mayoritarios en el parque) y los númerosos lagos y cursos fluviales que discurren por el mismo, es menos evidente y queda enmascarado por la elevada escorrentía superficial que se genera en el mismo.

Los cuatro parques que se localizan en el archipiélago de Canarias se presentan ligados a edificios y depósitos volcánicos. Los Parques Nacionales de Teide y Timanfaya se asientan sobre materiales que presentan una permeabilidad muy elevada ligada a erupciones volcánicas recientes y constituyen importantes áreas de recarga a los acuíferos. En los Parques Nacionales de Caldera de Taburiente y Garajonay se diferencian dos grandes bloques de unidades estratigráficas: el complejo Basal y las Unidades Volcánicas Subaéreas. El primero presenta un comportamiento prácticamente impermeable. Las segundas, por el contrario, constituyen acuíferos de entidad, que descargan a través de numerosos manantiales que se suelen localizar en el contacto geológico entre estas formaciones y el complejo Basal.

Los Parques Nacionales de Sierra de Guadarrama y marítimo-terrestre de las Islas Atlánticas están constituidos fundamentalmente por materiales graníticos que se alternan en mucha menor medida con materiales metamórficos (gneises en el primer parque y esquistos y gneises en el segundo). Cuando el granito se encuentra alterado (lehm) o diaclasado da lugar a acuíferos locales, más o menos extensos, que pueden presentar una significativa capacidad de almacenamiento y transmisión de agua que puede contribuir significativamente al mantenimiento ecológico de áreas sensibles.

Cabañeros y Monfragüe no presentan relación hídrica con las aguas subterráneas a escala regional. Sin embargo, sobre ellos se extienden formaciones cuarcíticas que dan lugar a manantiales de escaso caudal -cuando estas se encuentran fracturadas y permiten la infiltración de parte del agua de lluvia- pero de indudable interés medioambiental. Otros materiales que tienen un cierto interés hidrogeológico, bajo una óptica exclusivamente medioambiental, son las pedreras y los canchales, así como los depósitos aluviales, ligados al los ríos Tajo y Tietar, gracias a la relación río-acuífero que se establece entre unos y otros en los periodos de extrema sequía.

Los dos Parques Nacionales que restan de comentar constituyen los dos humedales que mejor y más se han estudiado en España, aunque esto no ha podido evitar que en uno de ellos (Parque Nacional de la Tablas de Daimiel) se hayan tenido que tomar medidas excepcionales, como exportar agua desde otra cuenca hidrográfica, para intentar frenar su degradación y mantener un aparente equilibrio hídrico. Por lo que respecta al Parque Nacional de Doñana no presenta una situación hídrica tan grave, pues desde hace ya muchos años se vienen tomando medida de control de la explotaciones en el entorno del parque para lograr en la medida de lo posible que el aprovechamiento de las aguas subterráneas se realice de una manera sostenible.

En la tabla 11 se aprecia que, tras los Parques Nacionales, son los Parques Naturales los espacios protegidos que presentan un mayor porcentaje de vinculación con las aguas subterráneas. Concretamente, este asciende al 72 por ciento. Este hecho se debe a que los Parques Naturales se extienden sobre una gran superficie del territorio nacional, un alto porcentaje de la misma de carácter permeable, que es equiparable a la de un país como Suiza, pues supera los $40.000 \mathrm{~km}^{2}$. Por término medio los Parques Naturales que se listan en la tabla 2 tiene una extensión de $263 \mathrm{~km}^{2}$ y se localizan en cualquier parte del territorio nacional, por lo que pueden estar ubicados en la cabecera de una cuenca, en su tramo medio o en la zona de desagüe. Además, dada su anárquica distribución espacial presentan una gran heterogeneidad en lo que respecta a su litología, parámetros hidráulicos, hidroquímica, relaciones río-acuífero y régimen de explotación entre otros parámetros, variables y condicionantes hidrogeológicos.

A escala del Estado español existe una notable carencia de información sobre la hidrogeología de un gran número de estos enclaves naturales, así como sobre la mejor forma de gestionar y proteger el agua subterránea ligada a los mismos. A título de ejemplo basta con buscar referencias bibliográficas sobre la hidrogeología de Doñana o las Tablas de Daimiel y comparar el número de reseñas que se pueden encontrar sobre aquellos con las que aparecen para cualquier otro espacio natural protegido, que, salvo excepciones, es generalmente reducida o incluso nula.

Por lo que respecta al resto de figuras de protec- 
José Manuel Murillo y Leticia Vega, 2019. Las aguas subterráneas y los Espacios Naturales... Boletín Geológico y Minero, 130 (4): $549-592$

\begin{tabular}{|c|c|c|c|}
\hline $\begin{array}{c}\text { Espacios naturales protegidos } \\
\text { por el Estado español }\end{array}$ & Total de espacios protegidos & $\begin{array}{c}\text { Total de espacios protegidos } \\
\text { vinculados con las aguas } \\
\text { subterráneas }\end{array}$ & $\begin{array}{c}\text { Porcentaje espacios protegidos } \\
\text { vinculados con las aguas } \\
\text { subterráneas }\end{array}$ \\
\hline Parques Nacionales & 15 & 15 & 100 \\
\hline Parques Naturales & 152 & 109 & 72 \\
\hline Reservas naturales & 291 & 94 & 32 \\
\hline Monumentos naturales & 342 & 74 & 35 \\
\hline Paisajes protegidos & 57 & 20 & 0 \\
\hline Áreas marinas protegidas & 2 & 0 & 36 \\
\hline Totales & 859 & 312 & \\
\hline
\end{tabular}

Tabla 11. Total de espacios naturales protegidos por el Estado español y por sus Comunidades Autónomas, así como los vinculados con las aguas subterráneas. Valores absolutos y porcentaje.

Table 11. Total natural areas protected by the Spanish State and its Autonomous Communities, as well as those linked to groundwater. Absolute values and percentages.

ción que se listan en la tabla 11 cabe indicar que generalmente se trata de lugares de pequeño tamaño y reducido ámbito espacial, cuyo objetivo es conservar elementos concretos y de relevancia singular por su fauna, flora o valores geológicos, que normalmente no están relacionados con las aguas subterráneas, como se desprende del bajo porcentaje de interrelación hídrica que presentan con el recurso hídrico subterráneo (Tabla 11). A escala de estos espacios naturales protegidos no existen muchos trabajos donde se hayan realizados estudios hidrogeológicos de una cierta envergadura. En el presente trabajo se proporcionan algunas referencias bibliográficas.

En la tabla 12 se muestran los datos relativos a los espacios naturales de la Red Natura 2000 para las 9 cuencas intercomunitarias del estado español. La información que se aporta no difieren de la proporcionada en el libro titulado "Las aguas subterráneas y la Red Natura 2000" (IGME-DGA, 2014). La principal novedad que se aporta tras contrastar y examinar la tabla 2, donde se listan los parques naturales vinculados con las aguas subterráneas, con la información que se proporciona en la publicación anteriormente citada relativa a los espacios naturales de la Red Natura 2000, es el solape parcial o total de dominios geográficos que caracteriza el ámbito espacial de muchos de los espacios naturales que constituyen ambas redes.

Por último, en la tabla 13 se proporciona el número de áreas protegidas por instrumentos internacionales que se encuentran vinculadas con las aguas subterráneas. Dado que se trata de espacios naturales de una gran significación y una notable importancia, se puede estimar que en muchos de ellos se posee un conocimiento hidrogeológico aceptable e incluso bueno. No obstante, es preciso continuar con la caracterización hidrogeológica de los humedales Ramsar iniciada por el IGME en 2004, pero que no se llevó a término y solo se ha finalizado la primera fase que incluía tan solo 13 humedales de los 75 enclaves

\begin{tabular}{|c|c|c|c|}
\hline $\begin{array}{c}\text { Espacios naturales protegidos } \\
\text { por la Red Natura 2000 }\end{array}$ & Total de espacios protegidos & $\begin{array}{c}\text { Total de espacios vinculados } \\
\text { con las aguas subterráneas }\end{array}$ & $\begin{array}{c}\text { Porcentaje espacios protegidos } \\
\text { vinculados con las aguas } \\
\text { subterráneas }\end{array}$ \\
\hline $\begin{array}{c}\text { Lugares de Importancia } \\
\text { Comunitaria }\end{array}$ & 1023 & 438 & 43 \\
\hline $\begin{array}{c}\text { Zonas de Especial Protección } \\
\text { para las Ave }\end{array}$ & 495 & 227 & 46 \\
\hline Totales & 1518 & 665 & 44 \\
\hline
\end{tabular}

Tabla 12. Total de espacios naturales protegidos por la Red Natural 2000 en las 9 cuencas intercomunitarias del Estado español, así como los vinculados con las aguas subterráneas. Valores absolutos y porcentaje.

Table 12. Total natural areas protected by the Natura Network 2000 in the 9 inter-community basins of the Spanish State, as well as those linked to groundwater. Absolute values and percentages. 


\begin{tabular}{|c|c|c|c|}
\hline $\begin{array}{c}\text { Áreas protegidas por } \\
\text { instrumentos internacionales }\end{array}$ & Total de espacios protegidos & $\begin{array}{c}\text { Total de espacios protegidos } \\
\text { vinculados con las aguas } \\
\text { subterráneas }\end{array}$ & $\begin{array}{c}\text { Porcentaje espacios protegidos } \\
\text { vinculados con las aguas } \\
\text { subterráneas }\end{array}$ \\
\hline Humedales Ramsar & 75 & 54 & 72 \\
\hline $\begin{array}{c}\text { Sitios Patrimonio Natural } \\
\text { Mundial (UNESCO) }\end{array}$ & 5 & 5 & 50 \\
\hline OSPAR & 2 & 1 & 44 \\
\hline ZEPIM & 9 & 4 & 77 \\
\hline Geoparques & 13 & 10 & 60 \\
\hline Reservas de la Biosfera & 52 & 1 & 106 \\
\hline Reservas biogenéticas & 1 & 157 & 68 \\
\hline Totales & 15 & & 60 \\
\hline
\end{tabular}

Tabla 13. Total de espacios naturales protegidos por convenios internacionales, así como los vinculados con las aguas subterráneas. Valores absolutos y porcentaje.

Table 13. Total natural areas protected by international conventions, as well as those linked to groundwater. Absolute values and percentages.

Ramsar que hay en España. También se estima necesario uniformizar el conocimiento hidrogeológico que se tiene sobre las reservas de la Biosfera que es notable en algunas de ellas pero escaso e incluso nulo en otras. Algo parecido ocurre con el conocimiento hidrogeológico de los Geoparques.

La propuesta de catalogación o de listado que se incluye en el presente artículo no pretende constituir un documento cerrado, sino todo lo contrario, ser un texto abierto a la crítica y a la incorporación de sugerencias y modificaciones que lo enriquezcan. A este respecto, resulta evidente que se precisa de una primera etapa en la que se impliquen hidrogeólogos conocedores en profundidad del ámbito de las aguas subterráneas a escala local y regional, que incorporen nuevas proposiciones y supriman algunas de las propuestas realizadas al objeto de mejorar el documento para posteriormente someterlo a la valoración y el refrendo de un comité experto que le confiera validez y legitimidad científica.

\section{Agradecimientos}

Los autores del presente artículo quieren resaltar e incidir en el extraordinario trabajo dirigido, coordinado y supervisado por el Doctor Roberto Rodríguez Fernández y desarrollado, elaborado, escrito y documentado por el mismo, junto a decenas de técnicos e investigadores, tanto del IGME como de otros organismos públicos y empresas consultoras. Loa autores son conscientes que la elaboración y edición de las
Guías Geológicas de los Parques Nacionales han facilitado enormemente la redacción y elaboración del presente artículo, por eso quieren agradecerles el enorme esfuerzo que tuvieron que realizar para llevar dicho proyecto a cabo.

\section{Referencias}

Alcolea, A; Contreras, S; Hunink, J.E. García-Aróstegui, J.L. y Jiménez-Martínez, J. 2019. Hydrogeological modelling for the watershed management of the Mar Menor coastal lagoon (Spain). Science of The Total Environment, 663, 901-914.

Alegre Fidalgo, P. 2000. Inventario y caracterización del agua subterránea en macizos rocosos fracturados. Islas Cies. Jornadas hispano-lusas sobre las aguas subterráneas en el noroeste de la península ibérica. 83-92.

Antón-Pacheco, C., Araguás, L., Ballesteros, B., Barnolas, A., Casas, A., Gil, I., Gumiel, J.C., López Gutiérrez, J., Mejías, M., Plata, J.L., Samsó, J.M., Jiménez, I., Marina, M., Mediato, J. y Núñez, I. 2005. Investigación sobre el comportamiento hidrogeológico de formaciones acuíferas profundas. Aplicación a la unidad hidrogeológica de EI Maestrazgo. $535 \mathrm{pp}$

APRODERVI. 2019. Estudio Hidrogeológico, Geofísico y Fotogeológico de la Comarca Villuerca-lbores-Jara. Asociación para la Promoción y el Desarrollo Rural de la Comarca de Villuerca-lbores- Jara. www.geoparqueviIluerca.es. 48 pp.

Bach, J. 1991. L'ambient hidrogeològic de la plana litoral de I'Alt Empordà (NE de Catalunya). Tesis Doctoral. Universidad Autónoma de Barcelona. 464 pp.

Ballesteros, B. 2001. La Albufera de Valencia: Pozos, canales y arroz. En: del Pozo, M; Durán, J.J.; Fernández, A.; 
García, C. y Murillo, J.M. (eds.) Aguas subterráneas, paisaje y vida. Acuíferos de España. IGME. 227-239.

Bayo Dalmau, A.; Custodio Gimena, E. y Loaso Vierbucher, C. 1997. Las aguas subterráneas en el Delta del Ebro. El Delta del Ebro (Monográfico). Revista de Obras Públicas.144 (3368): 47-65.

Carcavilla, L.; Ruiz, R. y Rodríguez, E. 2011. Guia geológica del Parque Natural del Alto Tajo. Segunda Edición. Instituto Geológico y Minero de España. 267 pp.

Castaño Castaño, S. 2002. Estudio Metodológico para el cálculo de la infiltración en el vaso de las tablas de Daimiel. Validación de resultados. Tesis Doctoral. Facultad de Geología. Universidad complutense de Madrid.

Castaño Castaño, S. 2008. Las Tablas de Daimiel: Un humedal interior dependiente de las aguas subterránea. Gestión de espacios naturales. Cursos de Verano de la Universidad de Burgos 1-16.

Castillo, A.; del Valle, M.; Rubio-Campos, J.C. y FernándezRubio, R. 1996. Síntesis hidrológica del macizo de Sierra Nevada (Granada y Almería). $1^{a}$ Conferencia Internacional Sierra Nevada. I. 389-417.

Coleto, C. 2003. Funciones hidrológicas y biogeoquímicas de las formaciones palustres hipogénicas de los mantos eólicos de El Abalario-Doñana (Huelva). Tesis doctoral. Departamento Interuniversitario de Ecología. Facultad de Ciencias. Universidad Autónoma de Madrid. 461 pp.

Custodio, E.; Barón, A.; Rodríguez-Morillo, H.; Poncela, R. y Bayó, A. 1992. Saline water in S'Albufera Natural Park aquifer system, Mallorca Island (Spain): a preliminary study. Study and Modelling of Salt Water Intrusion. CIMNE-UPC. Barcelona: 661-686.

Day, Jon, Dudley, Nigel, Hockings, Marc, Holmes, G., Laffoley, D., Stolton, Sue, Wells, Sue. 2012. Guidelines for applying the IUCN protected area management categories to marine protected areas. Gland. Switzerland. IUCN. 36 pp.

del Val Melús, J y Gálvez Maestre, M.J. 2010. El agua subterránea en el Parque Natural Sierra de Grazalema (Cádiz y Málaga). (Ed) López Geta, J.A.; Fernández Palacios Carmona, J.M.; Martín Machuca, M.; y Rubio Campos, J.C. Instituto Geológico y Minero de España. Consejería de Medio Ambiente de la Junta de Andalucía. 228 pp.

DGOH. 1975-a. Estudio científico de los recursos de agua en las islas Canarias (SPA/69/515) Volumen II provincia de Las Palmas. Ministerio de Obras Públicas Dirección General de obras Hidráulicas. Programa de las Naciones Unidas para el Desarrollo. UNESCO.

DGOH. 1975-b. Estudio científico de los recursos de agua en las islas Canarias (SPA/69/515) Volumen III provincia de Santa Cruz de Tenerife. Ministerio de Obras Públicas Dirección General de obras Hidráulicas. Programa de las Naciones Unidas para el Desarrollo. UNESCO. 238 pp.

DGOH. 1991. Estudio Hidrogeológico de las Unidades Hidrogeológicas 03.02 "Tajuña- Montes Universales" y 08.02 "Montes Universales". Documento Interno. Dirección General de Obras Hidráulicas. Ministerio de Obras Públicas y Transporte.

DGOH-ITGE. 1988. Estudio de delimitación de las unidades hidrogeológicas del territorio peninsular e Islas
Baleares, y síntesis de sus características. Dirección General de Obras Hidráulicas e Instituto Tecnológico Geominero de España.

DGRH-Govern Illes Balears. 2018. Plan Hidrológico de las Illes Balears. Revisión anticipada del $2^{\circ}$ ciclo 2015-2021. Memoria Propuesta aprobación inicial Consejo de Gobierno. 440 pp.

DOCE. 2000. Directiva 2000/60/CE del Parlamento Europeo y del Consejo, de 23 de octubre de 2000 por la que se establece el marco común de actuación en el ámbito de la política de aguas. Diario Oficial de las Comunidades Europeas. $\mathrm{n}^{\circ}$ L 327: 1-73, de 22 de diciembre de 2000. Bruselas.

DPB-ITGE. 1998. Sedano-La Lora. Atlas del Medio Hídrico de la Provincia de Burgos. Diputación Provincial de Burgos e Instituto Tecnológico Geominero de España. 148 pp.

Dudley, N. (Editor). 2008. Directrices para la aplicación de las categorías de gestión de áreas protegidas. Gland, Switzerland. IUCN. 96 pp.

Durán Valsero, J.J. 2002. El modelado Kárstico en los Parques Naturales de la Provincia de Jaén. Presente y Futuro de las Aguas Subterráneas en la Provincia de Jaén. Instituto Geológico y Minero de España. 39-43.

Durán Valsero, J.J. 2005. Agua y medio ambiente. Atlas Hidrogeológico de Cádiz. Instituto Geológico y Minero de España. 263 pp.

Durán Valsero, J.J. 2018. Hidrogeología de los espacios naturales protegidos. Aguas subterráneas, medio ambiente, salud y patrimonio. Congreso Ibérico. AlHGE. Salamanca. 97-101.

Durán Valsero, J.J., García de Domingo, A., López Geta, J.A., Robledo, P.A. y Soria, J.M. 2005. "Humedales del mediterráneo español: modelos geológicos e hidrogeológicos". Serie Hidrogeología y Aguas Subterráneas. Instituto Geológico y Minero de España.Tomo III. 160 pp.

Durán, J.J., y Murillo, J.M. 1998. El agua y los espacios naturales protegidos de Andalucía. Atlas Hidrogeológico de Andalucía. 47-54.

Empar Carrillo, I.A., Comas, J.; Ninot, J.M.; Ventura, M.; Rispa, J.M.; Monsó, A.; Aniz, M.; Arribas, J.; Canut, J. y Tartera, J. 2013. Guía de visita del Parque Nacional de Aigüestortes $i$ Estany de San Maurici. Organismo Autónomo de Parques Nacionales. 249 pp.

Fornés J.M. ${ }^{a}$; de la Hera, A., Ballesteros B.J. y Aragón R. 2008. Conflictos entre el desarrollo de las aguas subterráneas y la conservación de humedales del litoral mediterráneo español. Boletín Geológico y Minero. Vol. 119 (2): pp. 231-246

García Aróstegui, J.A.; Jiménez-Martínez, J.; Baudron, P. Hunink, J.; Contreras, S. y Candela, L. 2016. Las Aguas Subterráneas en el Campo de Cartagena-Mar Menor. En: Mar Menor una laguna singular y sensible. Evaluación científica de su estado. León, V.M. y Bellido, J.M. (Editores). Instituto Español de Oceanografía. Ministerio de Economía y Competitividad. 10. 231-249.

García Herrera J.J.; Carrasco Redondo, M.; Gómez Manzaneque, A. y Fernández Valero, E. 2011. Guía de visita del Parque Nacional de Cabañeros. Organismo Autónomo Parque Nacionales. 193 pp.

García Rodríguez, M. 1995. Hidrogeología de las Tablas de 
Daimiel y de los Ojos del Guadiana. Bases Hidrogeológicas para una clasificación funcional de humedales ribereños. Tesis Doctoral. Universidad Complutense de Madrid facultad de Geología. Departamento de Geodinámica.

García Rodríguez, M y Almagro Costa, J. 2004. LasTablas de Daimiel y los Ojos del Guadiana: Geología y evolución piezométrica. Revista Tecnologi@ y desarrollo. Escuela Politécnica Superior. Universidad Alfonso X el Sabio. VOLUMEN II. 19 pp.

Gollonet Fernández de Trespalacios, F.J.; Villalobos Mejías, M.; González Ramón, A.; Rubio Campos, J.C.; Salas Martín, R. y Pérez Muñoz, A.P. 2007. El agua subterránea en el Parque Natural de Sierra Mágina (Jaén). (Ed) Rubio Campos, J.C.; González Ramón, A.; y López Geta, J.A. Instituto Geológico y Minero de España. Diputación de Jaén. Consejería de Medio Ambiente de la Junta de Andalucía. 152 pp.

González-Bernáldez F. 1992. Ecological aspects of wetland/groundwater relationships in Spain. Limnetica. 8. 11-26.

González Monterrubio, J.M. 1985. Análisis Hidrológico de la Sobreexplotación y Protección de Humedales de la Ley de Aguas de 1985. Tesis Doctoral. Universidad Complutense de Madrid.

González Ramón, A.; Pérez Muñoz, A.P.; Villalobos Mejías, M.; Salas Martín, R.; Rubio Campos, J.C. y Jiménez Terrón, I. 2009. El agua subterránea en el Parque Natural de la Sierra de Castril (Granada). (Ed) Rubio Campos, J.C.; López Geta, J.A.; Beas Torroba, J. y Estirado Oliet, M. Instituto Geológico y Minero de España. Consejería de Medio Ambiente de la Junta de Andalucía. 200 pp.

Iglesias, M. 1999. Caracterización hidrogeoquímica del flujo de agua subterránea en El Abalario, Doñana, Huelva. Tesis Doctoral. ETSICCPB. Universidad Politécnica de Cataluña.

IGME. 1985. Estudio hidrogeológico general de la isla de La Gomera (Canarias). Instituto Geológico y Minero de España. 170 pp

IGME-DGA. 2014. Las aguas subterráneas y la red Natura 2000. Murillo, J.M. (editor). Instituto Geológico y Minero de España y Dirección General del Agua. 438 pp.

ITGE. 1989. Sistema acuífero $n^{\circ}$ 23. Mancha Occidental. Dirección de Aguas Subterráneas. Instituto Tecnológico y Geominero de España. Serie: Manuales de Utilización de Acuíferos.

ITGE. 1992. Hidrogeología del Parque Nacional de Doñana y su entorno. Colección: Informes Aguas Subterráneas y Geotécnia. Instituto Tecnomógico GeoMinero de España. 64 pp.

Jiménez-Martínez, J.; García-Aróstegui, J.L.; Hunink, J.E. Contreras, S.; Baudron, P. y Candela, L. 2016. The role of groundwater in highly human-modified hydrosystems: a review of impacts and mitigation options in the Campo de Cartagena-Mar Menor coastal plain (SE Spain). Environmental Reviews, 24 (4), 377-392.

Jodar, J.; Lamban, L.J. y Custodio, E. 2016. Estimación de la recarga mediante la modelación numérica del balance de agua en el suelo en el Parque Nacional de Ordesa y Monte Perdido (Huesca, España) Las Aguas
Subterráneas y la Planificación Hidrológicas. Congreso Hispano Luso. AlH-GE. Madrid. 193- 201.

Jodar, J. y Lamban, L.J. 2017. Seguimiento de la precipitación y de manantiales en el Parque Nacional de Ordesa y Monte Perdido. Boletín de la Red de Seguimiento del Cambio Global en Parques Nacionales. (6). 10-11.

Lambán,L. J.; Jódar J. y Custodio, E. 2014. Caracterización hidrogeoquímica del agua subterránea en el Parque Nacional de Ordesa y Monte Perdido (Pirineo Central, España). Il Congreso Ibérico de las Aguas Subterráneas. CIAS Valencia.

Linares Girela, L. 1989. Hidrogeología de la Laguna de Fuente Piedra (Málaga). Tesis Doctoral. Universidad de Granada. Departamento de Geotectónica.

López Alcaide, L. y Andreu Navarro, B. 2011. Actualización hidrogeológica en el Parque Natural de las Sierras de Tejera, Almijara y Alhama y Parque Natural de Acantilados de Maro-Cerro Gordo. Colección: Hidrogeología y Espacios Naturales. 93 pp.

López Chicano, M.; Martín Montañés, C.; Rubio Campos, J.C.; C; Salas Martín, R. y del Val Melús, J. 2013. El agua subterránea en el Parque Natural Sierras Subbéticas (Córdoba). Martín Montañés, C.; Rubio Campos, J.C.; López Geta, J.A. y Fernández Palacios Carmona, J.M. Instituto Geológico y Minero de España. Consejería de Medio Ambiente de la Junta de Andalucía. 256 pp.

López Geta, J.A.; Roso Sánchez, A. Batlle Gargallo, A.; Álvarez Seco, A.; Sebastian Alafont, L. 1990. Manuales de utilización de acuíferos: Isla de Ibiza. Instituto Tecnológico Geominero de España.

López Geta, J.A.; Martín Machuca, M. Mediavilla, C, Cozano, A. y Girón, J.L. 2011. Guía didáctica de las aguas subterráneas del Parque natural de Sierra Norte. Instituto Geológico y Minero de España.

Lozano, E. 2004. Las aguas subterráneas en los Cotos de Doñana y su influencia en las lagunas. Tesis Doctoral. Universidad Politecnica de Cataluña. 562 pp.

Martín Montañés, C; Salas Martín, R.; Rubio Campos, J.C.; González Ramón, A.; Villalobos Mejías, M. y Jiménez Terrón, I. 2011. El agua subterránea en el Parque Natural de la Sierra de Andújar (Jaén). (Ed) Rubio Campos, J.C.; López Geta, J.A.; Martín Montañés, C y Fernández Palacios Carmona, J.M. Instituto Geológico y Minero de España. Diputación de Jaén. Consejería de Medio Ambiente de la Junta de Andalucía. 153 pp.

Martín Montañés, C; González Ramón, A.; Rubio Campos, J.C.; Villalobos Mejías, M.; Salas Martín, R.; Pérez Muñoz, A.P. y Jiménez Terrón, I. 2009. El agua subterránea en el Parque Natural de Despeñaperros y el Paraje Natural de la Cascada de la Cimbarra (Jaén). (Ed) Rubio Campos, J.C.; López Geta, J.A. y Fernández Palacios Carmona, J.M.

Martínez-Santos, P.; Castaño, S.; Santisteban, J.I.; MartínezAlfaro, P.E.; Mediavilla, R.; López-Pamo, E. 2004. Evolución climática durante el último siglo (1904-2002) en el Parque Nacional de las Tablas de Daimiel (Ciudad Real). Geo-Temas, 6 (5); 129-132.

Martínez Santos P. 2007. Hacia la gestión adaptable del acuífero de la Mancha Occidental. Desarrollo de un modelo digital de flujo y elaboración participativa de escenarios 
de gestión del agua. Tesis Doctoral. Universidad Complutense de Madrid.

Martos-Rosillo, S.; Ruiz-Constána, A.; González-Ramón, A.; Mediavilla, R.; Martín-Civantos, J.M.; Martínez-Moreno, F.J.; Jódar, J.; Marín-Lechado, C.; Medialdea, A.; GalindoZaldívarg, J.; Pedrera, A. y Durán J.J. 2019. The oldest managed aquifer recharge system in Europe: New insights from the Espino recharge channel (Sierra Nevada, southern Spain). Journal of Hydrology (578): 124-147.

Marrero, R. 2010. Modelo hidrogeoquímico del acuífero de las Cañadas del Teide. Tenerife. Islas Canarias. Tesis Doctoral. Universidad Politécnica de Cataluña. 500 pp.

Mejías, M., García-Orellana, J., Plata, J.L., Marina, M., García-Solsona, E., Ballesteros, B., Masqué, López, J. and Fernández-Arrojo C. 2007. Methodology of hydrogeological characterization of deep carbonate aquifers as potencial reservoirs of groundwater. Case of study: the Jurassic aquifer of El Maestrazgo (Castellón, Spain). Enviromental Geology.

Mejías Moreno, M.; Fernández San Miguel, M.; Vías Alonso, J.; Castro Quiles, A.; del Pozo Tejado, J. 2015. El Parque Nacional de la Sierra de Guadarrama: cumbres, paisaje y gente. Editor: Mejías Moreno, M. Instituto Geológico y Minero de España. 151-225.

MITECO. 2019. Espacios Naturales Protegidos (ENP). Ministerio para la Transición Ecológica. https://www.miteco.gob.es

Montalván Toala, F.J. .2018.. Modelización de un sistema hidrogeológico con una variabilidad extrema de la densidad (Reserva Natural de la Laguna de Fuente de Piedra). Tesis (Doctoral), E.T.S.I. de Minas y Energía (UPM).

Montero González, E: 1994. Funcionamiento hidrogeológico del sistema de las Lagunas de Ruidera. Tesis Doctoral. Universidad Complutense de Madrid.

Moriz Sanchez, C. y Pérez Fernández, F. 2010. El agua subterránea en el Parque Natural Sierra de Aracena y Picos de Aroche (Huelva). (Ed) Martín Machuca, M.; López Geta, J.A.; y Fernández Palacios Carmona, J.M. Instituto Geológico y Minero de España. Consejería de Medio Ambiente de la Junta de Andalucía. 176 pp.

Múgica de la Guerra, M., Martínez Alandi, C., Puertas Blázquez, J. Atauri Mezquida, J.A., Gómez-Limón García, J. y García Ventura, D. 2019. Anuario 2018 del estado de las áreas protegidas en España. EUROPARCEspaña. 2019. Ed. Fundación Fernando González Bernáldez Madrid. 130 pp.

Murillo, J.M. 1994. Hidroquímica de Unidades Hidrogeológicas Asociadas a Espacios Naturales Protegidos. Actas del Congreso de la AlH celebrado en Alcalá de Henares sobre Análisis y Evolución de la Contaminación de las Aguas Subterráneas. Ponencias y Comunicaciones. Tomo 2. 325-344.

Navarro, J.M. 1995. Geología e Hidrogeología del Parque Nacional del Teide. Ministerio de Agricultura, Pesca y Alimentación, Subdirección General de Espacios Naturales, Parque Nacional del Teide, 103 pp.

Octavio de Toledo, F y García Lapresta, M 1992. Estudio Hidrogeológico de la cuenca de Gallocanta (Zaragoza).
Aplicación de un modelo de flujo subterráneo. $V$ Simposio Nacional de Hidrogeología (Alicante). Asociación Española de Hidrogeología y Recursos Hidráulicos. Tomo XVII. 261-271.

Olías Álvarez, M. 1994. Evaluación de la recarga y comportamiento de la zona no saturada en el acuífero de Almonte-Marismas (Huelva). Tesis Doctoral. Universidad de Granada. Departamento de Geodinámica.

Oliván Pociello, C. 2016. Delimitación, evaluación de la recarga y funcionamiento hidrodinámico del acuífero drenado por el manantial kárstico de Fuenmayor (prepirineo aragonés). Tesis Doctoral. Instituto Geológico y Minero de España. 262 p.

Pascual, M. 1992. Hidrogeología básica de las sierras marginales prepirenaicas de la provincia de Lleida. $V$ Simposio de Hidrogeología y Recursos Hidráulicos. Alicante AEHS. 115-129.

Pérez Muñoz, A.P.; González Ramón, A.; Villalobos Mejías, M.; Salas Martín, R.; Rubio Campos, J.C.; Jiménez Terrón, I. y Gollonet Fernández deTrespalacios, F.J. 2008. El agua subterránea en el Parque Natural de la Sierra de Huétor. (Ed) Rubio Campos, J.C.; González Ramón, A.; Beas Torroba, J. y López Geta, J.A. 2008. Instituto Geológico y Minero de España. Diputación de Granada. Consejería de Medio Ambiente de la Junta de Andalucía. $180 \mathrm{pp}$

PHEH. 2018. Plan Hidrológico de El Hierro. Ciclo de Planificación Hidrológica 2015-2021.Consejo Insular de Aguas de El Hierro. 102 pp.

PHIL. 2018. Plan Hidrológico de Lanzarote. Ciclo de Planificación Hidrológica 2015-2021. Demarcación Hidrográfica ES123 Lanzarote. Consejo Insular de Aguas de Lanzarote. 96 pp.

Poncela Poncela, R. 2015. Hidrogeología del sistema acuífero volcánico de La Palma (Islas Canarias). Tesis Doctoral. Universidad de Alicante. 227 pp.

Pulido-Bosh, A. y Sbih, Y. 1995. Centuries of artificial recharge on the southern edge of the Sierra Nevada (Granada, Spain). Environmental Geology, 26, 57-63

Robledo, P.A. 2016. El Parque Nacional Marítimo-Terrestre del Archipiélago de Cabrera: un paisaje entre la tierra y el mar. IGME-OOAA Parques Nacionales. 383 pp.

Rodríguez Arévalo, F. J. 1988. Origen y movimiento del agua intersticial en el acuífero arcilloso de las marismas del Guadalquivir. Tesis Doctoral, F. Ciencias Geológicas, Universidad Complutense de Madrid.: 316 pp.

Rodríguez Estrella, T. 1995. Funcionamiento Hidrogeológico del Campo de Cartagena (Murcia y Alicante). Hidrogeología. Madrid. 11. 21-38.

Rodríguez-Estrella, T. 2009. El Mar Menor: Geología y sus relaciones con las aguas subterráneas del continente. El mar Menor: estado actual del conocimiento científico. 47-49.

Romero, E.1998. Caracterización de las salinidades en el Preparque Norte del Parque Nacional de Doñana. Tesis Doctoral. Universidad de Huelva.

Ruiz Pico, A.A. y Samper Calvete, J. 2000. Hidrogeología de las Islas Ons. Jornadas hispano-lusas sobre las aguas subterráneas en el noroeste de la península ibérica. 93104. 
San Román Saldaña, J.; García Vera, M.A.; Blasco Herguedas, O.; Coloma López, P. 2007. Hidrogeología de la laguna de Gallocanta. Revista del Centro de Estudios del Jiloca, 35, 65-86. Teruel.

Sánchez, J.A. 1988. Los recursos hídricos de las Sierras de Guara y sus Somontanos. Colección de Estudios Altoaragoneses, 27, Huesca. $336 \mathrm{p}$.

SGOP-IGME-IRYDA. 1973. Estudio de los recursos hídricos totales de las islas de Mallorca e Ibiza. Informe de Síntesis General. Tomo I. Memoria. Servicio Geológico de Obras Públicas, Instituto Geológico y Minero de España e Instituto de Reforma y Desarrollo Agrario. 268 pp.

Skupien, E. 1998. Aguas subterráneas en las rocas volcánicas de La Gomera. Tesis Doctoral. Departamento de Geología de la Academia de Minería y Siderurgía "Stanislau Staszic" de Cracovia (Polonia). Facultad de Geología, Geofísica y Protección del

Trick Thomas, M. 1997. Impacto de la extracción de agua subterránea en Doñana. Aplicación de un modelo numérico con consideración de la variabilidad de la recarga. Tesis Doctoral. Escuela de Ingenieros de Caminos,
Canales y Puertos. Universidad Politécnica de Barcelona.

Vallejo, M y Duran, J.J. 1996. Estudio hidrogeológico del Parque Natural de los Montes de Málaga. IV Simposio Andaluz del Agua. Almería. 347-355.

Villalobos Mejías, M.; Gollonet Fernández de Trespalacios, F.J.; González Ramón, A.; Salas Martín, R. y Pérez Muñoz, A.P. 2006. El agua subterránea en el Parque Natural de las Sierras de Cazorla, Segura y Las Villas (Jaén). (Ed) González Ramón, A.; Rubio Campos, J.C. y López Geta, J.A. Instituto Geológico y Minero de España. Diputación de Jaén. Consejería de Medio Ambiente de la Junta de Andalucía. 201 pp.

Villalobos Mejías, M.; Salas Martín, R.; Pérez Muñoz, A.P.; Jiménez Terrón, I.; López Geta, J.A.; Fernández Palacios Carmona, J.M. y Rubio Campos, J.C. 2010. El agua subterránea en el Parque Natural marítimo-terrestre de Cabo de Gata-Nijar (Almería). (Ed) López Geta, J.A.; Rubio Campos, J.C y Fernández Palacios Carmona, J.M. Instituto Geológico y Minero de España. Consejería de Medio Ambiente de la Junta de Andalucía. 264 pp.

Recibido: julio 2018

Revisado: septiembre 2018

Aceptado: febrero 2019

Publicado: diciembre 2019 